\title{
COMPARISON OF MIST GENERATION RATES FOR AN EXPERIMENTAL METAL REMOVAL FLUID WITH A BASELINE FLUID DURING MILLING AND TURNING OPERATIONS
}

at

\section{TechSolve Inc.}

Cincinnati, Ohio

\author{
REPORT WRITTEN BY: \\ Amir Khan, Chemical Engineer \\ Michael Gressel, Ph.D., CSP \\ Stanley Shulman, Ph.D.
}

REPORT DATE:

November 2005

REPORT NUMBER:

EPHB 218-15a

U.S. Department of Health and Human Services

Centers for Disease Control and Prevention

National Institute for Occupational Safety and Health

Division of Applied Research and Technology

Engineering and Physical Hazards Branch

4676 Columbia Parkway, Mail Stop R-5

Cincinnati, Ohio 45226-1998 
STUDY SITE:

SIC CODE:

SURVEY DATES:

SURVEY CONDUCTED BY:

EMPLOYER REPRESENTATIVES CONTACTED:
Cincinnati, Ohio

9721

July 19-September 16, 2004

Amir Khan

Andrew Patterson

Mark Greeley

TechSolve Inc.

Thomas McClure

TechSolve Inc. 


\section{DISCLAIMER}

Mention of company names or products does not constitute endorsement by the Centers for Disease Control and Prevention. 


\section{ABSTRACT}

Metal removal fluids have been used since the mid-1800s, and their use and formulation have changed over the years to accommodate performance, health and safety concerns. Recently, adverse health effects were reported in industries using metal removal fluids, drawing renewed attention to methods for controlling occupational exposures to metal removal fluids. In addition to the potential occupational hazards associated with metal removal fluids, disposal of the used metal removal fluids is also a concern to many machining operations. Recently, the identification of many metal removal fluids as hazardous wastes has been a force of change in industry. This classification has lead to the need for more advanced waste treatment and increased disposal costs for common metal removal fluids. This situation has also led to the development of metal removal fluids that are "Environmentally Friendly" which are easily disposed of and have a reduced environmental impact.

To address the health, safety and environmental concerns, the U.S. Environmental Protection Agency (EPA) has been funding research at the University of Cincinnati to develop a metal removal fluid that is environmentally safer and has a good performance across a wide range of machining processes. Recently, research at the University of Cincinnati produced a synthetic metal removal fluid that is toxicologically and environmentally benign.

The primary objective of this study was to compare the generation rate of respirable aerosols between the EPA fluid and a baseline fluid. Two machining processes were studied: milling and turning. The mist generation rate for milling was evaluated at two speeds while the mist generation rate for turning was evaluated at a single speed.

The results of this study showed that, for the machining conditions studied, the EPA fluid produced significantly higher mist generation rates than the baseline fluid at lower and higher milling speeds. However, the differences in mist generation rates between the two fluids appear to diminish as machining speed increases. During turning, no statistically significant differences in mist generation rates between the EPA fluid and the baseline fluid were observed. Comparisons of the milling and turning operations by fluid type indicate that the mist generation rates for the EPA fluid during milling were significantly higher than those of this same fluid during turning, whereas baseline fluid generation rates during milling were significantly lower than those during turning. Overall, it can be concluded that the mist formation associated with the milling may be more dependent on the fluid characteristics of the metal removal fluids, while the turning operation may not be as dependent on the characteristics of the fluids, but more dependent on the operational variables.

Since the workers' exposure to EPA fluid during milling was above the NIOSH REL, any company planning to use this fluid in their milling operation should provide a mist collector. The mist generations associated with turning for the EPA and baseline fluids were very near the NIOSH REL. Therefore, companies with machining operations should consider mist collection devices on its turning equipment. 


\section{INTRODUCTION}

Due to recent increases in adverse health effects being reported related to metal removal fluids, there is a great urgency to reduce the exposure to these fluids. These health effects include skin diseases, acute respiratory illness, and potentially cancers. The primary routes for exposure to metal removal fluids are through dermal and inhalation. The dermal exposures occur from splashing and handling of parts coated with the metal removal fluid. The inhalation exposures occur when workers breathe air contaminated with metal removal fluid mist. The mist is generated by the machining process, from splashing, and from the application of fluid to spinning parts and tools. The aerosol generated in the machining process can contain the components of the metal removal fluid, as well as particulate from both the metal being cut and from tool wear. The components of the fluid can present a potential hazard to the worker along with any contaminants of the metal removal fluid. These metal removal fluids can be contaminated with microorganisms and tramp oil, which can be as hazardous as any of the components of the metal removal fluid, and may be extremely difficult to control.

In recent years, the identification of many metal removal fluids as hazardous wastes has been a force of change in industry. This classification has led to the need for more advanced waste treatment and increased disposal costs for common metal removal fluids. This situation has also led to the development of metal removal fluids that are "Environmentally Friendly" or "Green”, general terms that imply the fluids are easily disposed of and have reduced environmental impact. However, problems have been encountered with these Green Metal Removal Fluids. Formulating metal removal fluids that are easily waste-treated will likely increases the tendency for that metal removal fluid to degrade when in typical use. Additionally, fluids which are easily broken down in treatment are not necessarily benign when in use. In fact, many of the metal removal fluids in use today are still poisonous when inhaled, ingested, or come in contact with the skin.

To address the health, safety and environmental concerns, the U.S. Environmental Protection Agency (EPA) has been funding research at the University of Cincinnati to develop a metal removal fluid that is environmentally safer and has a good performance across a wide range of machining processes. Recently, research at the University of Cincinnati produced a synthetic metal removal fluid that contains triglycerol and propylene glycol esters of $\mathrm{C}_{8}$ and $\mathrm{C}_{10}$ acids, and is toxicologically and environmentally benign. Eye ${ }^{1}$, oral, and dermal toxicity ${ }^{2}$ tests found this metal removal fluid to be a minimal irritant and to have a $\mathrm{LD}_{50}$ in rats of greater than $2000 \mathrm{mg} / \mathrm{kg}^{3}$. The machining testing described in this report has been undertaken to assess its suitability as a metal removal fluid and mist generating properties of this fluid; part of a larger characterization of its place in the metal removal fluid marketplace.

A study to evaluate the performance of this new synthetic fluid relative to a baseline coolant (baseline) for general machining of ferrous and nonferrous materials was conducted in conjunction with TechSolve, Inc. (formerly known as the Institute for Advanced Manufacturing Sciences, IAMS) and NIOSH in TechSolve's Facility. The primary objective of this study was to compare the mist generation rate of respirable aerosols of EPA and baseline (Trim Sol manufactured by Master Chemical of Perrysburg, Ohio) fluids in milling and turning operation. 


\section{BACKGROUND}

Metal removal fluids serve several functions in the machining process. For some processes, the primary function is lubrication, while for others, it is cooling. In many processes, metal removal fluids are also used for chip removal; in some facilities, a large portion of the metal removal fluid pumped throughout the plant is for chip handling. In addition, metal removal fluids may also provide corrosion protection for the newly machined surface of the part being produced. All of these functions have an impact on the process, from tool life and power consumption, to part quality and operability.

Metal removal fluids can be applied in the machining process in a number of different ways. The most common is flood application, where a large volume of fluid is pumped to the metal removal interface. The fluid is collected and then reused many times. Another method, Micro-lubrication, provides fluid to the cutting interface in the form of a mist, providing the lubrication effect. Because of the small volume used, the fluid is not collected for reuse. Also related to the method of fluid application are the concepts of dry (no metal removal fluid used), near-dry, and semi-dry machining. The last two methods are different applications of methods for reducing the volume of fluid used in the machining process. In this study the flood application will be used to compare the performance and the mist generation of the new synthetic fluid relative to the baseline fluid. 


\section{SAMPLE METHODOLOGY}

The primarily goal of this study was to measure the mist generation rates for the EPA and the baseline metal removal fluids during their use in milling and turning. The mist generation rate for milling was evaluated at two speeds while the mist generation rate for turning was evaluated at a single speed. The mist concentrations for the EPA and baseline metal removal fluids were measured using an Aerodynamic Particle Sizer (APS). The mist generation rates for the fluids were computed by multiplying the mist concentrations data by the overall machine enclosure air flow.

\section{Experimental Design}

The study was conducted in four phases. In Phase I the mist generation rates for the EPA fluid was measured at lower and higher milling speeds. In this phase, ten runs were executed: five runs at the lower milling speed and five runs at the higher speed, in randomized pairs. Since all ten runs successfully completed 200 passes (one pass is the milling cutter traveling all the way across the work-piece 1 time.) without the tool failing, only one run per day could be completed. In Phase II, the mist generation rates for the baseline fluid were similarly measured as the EPA fluid in Phase I. This phase also consisted of five randomized pairs of runs at the lower and higher milling speeds. Since the tools for the majority of the runs failed after 70-80 passes, two runs could be completed each day. In Phase III, the mist generation rates for the baseline fluid were evaluated for turning operation. In Phase IV, the mist generation rates for the EPA fluid were measured in turning.

\section{Metal Removal Fluid Mist Measurements}

The TSI Aerodynamic Particle Sizer (APS), Model 3321 (TSI, Inc., St. Paul, MN) measured the metal removal fluid mist concentrations from the machining operations being evaluated. The APS is a time of flight aerosol spectrometer which counts all particles over a range of aerodynamic diameters from 0.5 to $32 \mu \mathrm{m}$. It samples at a total flow rate of $5.0 \mathrm{l} / \mathrm{min} ; 1.0$ $\mathrm{l} / \mathrm{min}$ is analyzed, $4.0 \mathrm{l} / \mathrm{min}$ is filtered and supplied as sheath air to the sample stream. Time of flight aerosol spectrometers such as the APS, are based on the principle that the magnitude of a particle's lag in an accelerating air flow is directly related to the particle's aerodynamic diameter. The lag is determined by measuring the transit time required for a particle to pass through two laser beams perpendicular to the air flow. A timer measures the time between the two pulses generated by the particle passing through the two laser beams. The transit time is related to the aerodynamic diameter through a calibration with spheres of a known density $^{4}$. The APS was calibrated prior to the start of this study. Information on the calibration of the APS is given in Appendix A.

The TSI Dilutor, Model 3302A (TSI, Inc., St. Paul, MN) was used with the APS to dilute the sample stream in tests where the sample concentration was high enough to saturate the detector. The diluter was capable of diluting the sample stream by a factor of 20 or 100, depending upon the nozzle installed. Dilutors were only used with the duct samplers during milling with both fluids. The turning operation and the background samplers did not require dilutors. 
The APSs were controlled by separate PC computers, a Dell Inspiron Dimension 8100, $1 \mathrm{GHz}$, Pentium III notebook computer and a Dell Inspiron 4100, $1.13 \mathrm{GHz}$, Pentium III notebook computer (Dell Computer Corp., Austin, TX). Each computer ran the Aerosol Instrument Manager software, version 5.2 (TSI, Inc., St. Paul, MN), allowing remote access to the instruments' parameters so that the sampling process could be controlled appropriately. In addition, this software received, displayed, and recorded the aerosol data as measurements were being made. At the conclusion of a sampling run, the software also allowed the data to be exported to an ASCII text file, which in turn, could then be imported to other software packages for data analysis.

The machining center used for milling in this study was equipped with an enclosure and mist collector. One APS was configured to sample from the mist collector ductwork using an isokinetic sampling probe, reducing aerosol losses in the sampling train. The probe was designed so that the air and aerosols in the exhaust stream entered the sampling probe at the same velocity as the air stream in the duct. The diameter of the sampling probe gradually increased to the diameter of the inlet of the APS, minimizing particle losses due to the changes in air stream velocity. The sampling probe was inserted through an elbow into a straight section of the exhaust ductwork. The sampling point was at the center line of the straight duct, more than 7.5 duct diameters (45 in, $1.15 \mathrm{~m}$ ) downstream and 3 duct diameters (18 in, $0.46 \mathrm{~m}$ ) upstream of any major air disturbance, in this case, two $90^{\circ}$ elbows ${ }^{5}$. A simplified diagram of the milling sampling setup is given in Figure 1. A second APS was used to monitor general background particulate concentrations.

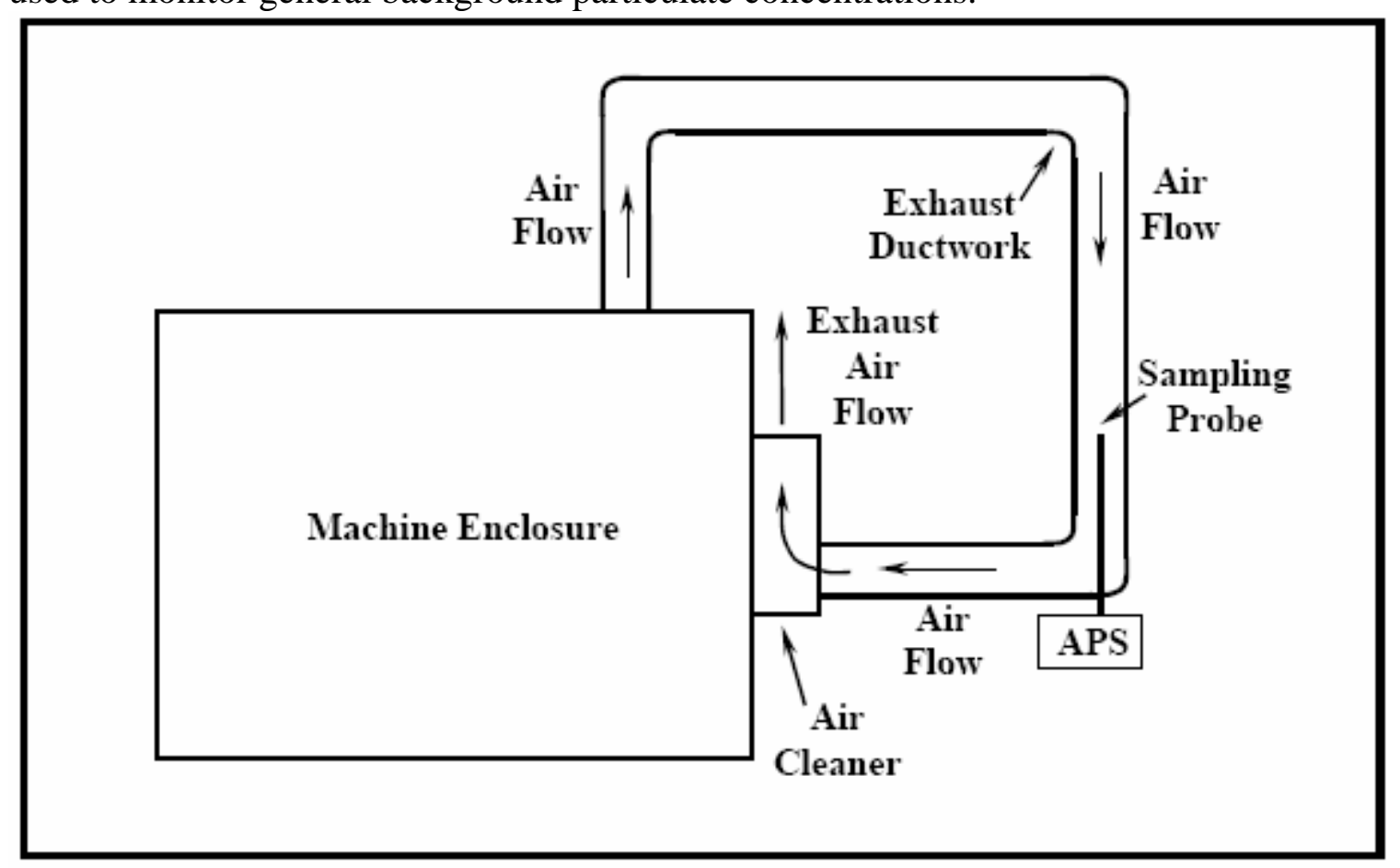

Figure 1. Diagram of milling aerosol sampling setup

The lathe used in the turning operation of this study was also equipped with an enclosure and mist collector. The APS setup for the lathe was similar to the milling setup. However, the configuration of the exhaust ductwork for the turning machine enclosure was slightly different from the milling machine enclosure due to the space limitation of where the air 
cleaner could be installed. In the milling operation the air cleaner was attached to the enclosure while in the turning operation the air cleaner was placed on a moveable cart. A simplified diagram of the sampling setup for the turning operation is illustrated in Figure 2. A second APS was used to monitor the general background particulate concentrations for all operations.

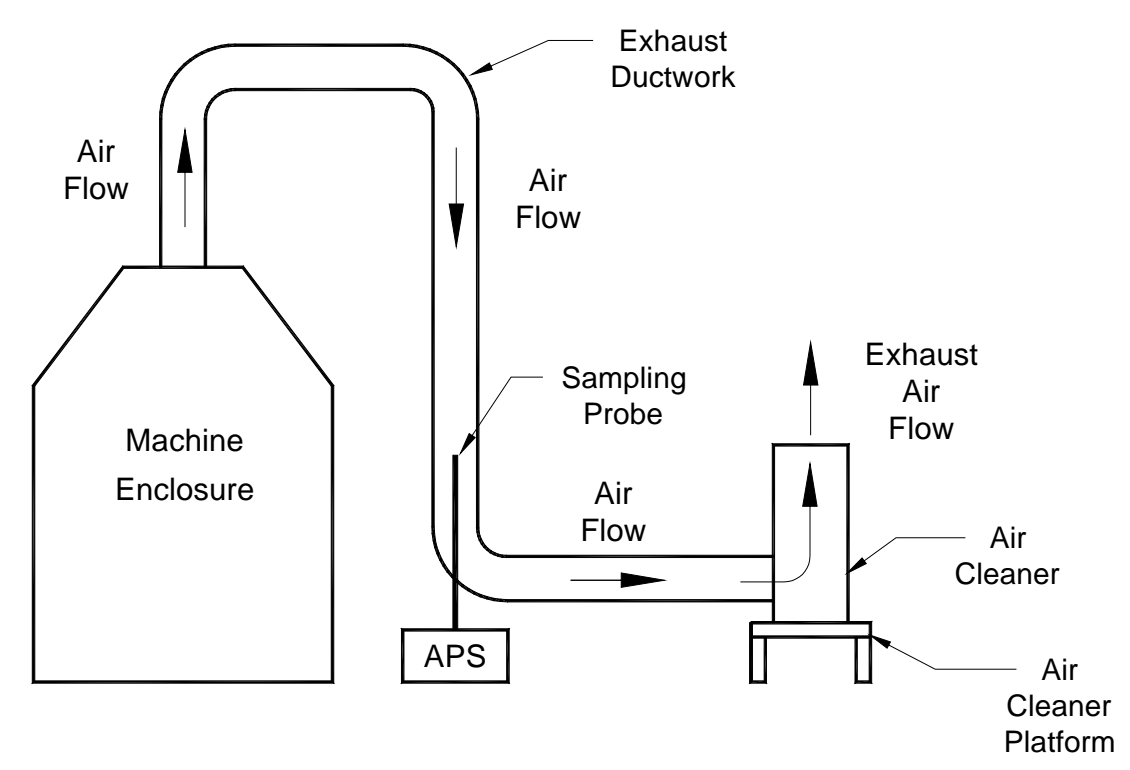

Figure 2. Diagram of turning aerosol sampling setup

\section{Temperature and Humidity Measurements}

Temperature and humidity inside the machine enclosure and in the work environment were monitored and recorded continuously using a HOBO ${ }^{\circledR}$ H8 Pro Relative Humidity and Temperature Logger, Model Number H08-032-08 (Onset Computer Corporation, Cape Cod, MA). The temperature and relative humidity data were collected to identify if there were any work environment changes occurring within the enclosure during machining. After completion of daily sampling, the temperature and humidity monitor was downloaded to a PC computer using the BoxCar® Pro software (version 3.7.3, April 1, 2002) supplied with the HOBO monitor. Instantaneous temperature and humidity measurements were made in the work environment at the start of each sampling run using a RG7G model 911S1 (manufactured by Control Company, Friendswood, TX, supplied by Fisher Scientific, Pittsburgh, PA, and catalog number 11-661-14). Continuous recording of the temperature and relative humidity measurements will provide a basis for tracking the conditions in the work environment, which could be beneficial in characterizing major differences that may occur in the generation rates from one run to the next.

\section{Machine Enclosure Efficiency}

The exhaust flow rates of the mist collectors were measured by performing a pitot tube traverse at the sampling point in the ductwork ${ }^{5}$. The 7-point traverses were made with a Dwyer Model 166-12 pitot tube (Dwyer Instruments, Inc., Grandview, MO). An Airflow Model PVM100 electronic digital micromanometer (Airflow Developments Limited, 
Buckinghamshire, England) was used to measure the pressure drop across the pitot tube. The efficiencies of the mill and lathe machining enclosures were evaluated using a tracer gas, sulfur hexafluoride $\left(\mathrm{SF}_{6}\right)$, and a monitor calibrated to detect low levels of the tracer gas ${ }^{6}$. This evaluation was accomplished by comparing the in-duct $\mathrm{SF}_{6}$ concentrations when the tracer gas was released at the cutting interface with the concentrations when it was released directly into the exhaust duct. The concentration of $\mathrm{SF}_{6}$ in the duct was measured with a Bruel \& Kjaer (B\&K) Multi-gas Monitor, Type 1302 (Bruel \& Kjaer, Naerum, Denmark). The $\mathrm{B} \& \mathrm{~K}$ is a photo acoustic gas monitor capable of measuring $\mathrm{SF}_{6}$ concentrations down to the parts per billion levels. This instrument had been recently serviced and calibrated by the manufacturer.

The flow of the $\mathrm{SF}_{6}$ to the machine enclosure was controlled by a MKS Model 247-C mass flow controller (MKS Instruments, Inc., Andover, MA), and was verified by a Drycal Flow calibrator (SKC Inc. Eighty Four, PA). The mass flow controller set point was adjusted to provide a duct concentration of $\mathrm{SF}_{6}$ of $15 \mathrm{ppm}$ at $100 \%$ capture efficiency. Based on the duct flow rate of $14.4 \mathrm{~m}^{3} / \mathrm{min}$ (510 CFM), as measured from the pitot tube traverse, the $\mathrm{SF}_{6}$ was delivered at a flow rate of $0.215 \mathrm{l} / \mathrm{min}$.

The $\mathrm{SF}_{6}$ was released at $0.215 \mathrm{l} / \mathrm{min}$ at two positions in each of the machine enclosures: near the cutting interface and at the entry of the enclosure exhaust duct. The capture efficiency at the duct entry was assumed to be $100 \% . \mathrm{SF}_{6}$ concentration measurements were made in pairs, with the tracer gas released at the cutting interface or at the entry of the exhaust duct. The order of the pairs was randomized, and a total of 5 pairs of measurements were made in each enclosure. Background $\mathrm{SF}_{6}$ concentrations were measured before and after each duct or cutting position concentration measurement. Data from the B\&K were downloaded to a personal computer for analysis.

The duct and cutting position concentration measurements were corrected for the background concentrations by calculating the mean of the before and after background measurements, and subtracting this value from the respective concentration measurement. Enclosure efficiency was then determined by the following:

$$
E=\frac{C_{c u t}}{C_{d u c t}} \times 100 \%
$$

Where $\mathrm{E}=$ the enclosure efficiency, \%

$C_{C u t}=$ background corrected $\mathrm{SF}_{6}$ concentration with $\mathrm{SF}_{6}$ supply located near the cutting interface, entry,

$$
C_{\text {Duct }}=\text { background corrected } \mathrm{SF}_{6} \text { concentration with } \mathrm{SF}_{6} \text { supply located at the duct }
$$

The exhaust flow rate of the enclosure was calculated from the duct position concentration by the following equation:

$$
Q_{\text {Enclosure }}=\frac{W_{S F_{6}}}{C_{\text {Duct }}}
$$

Where $Q_{\text {Enclosure }}=$ the air flow rate from the machine enclosure, 


$$
W_{S F_{6}}=\text { the mass flow rate of } \mathrm{SF}_{6} \text { to the enclosure. }
$$

The exhaust flow rate determined by the pitot tube traverse was compared to the calculated flow rate from the tracer gas evaluation.

\section{Machining Procedures}

The mist generation for the EPA and baseline metal removal fluids was characterized for milling and turning using flood application. These tests were conducted according to published methods outlined in the International Working Industrial Group (IWIG) manual ${ }^{7}$. The milling tests were conducted in a Tongil TNV-80 CNC vertical machining center, shown in Figure $3^{8}$ and the turning tests were conducted in a Hardinge Cobra 65 lathe, shown in Figures 4 and 5. For both machines, fluid was pumped from a sump to the cutting interface, and collected for reuse. Fluid in milling was applied using the Tongil's normal metalworking fluid sump as illustrated in Figure 6.

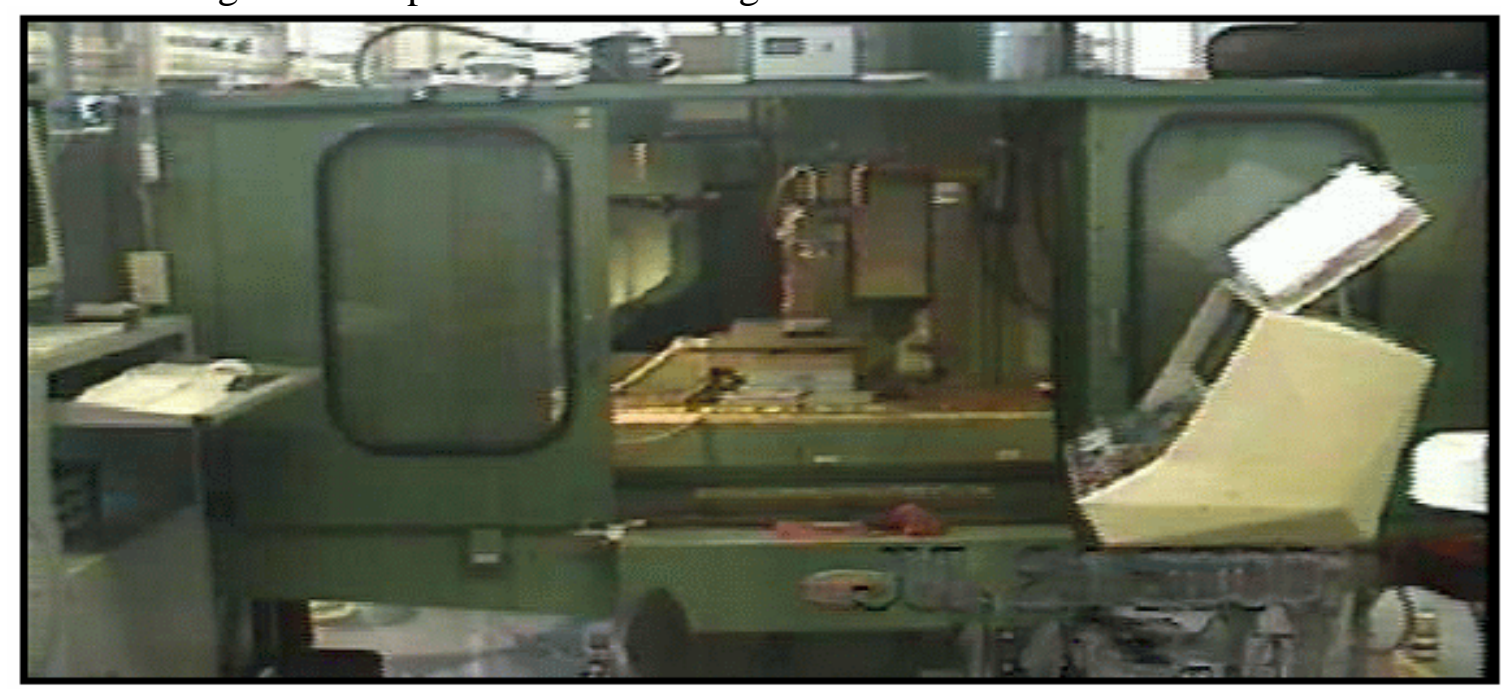

Figure 3. Tongil TNV0CNC vertical machining center for milling tests.

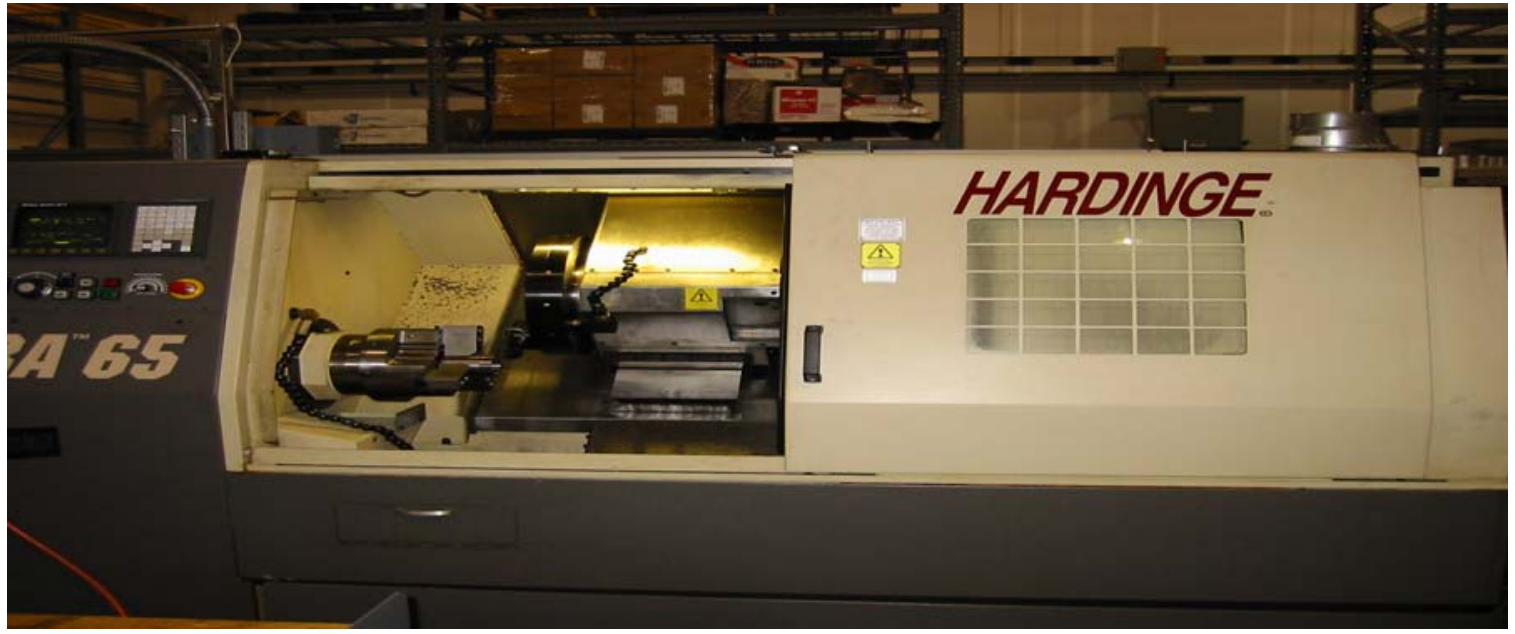

Figure 4. Hardinge Cobra 65, machining center for turning tests. 


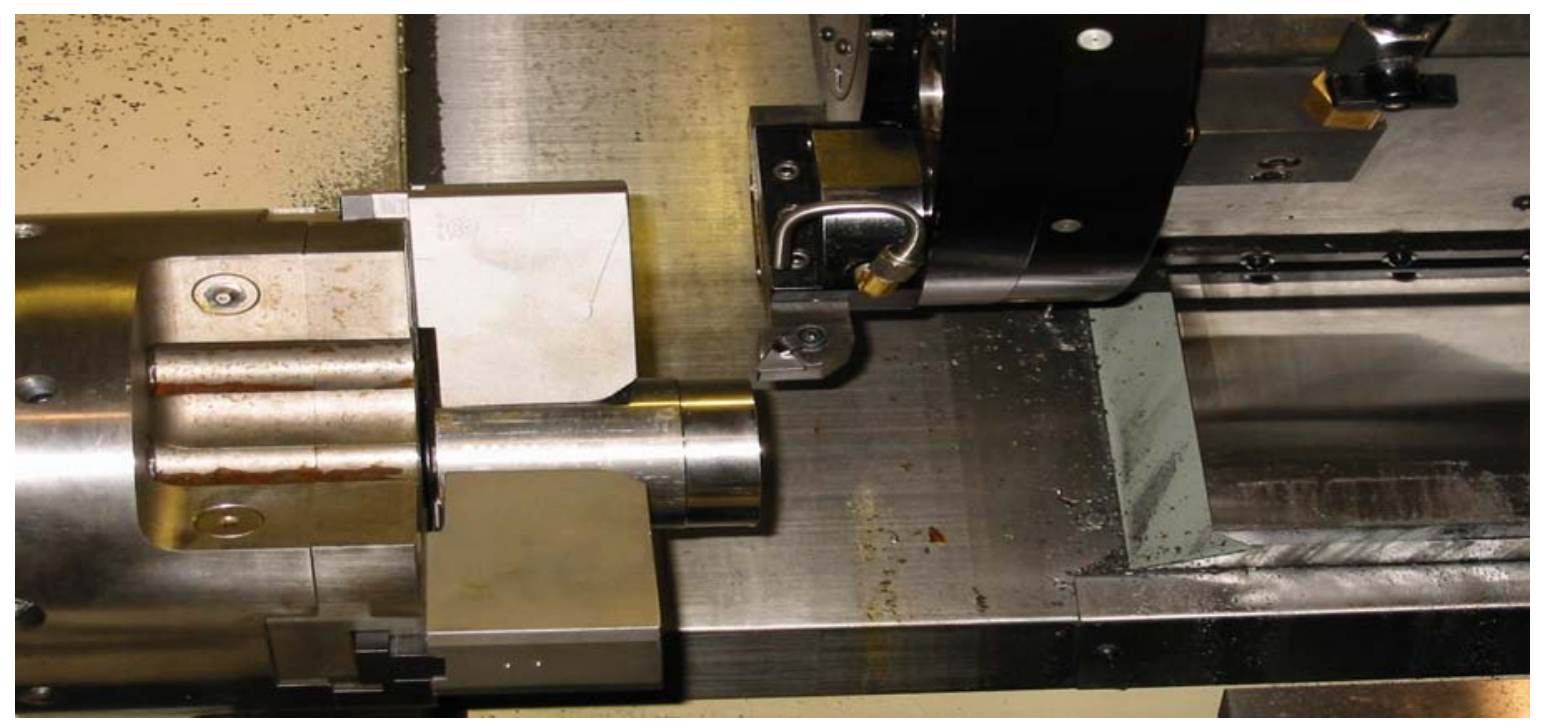

Figure 5. The inside of the lathe machining center

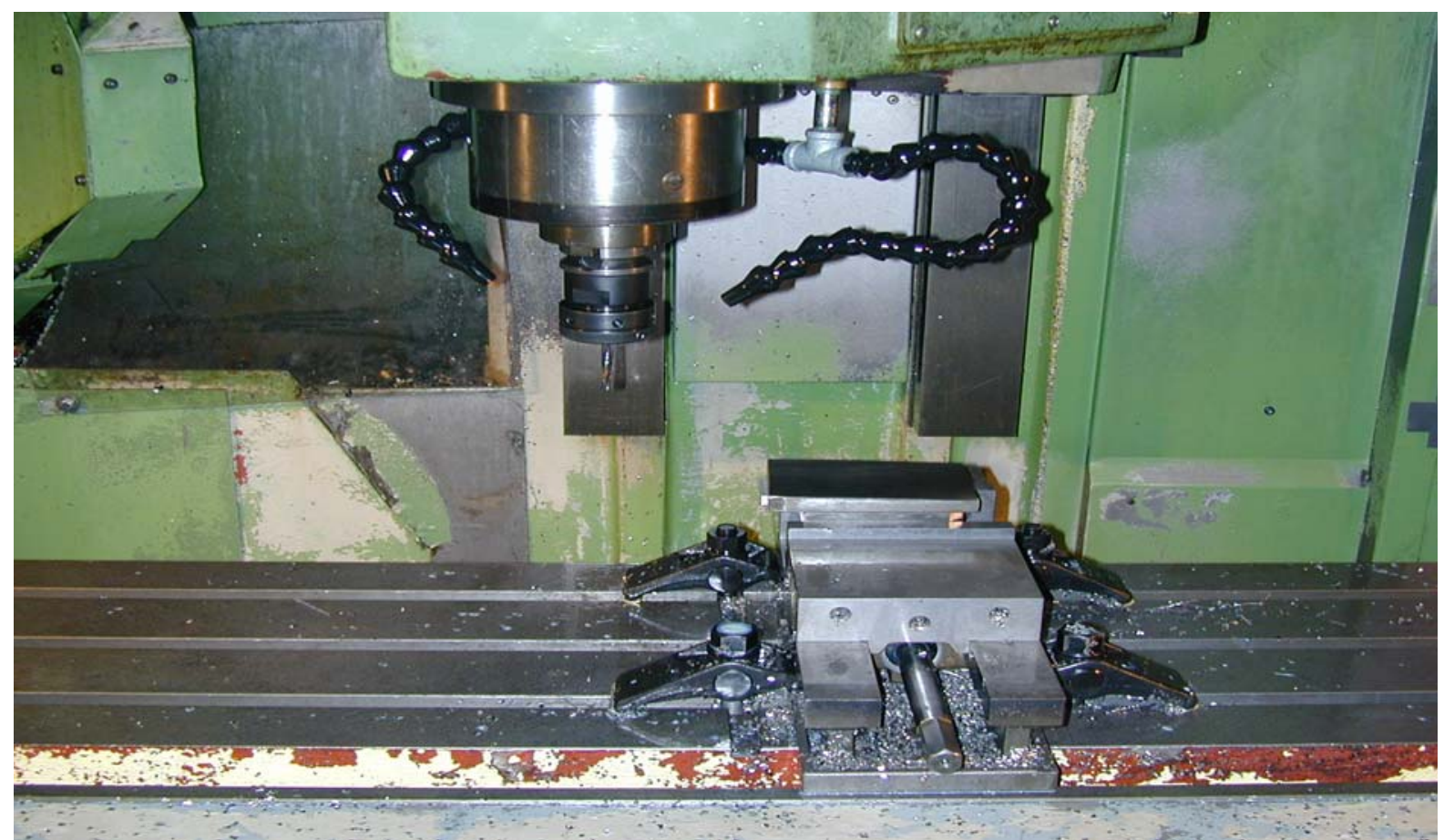

\section{Figure 6. Metal removal fluid sump used for milling in the tongil machining center.}

\section{Milling}

The milling tests were conducted at two speeds: $1528 \mathrm{rpm}$, with a feed rate of $194 \mathrm{~mm} / \mathrm{min}$ (7.64 in/min) or $0.13 \mathrm{~mm}$ (0.005 in) per revolution with an axial depth of cut of $12.7 \mathrm{~mm}$ (0.500 in) and $2292 \mathrm{rpm}$, with a feed rate of $291 \mathrm{~mm} / \mathrm{min}(11.46 \mathrm{in} / \mathrm{min})$ or $0.113 \mathrm{~mm}(0.005$ in) per revolution, with an axial depth of cut of $12.7 \mathrm{~mm}(0.500 \mathrm{in})$. Fluid for flood application was applied at a rate of $6.4 \mathrm{l} / \mathrm{min}(1.7$ gallon/min). The milling cutter was a 25.4 mm (1 in) diameter with an end mill cutter body, model RA215.44-25MN25-15C (Sandvik Group, Sandviken, Sweden) and a single Sandvik carbide, grade SM30 insert, model R215.44-157308-AAM. The metal being machined in the milling test was hot rolled 4140 steel with a hardness of 24-26 HRC. The test piece measured $12.7 \mathrm{~mm}$ (0.5 in) thick. During 
the milling tests, the metal was removed from the edge of the test piece over a distance of $102 \mathrm{~mm}$ (4 in). The photograph in Figure 6 shows the orientation of the work piece, the machined edge of the work piece, and the position of the cutter. Cutting force data for the baseline fluid were collected for the first and tenth passes of the milling cutter, and then every tenth pass thereafter. Cutting force data for the EPA fluid were collected for the first and tenth passes of the milling cutter and then every tenth pass until completing 60 passes, and then twentieth pass thereafter. Tool wear measurements were made immediately following the cutting force measurements. Tests were terminated when the tool wear measurement exceeded 0.015 in $(0.38 \mathrm{~mm})$ uniform wear or 0.030 in $(0.762 \mathrm{~mm})$ maximum wear. The tests were also terminated if they successfully completed 200 passes even though the tool wear did not exceed the maximum uniform wear allowed.

\section{Turning}

The turning tests were conducted at single speed of $700 \mathrm{rpm}$, with a feed rate of 0.0015 in per revolution. Fluid was applied at a rate of $1.7 \mathrm{gal} / \mathrm{min}(6.4 \mathrm{l} / \mathrm{min})$. The turning insert was a Kennametal TNG 322 Carbide and the insert holder was a Kennametal CTFNL-163D (Latrobe, PA 15650). The metal machined in the turning tests was 4140 hot rolled steel with a hardness of 24-26 HRC. The test piece measured 1in diameter and was approximately 8 feet long. The width of cut was 0.100 inch and depth of cut was 0.550 inch. The overall setup of the lathe is illustrated in Figure 5. Torque and force data were collected on the fifth, twenty-fifth and then every twenty-fifth plunge (a plunge is when the cutter starts at the surface or radius of the test piece and cuts to the center). The tool wear measurements were made immediately following the torque and force measurements. A test was terminated when the tool wear measurement exceeded 0.0075 in $(0.19 \mathrm{~mm})$ uniform wear or 0.015 in $(0.38 \mathrm{~mm})$ maximum wear. All tests were terminated after completion of 110 plunges regardless of whether the tool wear exceeded the maximum wear or not.

\section{Metal Removal Fluids}

Two different metal removal fluids were compared in this study, the EPA fluid and the baseline fluid. The EPA fluid was a synthetic metal removal fluid, containing triglycerol and propylene glycol esters of $\mathrm{C}_{8}$ and $\mathrm{C}_{10}$ acids, and was used straight (no dilution) as delivered from the manufacturer. The Trim Sol baseline fluid is manufactured by the Master Chemical Corporation of Perrysburg, Ohio. It is soluble oil (emulsion) and a general-purpose coolant for machining of ferrous and nonferrous materials.

\section{Sampling Procedures}

The sampling procedures were designed to collect time dependent data from the APS and to determine the factors affecting the generation of metal removal fluid mist. Equipment used in this study consisted of two APSs (with diluters if needed), an instantaneous temperature and humidity monitor, continuous recording temperature and humidity monitors, two PC notebook computers, and a video camcorder. The first notebook computer controlled the APS monitoring the background mist concentrations while the second notebook computer controlled the APS measuring the in-duct aerosols. The camcorder was used to document the process activities such as machining start and stop times. The clocks on the two computers and the camcorder were synchronized manually to within less than one second. Both APSs were allowed to warm-up at least one hour prior to any sampling. Using the Aerosol Instrument Manager software, the APSs were configured to record 5000 five second samples. 
This gave a sampling period of seven hours, although sampling for a given test could be terminated earlier without the loss of data. If the diluter was used, a dilution file corresponding to the required dilution ratio was selected in the Aerosol Instrument Manager. This file contained the necessary values to calculate the size distributions accounting for the dilution of the sample stream. Particle size data were collected for aerosols between 0.523 and $20.535 \mu \mathrm{m}$. After setting the sampling parameters, the APSs were set to begin sampling at a specific time, thirty minutes before machining commenced. Both the in-duct and background APSs were configured similarly, with the exception of the use of the diluter on some runs.

Individual sampling sheets were used to document each machining test. An example sample sheet is given in Appendix B. The sampling sheet included entries for: date, fluid type, fluid concentration, sample start time, temperature, humidity, test identification number, in-duct sample filename, background sample filename, and machining process. The sampling sheet also included entries for sample numbers by pass or plunge (i.e., first pass started during APS sample 30, fifth pass started during APS sample 74, etc.). Temperature and humidity measurements were made at the start of a test. In addition to the sampling sheets, additional notes were recorded for each machining test. This information included the machining start times, the passes or plunge at which cutting force and tool wear measurements were made, and information on process upsets.

The video camcorder was started prior to the startup of the machining and was used to document the process upsets and the start and stop times for each pass or plunge. Sample numbers for various passes or plunges (usually every 4-6 passes) were recorded on the sampling sheets to ensure that start and stop times of the machining passes matched with the appropriate samples in the APS data file. Prior to the torque and cutting force measurements, the machining process was placed on hold to configure the data acquisition system for the dynamometer. After collecting the torque and cutting force data, fluid delivery was halted and the tool was removed for wear measurements. The tool was then placed back into the machine, fluid application was restarted, and machining continued. Machining progressed with periodic torque, force, and tool wear measurements (as previously discussed) until the measured tool wear reached the pre-specified value or the maximum number of passes or plunges for the test. At that point, air sampling was discontinued, and the APS data exported to formatted text files. These data files contained particle count aerosol size distributions for each of the five second sampling periods.

\section{Data Calculations}

The text files containing the size distribution data from the APSs were imported into an Excel spreadsheet (Microsoft Corp., Redmond, WA), where additional calculations were made to convert the size distributions to generation rates. The data recorded from the APS consisted of a series of 5 second count distributions of particle size. While these files contained size data from 0.523 to $20.535 \mu \mathrm{m}$, the sizes of interest in this study were $10 \mu \mathrm{m}$ and smaller. Therefore, the particle counts for each of 43 sizes ranges between 0.523 and $10.37 \mu \mathrm{m}$ were included in these analyses. From the count distributions, particle volume was determined by calculating the volume of particulate for each size interval and then summing all of the intervals for all sizes less than $10.37 \mu \mathrm{m}$, as shown in Equation 3. This gives the particle volume for each 5 second sampling interval. 


$$
V_{p_{i}}=\sum_{i=1}^{43} c_{i}\left(\frac{4}{3} \pi\left(\frac{d_{i}}{2}\right)^{3}\right)
$$

Where: $c_{i}=$ the particle counts for the $\mathrm{i}^{\text {th }}$ size range,

$d_{i}=$ the midpoint diameter of the $\mathrm{i}^{\text {th }}$ size range,

$V_{p_{i}}=$ the volume of the particles in the $\mathrm{j}^{\text {th }}$ sample.

The particle volume data were then converted to mass measurements by equation 4 .

$$
M_{p_{j}}=V_{p_{j}} \rho
$$

Where: $M_{p_{j}}=$ Mass of particulate in the $\mathrm{j}^{\text {th }}$ sample,

$\rho=$ Density of the fluid. The density for the EPA fluid was $0.9659 \mathrm{gm} / \mathrm{cc}$ and for the baseline fluid was $0.99 \mathrm{gm} / \mathrm{cc}$

The volume of air sampled for each measurement, $V_{i}$ was $8.33 \times 10^{-5} \mathrm{~m}^{3}(1.0 \mathrm{l} / \mathrm{min}$ for $5 \mathrm{sec})$. Equation 5, then gives the mean particle concentration for each 5 sec sampling interval.

$$
C_{j}=\frac{M_{p_{j}}}{V_{s}}
$$

Where: $C_{j}=$ mean concentration of the $\mathrm{j}^{\text {th }}$ sample.

To this point, both the in-duct and background measurements were treated the same, converting the size distribution data to concentration measurements. The background measurements were used to correct the corresponding duct measurements to account for other activities occurring in the laboratory. The magnitude of this correction was determined by calculating the mean of the lowest $10 \%$ of the background measurements over the duration of the sampling run. In plotting the background data, it was apparent that there was a baseline concentration of particulate, above which, the background concentrations normally remained. This calculation methodology provides an estimate of this baseline concentration and corrects for it.

The duct sample data were coded with a pass or plunge variable, allowing a sample to be associated with the number of the pass or plunge being cut at a particular time. If no pass or plunge was being cut during the collection of a particular sample, then no variable was entered. Each pass or plunge had several samples associated with it, depending upon the length of time required to make the cut. 
The concentration of the mist inside the duct was measured every 5-second. The mist generation rate for each run was computed from a selected sample of the concentration data from the middle (total passes or plunges for the tool divided by two) of the tool's life. However, for runs in which tools did not fail even after completing the maximum number of passes (200 passes for milling) or plunges (110 plunges for turning), the middle of the tool's life was determined from the plot of uniform wear versus passes, at the point when half of the maximum wear occurred. The main concern with using data from the entire life of the tool was that the samples at the beginning and the end of the tool's life would reflect aerosol generation during startup or process upset conditions. Data from the middle of the tool's life would better reflect the generation rate over the majority of the life of the tool. At the beginning of the tool's life, the tool's wear pattern is just being established, while at the end of tool life, the cutting forces are increasing with more heat being generated. These factors may impact the generation rate of the metal removal fluid aerosols. The data in the middle of the tool's life, however, will be closer to steady-state, with wear patterns established and the cutting forces and heat generation being more consistent. For both the milling and turning tests, concentration data from the middle 11 passes or plunges at the middle of tool life were used to calculate the mean concentration for the run.

The data used for the mean concentration for the sampling run covered a period of time when tool wear measurements were made. When the tool was inspected for wear, the machine was not operating, no fluid was being delivered, and the enclosure was opened. To address these conditions, two data points after the last pass before the tool inspection, and two data point before the first pass after tool inspection were included in the mean calculation. Data collected during tool measurements were excluded from the calculation, while data during tool movement between passes were included, as the enclosure was not opened, the tool was still turning, and the fluid was still flowing to the tool. For example, assume a tool's life was 70 passes with tool measurements made every 10 passes. The data points included in the mean concentration calculation would include: two points before pass 30, all of the points during pass 30, two points after pass 30, two points before pass 31, all of the points for passes 31-40 as well as periods between these passes, and two points after pass 40 .

After determining the data to be included in the calculations, the mean concentration was calculated for the 11 passes (or plunges) of the tool's life. This mean concentration was corrected for the background aerosols by subtracting the background concentration (as determined from the background calculation discussed above). This results in a mean concentration for the mid-life of the tool, which was then converted to a generation rate. For a given generation rate, the measured concentration will be a function of the generation rate and the ventilation rate diluting the contaminant. Therefore, for a given concentration and ventilation flow rate, the generation rate can be determined from Equation 6.

$$
G=\bar{C} \cdot Q
$$

Where: $G$ = aerosol generation rate, given run,

$\bar{C}=$ background corrected mean concentration for middle 11 passes (plunges) of a

$Q=$ ventilation flow rate through the machine enclosure. 
Calculations for each run were made to develop a data set including sampling date, machining process, fluid identification, and generation rate. These data were analyzed to determine if there was a difference in the generation rates due to the type of fluid used. 


\section{$\underline{\text { RESULTS }}$}

The results of this study are discussed below under enclosure efficiency and aerosol measurements and generation rates.

\section{Enclosure Efficiency Results}

A series of tests were conducted to determine the efficiency of the enclosure on the Tongil and Hardinge Cobra machines. If the results indicated enclosure efficiencies significantly different from 1.0, the metal removal fluid mist generation rates would be adjusted to account for aerosol losses from the enclosure. The $\mathrm{SF}_{6}$ measurements were made in pairs, with one measurement made with the $\mathrm{SF}_{6}$ released at the cutting interface, and the other measurement with the $\mathrm{SF}_{6}$ directly released into the exhaust ventilation duct. Using Equation 1, the enclosure efficiency for each pair of measurements was determined, resulting in five efficiency values. Appendix $\mathrm{C}$ gives the concentration measurements and the calculated enclosure efficiencies for all pairs. For the Tongil machining center, the mean efficiency was 98.04\% and for the Hardinge Cobra machining center the mean efficiency was $100.23 \%$. A t-test of the duct and cutting position concentration was performed to determine if the enclosure efficiencies were different than $100 \%$. If the differences in the duct and cutting position concentrations were statistically significant, the enclosures efficiencies could be said to be different than $100 \%$, and the mist generation data would need to be adjusted. For the Tongil machining center, the t-test results showed no statistically significant differences between the duct and cutting position concentrations $(\mathrm{P}(\mathrm{T}>\mathrm{t})=0.33)$. For the Hardinge Cobra machining center, the t-test results also showed no statistically significant differences between the duct and cutting position concentrations $(\mathrm{P}(\mathrm{T}>\mathrm{t})=0.94)$. Because of these results, no corrections for enclosure efficiency in either machine were made to the metal removal fluid mist generation rate data collected in this study.

From the tracer gas measurements, the air flow rate through the machine enclosures can be calculated from Equation 2. In Equation 2, $\mathrm{C}_{\text {Duct }}$ was determined by calculating the mean concentration from the five duct concentration samples for each enclosure. The Tongil machining center's calculated exhaust air flow rate was $14.4 \mathrm{~m}^{3} / \mathrm{min}(510 \mathrm{cfm})$. This was the same as the flow rate measured by the pitot tube traverse flow rate of $14.4 \mathrm{~m}^{3} / \mathrm{min}(510 \mathrm{cfm})$. The Hardinge Cobra lathe's calculated exhaust air flow rate was also $14.4 \mathrm{~m}^{3} / \mathrm{min}(510 \mathrm{cfm})$. This also compared closely to the pitot tube traverse flow rate of $14.7 \mathrm{~m}^{3} / \mathrm{min}(519 \mathrm{cfm})$. The pressure drop measurements for the pitot tube traverses before and after the study are given in Appendix C.

\section{Aerosol Measurement Results}

The aerosol data from the APSs were exported by the APS software to text files, which were then imported into individual Excel spreadsheets. Data for particles smaller than $10.37 \mu \mathrm{m}$ were included in the calculations of the mist generation rates as earlier outlined in the Methodology section of this report. Plots of the aerosol concentration versus time for both the duct and background samples are given in Appendix D. Appendix E gives the calculated mist generation rates, along with the experimental parameters (fluid, machining process, fluid rpm, temperature, relative humidity) for each run. Appendix F gives the plots of the temperature and relative humidity inside the enclosure for each sampling day. 


\section{Statistical Data Analysis}

The statistical models used to determine statistical significance are described in the Statistical Appendix, Appendix G. The approach taken was to model the data on the natural log scale, which is appropriate for estimation of ratios. The models fitted to the data were based on the analysis of variance for mixed models, which allow for more than one variance, since for these data, the day-to-day variability and within-day variability must both be determined. All confidence intervals and statistical comparisons discussed below were based on Student's t-tests, using the Bonferroni adjustment, and were based on equations (5) and (6) of Appendix G.

\section{Metal removal fluid mist generation comparison during milling}

The mist generation data were collected for the EPA and baseline fluids at lower and higher milling speeds. The results are summarized in Table 1 and plotted in Figure 7. Of interest are the ratios of the EPA/baseline generation by speed, and the higher/lower speed generation by fluid. The ratio of geometric mean generation rates of EPA to baseline fluid is 85.8 for the lower speed and 25.7 for the higher speed. Since the lower limits of the $95 \%$ confidence intervals for the EPA/Baseline ratios exceed 1, EPA/Baseline > 1 or EPA> baseline at both speeds at the 5\% level. At the lower speed, the mist generation rate of the EPA fluid is at least 12.60 times (lower confidence limit) that of the baseline fluid. For the higher speed, the corresponding lower confidence limit is 3.78. Thus, the percent difference of the two fluids in mist generation rate decreases with increasing milling speed and this decrease is significant at the $5 \%$ level.

The effect of spindle speed on mist generation rate (for each fluid) is much smaller, than the effect of fluid (See Figure 7). However, at the 5\% significance level, the higher speed produced statistically significantly higher generation rates relative to the lower speed based on the fact that the confidence intervals (Table 1) do not include 1.

Table 1

Comparisons of the Geometric Means of Two Fluids at the Two Speeds during Milling

\begin{tabular}{|l|l|l|l|}
\hline & $\begin{array}{l}\text { Higher Speed } \\
\mathrm{mg} / \mathrm{min}\end{array}$ & $\begin{array}{l}\text { Lower Speed } \\
\mathrm{mg} / \mathrm{min}\end{array}$ & $\begin{array}{l}\text { Higher/Lower: Ratio** } \\
\mathbf{9 5 \%} \text { Conf. Interval }\end{array}$ \\
\hline EPA Fluid & 10.69 & 6.95 & $\mathbf{1 . 5 4}$ \\
95\% Conf. Interval & $(7.80,14.65)$ & $(5.07,9.52)$ & $\mathbf{( 1 . 0 4 , 2 . 2 7 ) *}$ \\
\hline Baseline Fluid & 0.416 & 0.0810 & $\mathbf{5 . 1 4}$ \\
95\% Conf. Interval & $(0.0442,3.91)$ & $(0.0086,0.762)$ & $\mathbf{( 1 . 0 1 , 2 5 . 9 4 ) *}$ \\
\hline EPA/Baseline Ratio** & $\mathbf{2 5 . 7 0}$ & $\mathbf{8 5 . 8 0}$ & \\
95\% Conf. Interval & $\mathbf{( 3 . 7 8 , 1 7 5 . 1 1 ) *}$ & $\mathbf{( 1 2 . 6 0 , 5 8 3 . 7 6 ) *}$ & \\
\hline
\end{tabular}

*All confidence limits are computed individually. Thus, confidence limits for a ratio are not the ratios of the confidence limits of the numerator and denominator of the ratio.

** Although confidence intervals for EPA/Baseline ratios for higher and lower speeds overlap, a Student's t-test indicates that the lower speed ratio exceeds the higher speed ratio, at the $5 \%$ level. Similarly the higher speed/lower speed ratio for the baseline exceeds that for the EPA fluid at the 5\% level. 


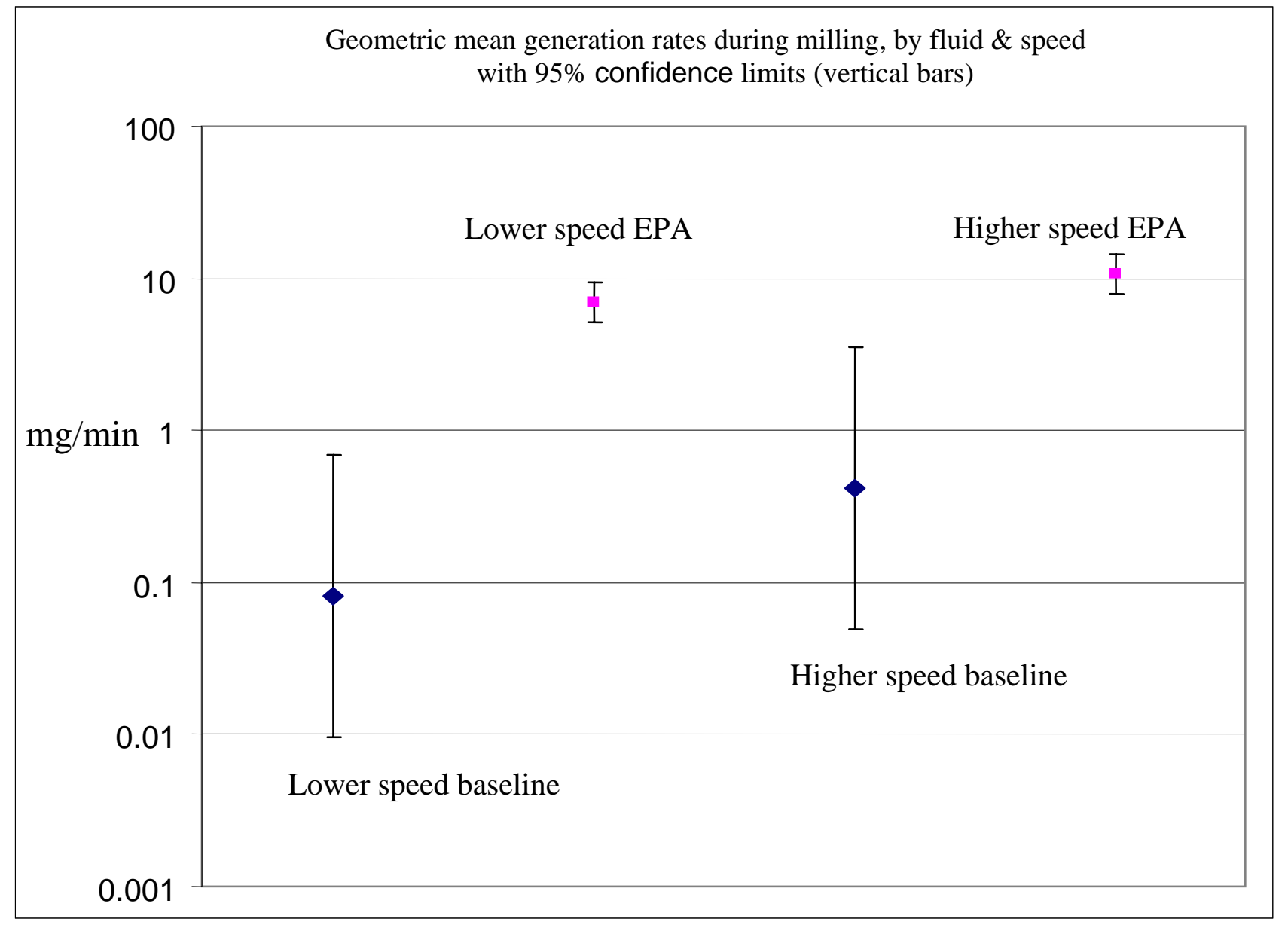

Figure 7. Milling Generation Rates

Table 2

Comparison of EPA and baseline Fluids during Turning

\begin{tabular}{|l|l|}
\hline & Geometric Mean $(\mathrm{mg} / \mathrm{min})$ \\
\hline EPA & 2.37 \\
95\% Conf. Interval & $(1.14,4.88)$ \\
\hline Baseline & 2.83 \\
95\% Conf. Interval & $(1.31,5.60)$ \\
\hline EPA/Baseline Ratio & $\mathbf{0 . 8 4}$ \\
95\% Conf. Interval & $\mathbf{( 0 . 3 8 , \mathbf { 2 . 0 3 } ) *}$ \\
\hline
\end{tabular}

*All confidence limits are computed individually. Thus, confidence limits for a ratio are not the ratios of the confidence limits of the numerator and denominator of the ratio. 


\section{Metal removal fluid mist generation comparison during turning}

Table 2 indicates that the ratio of EPA/baseline is not statistically different from 1, since 1 is in the confidence interval shown in the table. The geometric means of the generation rates of the two fluids are between 2 and 3, and there is no statistical difference between their generation rates.

\section{Metal removal fluid mist generation comparison during milling and turning}

Since the ratio of EPA/baseline was about 0.84 for turning, and greater than 80 for milling at the lower speed, these results are very different. To explain this large difference, the generation rates of the same fluids for the two processes are compared. Figure 8 presents estimates and 95\% confidence intervals for the two fluids' generation rates during lower speed milling and turning. Statistical tests indicate that at the 5\% significance level the baseline generation rates are lower for milling than for turning, and the EPA generation rates are higher for milling at lower speed than for turning. When the corresponding comparisons are made between turning and milling at higher speed, only the EPA fluid yields statistically significant differences at the $5 \%$ level.

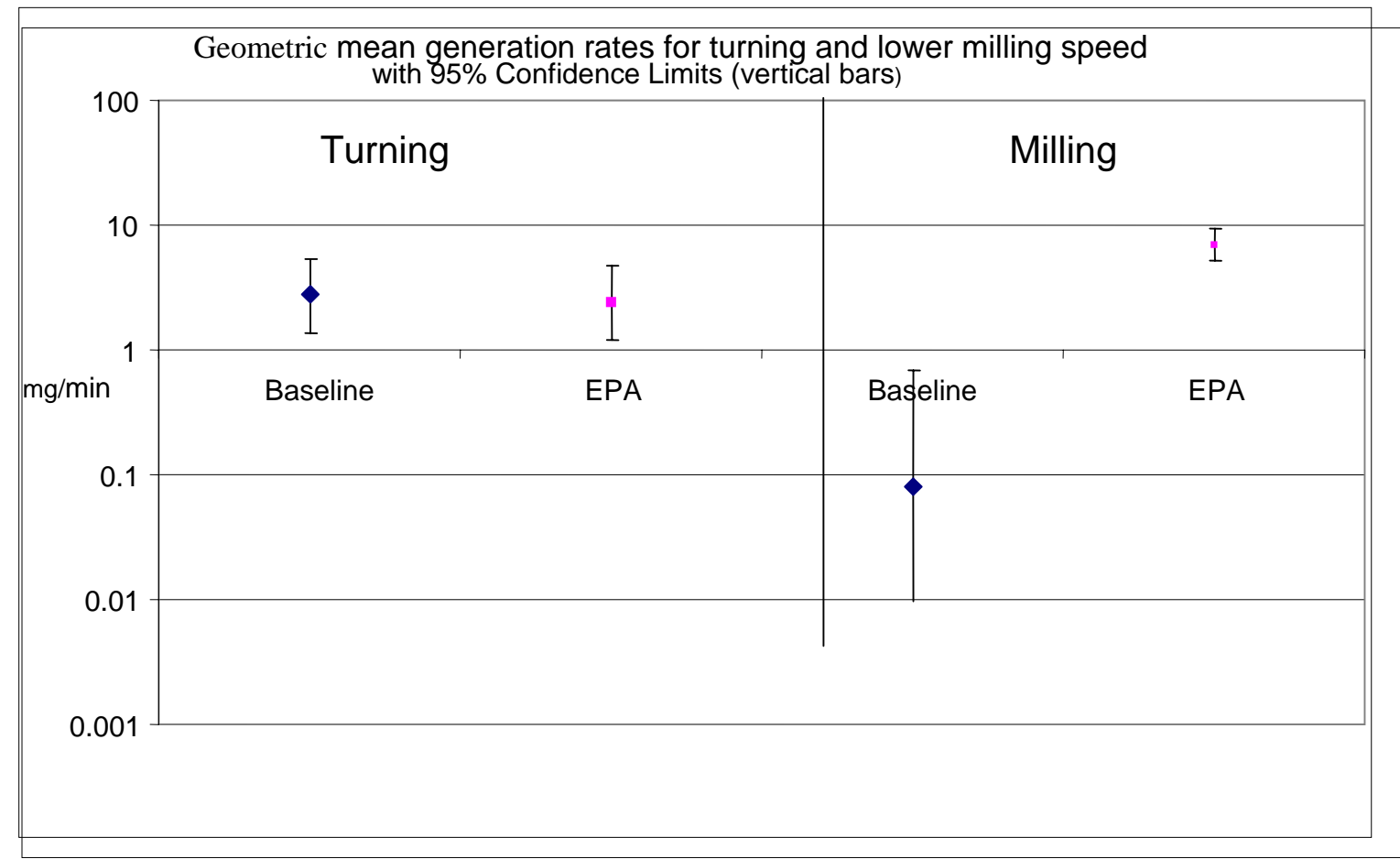

Figure 8. Data during Lower Milling Speed and Turning 


\section{DISCUSSION}

In this section, the overall results of this study associated with evaluating the performance of the EPA and baseline fluids in milling and turning operations are briefly discussed. The major emphasis of the discussion centers around the milling operation since it was evaluated at two speeds, whereas the turning operation was only evaluated at a single speed. For milling the mist generation rates for the EPA and baseline fluids are compared at lower and higher speeds and then the mist generation rates for each fluid is compared at lower and higher speeds. For turning, the mist generation rates for the EPA and baseline fluids are compared at only one speed. Also, the mist generation rates for milling and turning are compared for each fluid. Finally, the generation rates are placed in perspective by calculating equilibrium concentrations from each rate.

The statistical analysis of the milling data indicated there were statistically significant differences at the 5\% level in mist generation rates between the EPA and the baseline fluids at both speeds. The greater differences in mist generation rates occurred at the lower milling speed. At the lower milling speed, the mist generation rates for the baseline fluid ranged from a minimum of 0.024 to a maximum of $0.23 \mathrm{mg} / \mathrm{min}$ and for the EPA fluid ranged from a minimum of 5.501 to a maximum of $9.11 \mathrm{mg} / \mathrm{min}$ ( See Appendix E). The geometric mean mist generation rate of the EPA fluid $(6.95 \mathrm{mg} / \mathrm{min})$ was approximately 86 times the geometric mean mist generation rate of the baseline fluid $(0.081 \mathrm{mg} / \mathrm{min})$. At the higher milling speed the mist generation rates for the EPA and the baseline fluids were closer. The mist generation rates for the baseline fluid ranged from a minimum of 0.039 to a maximum of $1.41 \mathrm{mg} / \mathrm{min}$ and for the EPA fluid ranged from a minimum of 9.03 to a maximum of $13.82 \mathrm{mg} / \mathrm{min}$. Nevertheless, the geometric mean mist generation rate for the EPA fluid $(10.69 \mathrm{mg} / \mathrm{min})$ was more than 26 times higher than the geometric mean mist generation rate for the baseline $(0.416 \mathrm{mg} / \mathrm{min})$. Thus, for milling the differences in mist generation diminishes as machining speed increases, and this difference is significant at the $5 \%$ level.

One explanation for the significant differences in the mist generation between the EPA fluid and the baseline fluid could be attributed to the evaporation of water from the baseline fluid mist during its flow toward the enclosure duct. According to the particle size distribution recorded by the APS, the EPA fluid had a slightly larger particle size distribution relative to the baseline fluid. It is possible that during milling, similar mist generation rates may have been produced with both of the fluids. However, during their journey to the enclosure exhaust duct, the baseline fluid aerosol, which was predominantly water (compared to the EPA fluid, which was straight fluid, no water), may have experienced a significant evaporation of water, resulting in a lower measured mist generation rate for the baseline fluid inside the enclosure duct.

The above results can also be stated in terms of the ratio of higher (2292 rpm) to lower (1528 rpm) speeds for each fluid. The geometric mean mist generation rate for the EPA fluid at the higher milling speed $(10.69 \mathrm{mg} / \mathrm{min})$ was approximately 1.54 times the geometric mean mist generation rate for the EPA fluid at the lower milling speed $(6.950 \mathrm{mg} / \mathrm{min})$. The corresponding ratio of the baseline fluid at the higher milling speed $(0.416 \mathrm{mg} / \mathrm{min})$ to the geometric mean mist generation rate for the baseline fluid at the lower milling speed (geometric mean $0.081 \mathrm{mg} / \mathrm{min}$ ) was approximately 5.14. The baseline fluid appears to 
display a greater increase in mist generation rates relative to the EPA fluid with increasing milling speed. This rapid increase in the mist generation rate may be attributed to differences in the fluids' physical characteristics.

The statistical analysis of the turning data indicated there were no significant differences in the mist generation rates between the EPA fluid and the baseline fluid. The mist generation rates for the baseline fluid during turning ranged from 2.09 to $3.41 \mathrm{mg} / \mathrm{min}$ and for the EPA fluid ranged from 1.89 to $2.98 \mathrm{mg} / \mathrm{min}$. The geometric mean mist generation rate was 2.83 $\mathrm{mg} / \mathrm{min}$ for the baseline fluid, and for the EPA fluid was $2.37 \mathrm{mg} / \mathrm{min}$. One possible explanation for the lack of fluid differences may be the mechanism associated with mist formation during turning. It is possible that mist formation mechanism for the turning operation may not be as dependent of the fluid characteristics and be more dependent on the operational variables of the turning operation such as feed speed, fluid recirculation rate etc. Since the same settings were used for all operational variables associated with the turning operation, it therefore resulted in similar mist generation rates for both fluids.

Comparisons of the milling and turning operations by fluid type indicate that the mist generation rates for the EPA fluid during milling were significantly higher than those of this same fluid during turning, whereas baseline fluid generation rates during milling were significantly lower than those during turning. Overall, it can be concluded that the mist formation associated with the milling may be more dependent on the fluid characteristics of the machine working fluids, while the turning operation may not be as dependent on the characteristics of the fluids, but more dependent on the operational variables.

It is also important to put these generation rates into proper perspective. Stating that a fluid, used with a given machining process and fluid application method has a certain generation rate, does not easily translate into what a worker's actual exposure might be. With few assumptions, the equilibrium concentrations can be estimated for the generation rates with the following equation ${ }^{9}$.

$$
C_{t_{2}}=\frac{K G}{Q}\left[1-e^{\left(\frac{-Q}{K V}\left(t_{2}-t_{1}\right)\right)}\right]+C_{t_{1}} e^{\left(\frac{-Q}{K V}\left(t_{2}-t_{1}\right)\right)}
$$

Where: $C_{t_{2}}=$ Concentration at time $t_{2}$

$C_{t_{1}}=$ Concentration at time $t_{1}$

$t_{1}=$ Time 1

$t_{2}=$ Time 2 , later than time 1

$\mathrm{K}=$ Mixing factor

$\mathrm{G}=$ Generation rate

$\mathrm{Q}=$ Ventilation volumetric flow rate

$\mathrm{V}=$ Volume of room or enclosure.

The mixing factor, $\mathrm{K}$, takes into account the inefficient mixing present within a room or enclosure. Perfect mixing corresponds to a mixing factor of 1 . In an industrial setting, mixing factors will usually range from 3 to 10, with 3 being well mixed and 10 being poorly 
mixed. If $t_{2}$ is allowed to approach infinity, $C_{t_{2}}$ become the equilibrium concentration, $C_{e q}$, and Equation 7 can be reduced to the following:

$$
C_{e q}=\frac{K G}{Q}
$$

For this calculation, assume a ventilation rate (Q) of 1000 CFM (28.31 $\left.\mathrm{m}^{3} / \mathrm{min}\right)$ and a mixing factor of 5, moderately well mixed. In a small manufacturing facility, these assumed values would be reasonable. In a large manufacturing facility, the ventilation rate will be much higher, but the mixing factor may also be somewhat higher. In addition, larger facilities will have multiple machines operating at a given time, increasing the generation rate by some factor. Table 4 summarizes the equilibrium concentrations for the estimated generation rates for milling at two speeds and turning at a single speed.

Table 4

Equilibrium Concentration Based on Geometric Means

\begin{tabular}{|c|c|c|c|c|}
\hline Fluid & $\begin{array}{l}\text { Machine } \\
\text { Process }\end{array}$ & Speed & $\begin{array}{c}\text { Geometric Means } \\
\text { Generation Rate } \\
\text { (mg/min) }\end{array}$ & $\begin{array}{c}\text { Equilibrium } \\
\text { Concentration } \\
\left(\mathbf{m g} / \mathbf{m}^{3}\right)\end{array}$ \\
\hline \multirow[t]{2}{*}{ EPA } & \multirow[t]{2}{*}{ Milling } & Low & 6.95 & 1.23 \\
\hline & & High & 10.69 & 1.89 \\
\hline \multirow[t]{2}{*}{ Baseline } & \multirow[t]{2}{*}{ Milling } & Low & 0.081 & 0.014 \\
\hline & & High & 0.416 & 0.073 \\
\hline EPA & Turning & Low & 2.37 & 0.42 \\
\hline Baseline & Turning & Low & 2.83 & 0.50 \\
\hline \multicolumn{5}{|c|}{ Mixing factor $=5$} \\
\hline
\end{tabular}

During analysis of the equilibrium concentration data in Table 4, the following key observations were noted:

(1).The equilibrium concentrations for the baseline fluid during milling were relatively low, under $0.015 \mathrm{mg} / \mathrm{m}^{3}$, below the current ACGIH and OSHA Permissible Exposure Limit (PEL) for mineral oil mist of $5.0 \mathrm{mg} / \mathrm{m}^{3} \mathrm{TWA}^{10}$ and the NIOSH REL of $0.4 \mathrm{mg} / \mathrm{m}^{3}$ thoracic particle mass or $0.5 \mathrm{mg} / \mathrm{m}^{3}$ total particle mass. ${ }^{11}$

(2). The equilibrium concentrations for the EPA fluid for milling were $1.23 \mathrm{mg} / \mathrm{m}^{3}$ and 1.89 $\mathrm{mg} / \mathrm{m}^{3}$ at the lower and higher speeds, respectively. The concentrations were above the NIOSH REL, but less than the OSHA PEL. 
(3). The equilibrium concentrations for the baseline fluid during turning was $0.50 \mathrm{mg} / \mathrm{m}^{3}$, slightly above the NIOSH REL but below the OSHA PEL. The equilibrium concentration for the EPA fluid during turning was $0.42 \mathrm{mg} / \mathrm{m}^{3}$, below the NIOSH PEL and OSHA PEL.

\section{Study Assumptions}

There were several assumptions made during the execution of this study. Since these assumptions play a significant role in the computations of the mist generation rates, the impact of these assumptions on the overall study needs to be discussed. The major concerns associated with these issues are briefly outlined below.

(1) Only a selected sample of the concentration data from the middle of the tool's life were used for the calculation of the generation rates. It was assumed that at the beginning of the tool's life the tool's wear pattern is being established, and that at the end of tool life the cutting forces increase and more heat is generated. The data from the middle of the tool's life was assumed to be at the steady-state because the wear patterns are established and the cutting forces and heat generation are more consistent. Hence the mean concentration for each run for both milling and turning tests were computed from the concentration data from the middle 11 passes or plunges at the middle of tool life.

(2) The middle of the tool's life for all runs that successfully completed the maximum number of passes or plunges without the tool failing was determined from the point on the curve (passes versus tool wear plot) where half of the uniform tool wear occurred. For most trials, the tool did not fail, but the trial was stopped at a fixed number of passes. Therefore, this alternative method for determining the middle of the tool life was used. (Only for baseline fluid during milling did tools reach the maximum uniform wear)

(3) The overall mist generation rates were corrected for the background levels by computing the background level correction as the average of the lowest $10 \%$ of the measurements taken at a location near the study location. This assumption assumes the background levels remain constant at the low levels throughout the run, even though the background levels in reality may be unstable and non-linear. 


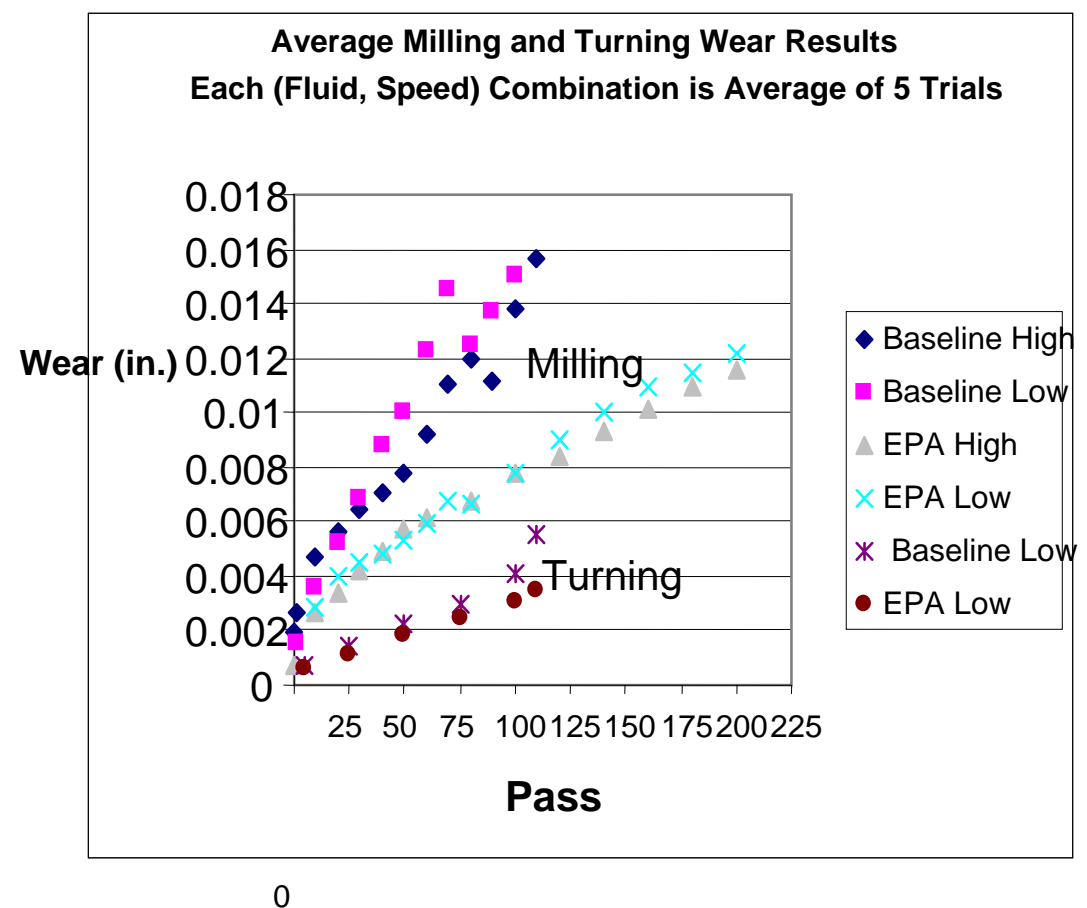

Figure 9. Average Milling and Turning Wear Results

1) \& 2) The first two assumptions are related and discussed together. The Figure 9 illustrates the milling and turning wear data as functions of the number of passes. For large portions of the runs there exists an approximately linear relationship between the wear and the number of passes. Since the wear is approximately linear for much of each run, the rate of wear for each run can, therefore, be assumed to be constant. Since these operational variables such as spindle speed and feed rate apply to both rate of wear and to generation rate, approximate constancy of the spindle speed and the feed rate suggests approximate constancy of generation rate for large portions of each run. Therefore, the choice of passes used in this study to compute the generation rates should not significantly affect the results.

3) Background correction: There are several methods available for correcting the mist generations rate for the background levels. From the statistical point of view any of these methods can be used without compromising the overall results of the study. Since there is no standard method recommended, the selection of a method is entirely at the discretion of the researcher.

Background correction is time consuming and complex. The need for such correction is based on the observation that even if there was no ongoing work generating the contaminant of interest, that contaminant may still be present. Thus, it is logical to estimate what that concentration of contaminant might be, and then adjust measurements taken during the trial for the background estimate. In practice, this adjustment is usually made by subtracting the background estimate from the measured value during the trial. Since the measurements made at a suitable background location during the trial will undergo variation, it is logical to use the lowest measurements made there as a background estimate. Thus, the average of the lowest $10 \%$ of measurements taken at a location near the study operation is used in this study to represent the background level. 
There were several limitations to the data collected in this study, the primary one being the limited variation in the machining parameters. In this study only milling and turning operations were evaluated with limited machining conditions. All the various machining parameters such as spindle speed, depth of cut, feed rate, metal hardness, metal type, etc., may well have a dramatic impact on the metal removal fluid mist generation rate. The effects of process parameters affecting heat generation were also not evaluated. Other parameters that affect the generation of heat include tool geometry, feed rate, depth of cut, and metal hardness and type. The generation of heat is a concern since evaporation and condensation of the metal removal fluid may be a source of metal removal fluid mist generation. If a process generates more heat than was produced in this study (i.e., during machining under severe conditions), metal removal fluid mist generation rates would be expected to increase due to the evaporation and condensation of the fluid applied into the cutting zone. 


\section{CONCLUSIONS AND RECOMMENDATIONS}

During milling, at lower and higher milling speeds, the EPA fluid generated significantly higher mist relative to the baseline fluid. At the lower milling speed, the mist generation rate for the EPA fluid was approximately 86 times greater than the baseline fluid, while at the higher milling speed, it was approximately 26 times greater than the baseline fluid. During turning, the EPA fluid generated similar mist relative to the baseline fluid. This study demonstrates the EPA fluid tends to produce significantly greater mist levels than the baseline fluid at both the lower and higher milling speeds but similar mist levels at the single turning speed evaluated.

According to the data summarized in Table 4, the equilibrium concentrations for the EPA fluid at the lower milling speed was approximately three times above the NIOSH REL while for the higher milling speed was approximately four times above the NIOSH REL. Thus, during milling operations, the workers are at greater risk of significantly higher exposure to the EPA metal removal fluid than to the baseline fluid. Therefore any company planning to use this fluid in their milling operation should provide a mist collector. Since there is significant increase in mist generation rate with increasing milling speed, the critical operational parameters of the mist collector will have to be optimized for each milling speed. The mist generation for the baseline fluid at lower and higher milling speeds was at least 85\% lower than the NIOSH REL and, hence mist collection devices are not as critical. However, under more severe machining conditions, mist generation with the baseline fluid could be significantly higher, requiring the use of mist collection.

The performances of the EPA and baseline fluids were very similar in the turning machining process. No significant differences were detected in the mist generation rates between the EPA and baseline fluids at the turning speed evaluated. Hence, it can be concluded that the worker's exposure to the two fluids will be similar and therefore they could face similar risks of exposure to the two metal removal fluids. Since the mist generations associated with turning are very near the NIOSH REL, companies with machining operations should consider mist collection devices on its turning equipment.

The EPA fluid represents a very strong candidate for use in machining process from an environmental point of view. The major disadvantage of this fluid is that it produces significantly higher mist during its use in milling relative to the baseline fluid. If we can better understand the mist formation mechanism associated with the EPA fluid during milling, we may be able to optimize the critical operational variables that are directly influencing the formation of the mist and thus control mist formation. According to the Thornburg and Leith ${ }^{12}$ there are three mechanisms that lead to mist formation: impaction, centrifugal force and evaporation/condensation. Impaction is associated with fluid spray striking a surface and then bouncing off as droplets. Centrifugal force is associated with mist generated as a fluid-covered surface rotates, thereby releasing droplets. In the third mechanism, the fluid can evaporate under the heat of machining and then re-condense as the air stream cools. Of the three formation mechanisms, evaporation and condensation generate the smallest drops, whereas centrifugal force produced the largest drops. Additional research needs to be conducted with the EPA fluid to identify the mechanism or mechanisms responsible for the higher mist generation rate for the EPA fluid. Once the operational 
variables responsible for generating higher mist are identified, they can then be optimized to produce minimum mist.

Since the mist generation rates for the EPA fluid increased slowly while the baseline fluid increased rapidly with increasing milling speed, it is possible at much higher milling speeds the mist generation of the baseline fluid might meet or exceed that for the EPA fluid. In order to prove this hypothesis, additional research needs to be conducted to determine the effects of higher milling speeds on mist generation for the two fluids. This research would enable us to determine whether the EPA fluid would be a good candidate for use in higher speed machining.

In this study, the mist generation for milling was evaluated at two different feed-rates and speeds while the mist generation rate for the turning was measured at single machining parameters. The effects of such parameters as cutting speeds, rates, tool geometry, material hardness and metal type were not evaluated. Many of these operational variables may directly or indirectly affect the mist generation of the two fluids being investigated in this study. Therefore, additional research needs to be conducted with the EPA and the baseline fluids to evaluate the impact of other operational variables on the mist generation.

It should be understood that this evaluation is limited to one milling machine and one turning machine. It could be more informative to do a longer study of these processes. Also, since the research of this study has shown some potential for the new EPA fluid in milling and turning machining process, it is recommended that additional research be conducted in evaluating the performance of this new fluid in other common machining process such as drilling and grinding. 


\section{REFERENCES}

1. Cerren, Daniel R: Acute Eye Irritation in Rabbits: MB Research Laboratories: Project No. MB 03-11670.04. Spinnerstown, Pennsylvania. 2004.

2. Hoff, Theresa: Acute Dermal Irritation in Rabbits: MB Research Laboratories: Project No. MB 03-11670.03. Spinnerstown, Pennsylvania. 2004.

3. Cerren, Daniel R: Acute Oral Toxicity LD 50 in Rats: MB Research Laboratories: Project No. MB 03-11846.01. Spinnerstown, Pennsylvania. 2004..

4. Heitbrink, WA; Baron, P: Coincidence in Time-of-Flight Aerosol Spectrometer: Phantom Particle Creation. Aerosol Sci Tech 14:112-126. 1991

5. American Conference of Government Industrial Hygienists (ACGIH): Industrial Ventilation - A Manual of Recommended Practices, 23 rd edition. Cincinnati, Ohio. 1996.

6. Earnest, GS; Heitbrink, WA; Mickelsen, RL; Mead, KR; D’Arcy, JB: Leakage from a Metal Machining Center - A Case Study. AAMA Symposium Proceedings: metal removal Symposium II - The Industrial Metalworking Environment: Assessment and Control of Fluids, September 15-18, 1997, Detroit, Michigan. pp 163-167. American Automobile Manufacturers Association, Washington D.C. 1998.

7. TechSolve: The IWIG manual is available on TechSolve's website: http://www.techsolve.org/pdf/Pollution\%20Prevention_GreenFluidsManual.PDF. Institute for Advanced Manufacturing Sciences, Inc. Cincinnati, Ohio. April 2001.

8. TechSolve: Pollution Prevention Guide to Using Metal Removal Fluids in Machining Operations.

http://www.techsolve.org/pdf/Pollution\%20Prevention_GreenFluidsManual.PDF Institute for Advanced Manufacturing Sciences, Inc. Cincinnati, Ohio. April 2001.

9. Gressel, MG, Heitbrink, WA, ed: Analyzing Workplace Exposures Using Direct Reading Instruments and Video Exposure Monitoring Techniques. DHHS (NIOSH) Publication No.92-104. National Institute for Occupational Safety and Health, Cincinnati, Ohio 1992.

10. Code of Federal Regulations. 29 CFR 1910.1000 Air Contaminants.

11. NIOSH: Criteria for a Recommended Standard: Occupational Exposure to Metalworking Fluids. DHHS (NIOSH) Publication No. 98-102. National Institute for Occupational Safety and Health, Cincinnati, Ohio. 1998.

12. Thornburg, J. and Leith, D. “ Size Distribution of Mist Generated During Metal Machining,” Appld. Occup. Environ. Hyg.,15.8 pp618-628.

- 13. SAS Institute: SAS/STAT Users Guide, Version 8. Cary, N.C.: SAS Institute, 1999.

- $\quad$ pp.2083-2226. 
14. Littell, R. C., Milliken, G.A., Stroup, W.W., Wolfinger, R.D. Sas System for Mixed Models. Cary, NC: SAS Institute, Inc. 1996, p.49.

15. Barnett, V., and Lewis, T. Outliers in Statistical Data. New York, John Wiley \& Sons, Inc.

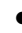

- $\quad$ 16. Miller, Jr., R. Simultaneous Statistical Inference, $2^{\text {nd }}$ Ed. N.Y.: Springer-Verlag, 1981. 


\section{APPENDIX A}

\section{Instrument Calibration Data}

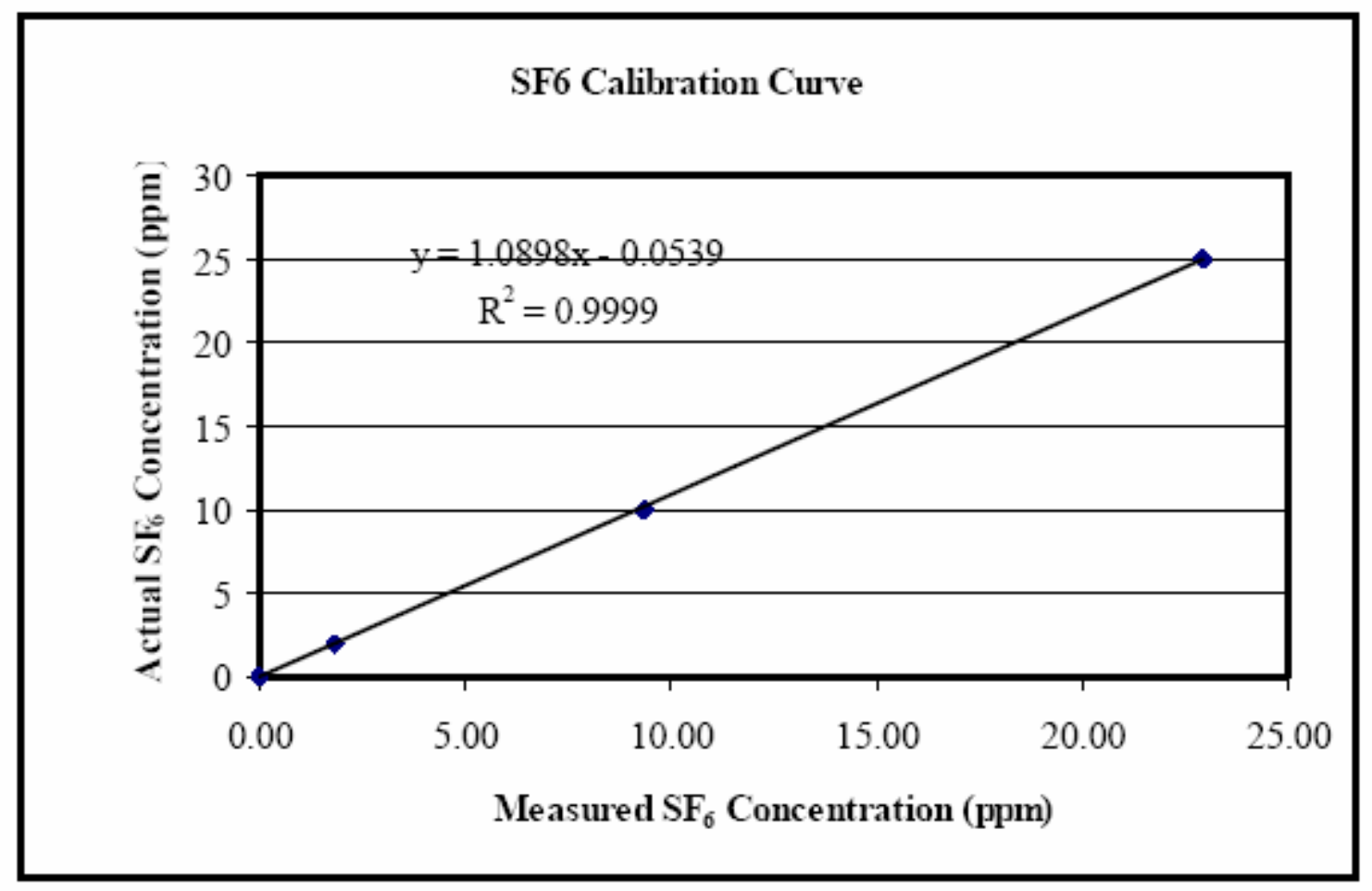

Figure A-1. $\mathrm{SF}_{6}$ calibration curve for $\mathrm{B} \& \mathrm{~K}$ used in Tongil machining center enclosure efficiency evaluation. Line shown is the regression line. Linear regression equation and $\mathrm{R}^{2}$ values are also given. 


\section{Data Sheet \\ TSI Model 3302A Diluter}

Date of Calibration: October 29, 1997

Serial Number: 117

20:1 Dilution Capillary

Flowrate $=0.25$ SLPM

Serial Number: $117 \mathrm{~A}$

Aerosol Path DeltaP $=0.235$ inH2O

Total DeltaP $=0.420 \mathrm{inH} 2 \mathrm{O}$

100:1 Dilution Capillary

Flowrate $=0.05$ SLPM

Serial Number: $117 \mathrm{~A}$

Aerosol Path DeltaP $=0.305$ in $22 \mathrm{O}$

Total DeltaP $=0.510 \mathrm{inH} 2 \mathrm{O}$

\footnotetext{
TSI Incorponated does hereby certify that all materials, components, and workmanship used in the marufacture of this equipment are in strict accondance with the applicable specifications agreed upon by TSI and the customer and with all published specifications. Alt performance and acceptance tests were successfully conducted according to required specifications. TSI thcorporated certifies that the instruments used to calibrate this instument are traceable to the National Institute of Standards and Technology (NIST), where applicable, and internal TSI calibration standards where NIST standards do not exist

Recorded by:
} 


\section{TSI.}

Particle Instrument Division

Mailing Address: P.O. Box 64394 St.Paul, MN 55164 USA

Shipping Address: 500 Cardigan Raad Shareview. MN 55126 USA

Phipping Address: 500 Cardigan Roud 1 . $800-677.2708$ or $(651) 490.2833$ FAX: $(651) 490-3860$

\section{Certificate of Calibration}

TSI model 3321

Date of Calibration: February 14, 2005

Serial Number: 1013

$\begin{array}{cccc} & \begin{array}{c}\text { Geometric } \\ \text { Diameter }(\mu \mathrm{m})\end{array} & \begin{array}{c}\text { Accumulator } \\ \text { Median Bin }\end{array} & \begin{array}{c}\text { Particle } \\ \text { Density }(\mathrm{g} / \mathrm{ml})\end{array} \\ \text { Particle \#1 } & .360 & 181.0 & 1.05 \\ \text { Particle \#2 } & .404 & 182.8 & 1.05 \\ \text { Particle \#3 } & .519 & 187.6 & 1.05 \\ \text { Particle \#4 } & .701 & 196.3 & 1.05 \\ \text { Particle \#5 } & .993 & 212.7 & 1.05 \\ \text { Particle \#6 } & 2.013 & 272.5 & 1.05 \\ \text { Particle \#7 } & 4.996 & 416.6 & 1.05 \\ \text { Particle \#8 } & 6.992 & 501.3 & 1.05 \\ \text { Particle \#9 } & 10.15 & 606.0 & 1.05 \\ \text { Particle \#10 } & 15.02 & 755.0 & 1.05 \\ \text { Particle \#11 } & 20.00 & 889.3 & 1.05\end{array}$

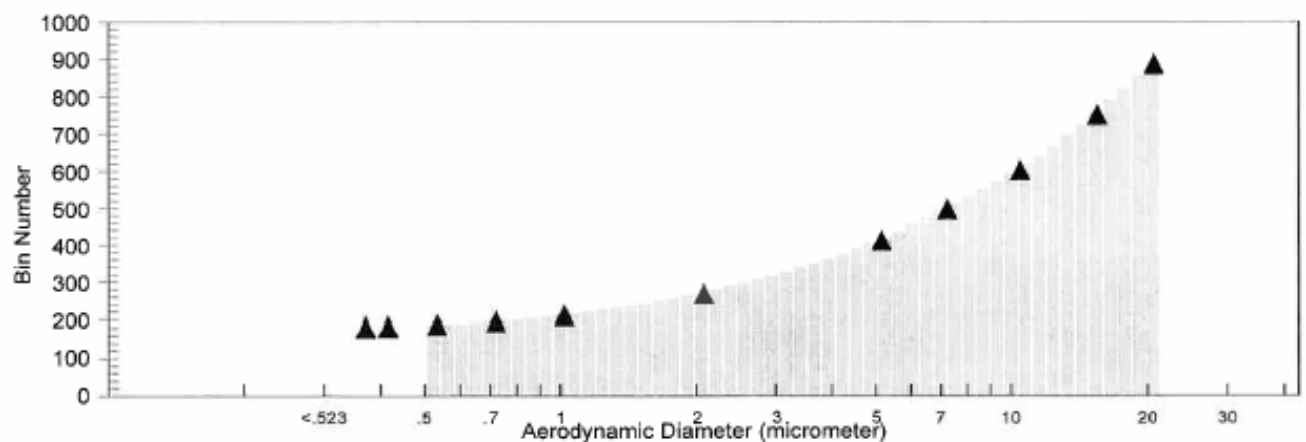

TSI Incorporated does hereby certify, that all materials, components, and workmanship used in the manufacture of this equipment are in strict accordance wish the applicable specifications agreed upon by 787 and the customer and with all published specifications All perfarmance and acceptance tests vere successully conducled according to required specifications. $7 \mathrm{~S} /$ /ncorporated certifies that the instruments used to calibrate this instrument are traceable to the National Institute of Standards and Technology (NIST), where applicable, and internal TSI calibration standards where NIST standards do not exist

Calibrated by: 
TSI.

Particle Insfrument Divisian

Mailing Address: P.O. Box 64394 St. Paul, MN 55I64 USA

Shipping Address: 500 Cardigan Road Shareview, MN 55126 USA

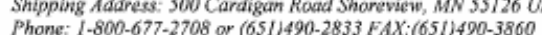

\section{Certificate of Calibration}

TSI model 3321

Date of Calibration: February 14, 2005

Serial Number: $\quad 1314$

$\begin{array}{cccc} & \text { Diameter }(\mu \mathrm{m}) & \text { Median Bin } & \text { Density }(\mathrm{g} / \mathrm{ml}) \\ \text { Particle \#1 } & .360 & 181.0 & 1.05 \\ \text { Particle \#2 } & .404 & 182.8 & 1.05 \\ \text { Particle \#3 } & .519 & 187.6 & 1.05 \\ \text { Particle \#4 } & .701 & 197.3 & 1.05 \\ \text { Particle \#5 } & .993 & 216.4 & 1.05 \\ \text { Particle \#6 } & 2.013 & 273.9 & 1.05 \\ \text { Particle \#7 } & 4.996 & 427.9 & 1.05 \\ \text { Particle \#8 } & 6.992 & 503.0 & 1.05 \\ \text { Particle \#9 } & 10.15 & 637.5 & 1.05 \\ \text { Particle \#10 } & 15.02 & 807.9 & 1.05 \\ \text { Particle \#11 } & 20.00 & 936.0 & 1.05\end{array}$

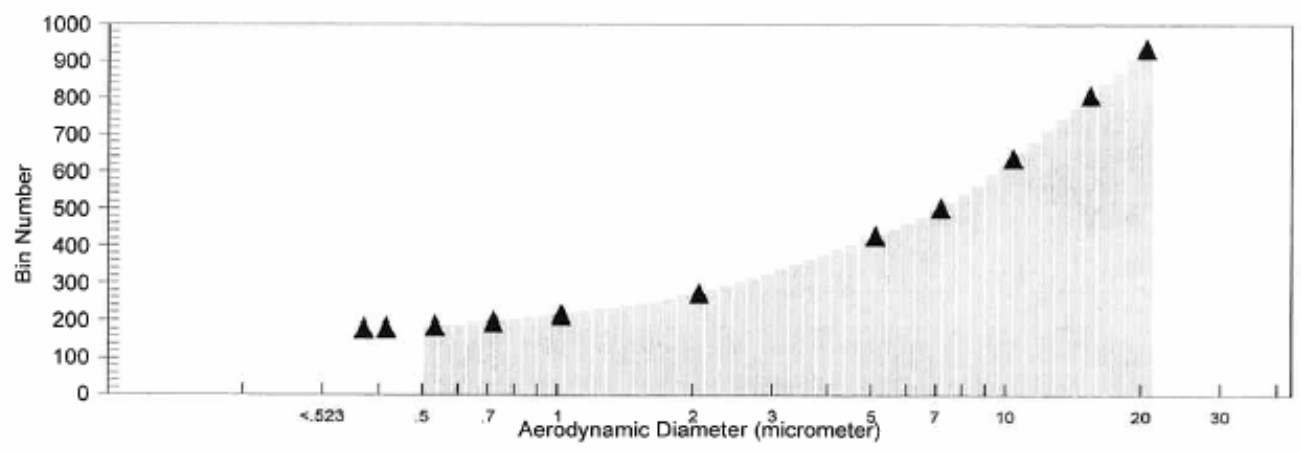

TSI Incorporated does hereby certify that all materials, components, and warkmanship used in the manufacture of this equipment are in strict accordance with the applicable specifications agreed upon by TSI and the customer and with all published specifications. All performance and acceptance tests were successfully conducted according to requined speciffeations TSI incorporated certifies that the instruments used to calibrate this instrument are traceable to the National Institute of Standards and Technology (NIST). where applicable, and internal TS/ calibration standards where NIST standards do not exist

Calibrated by:

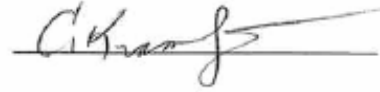

\section{APPENDIX B}




\section{Sample Data Sheet Example}

\begin{tabular}{|c|c|c|c|c|c|c|c|}
\hline Date & 1 & 1 & Tem & $\mathrm{re}$ & $\mathrm{H}$ & Hum & $\%$ \\
\hline Sampl & ta File & & & Samp & rt Tim & $\therefore$ & \\
\hline Porlo & $d D^{2}$ & & & Mach & tart Ti & : & \\
\hline Backg & a Date & & & 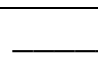 & od & - Mic & rication \\
\hline Fluid & & oncent & & & & Drill & Turn \\
\hline Pass & Pass & Pass & Pass & Pass & Pass & Pass & Pass \\
\hline 1 & 6 & 11 & 16 & 21 & 26 & 31 & 36 \\
\hline 2 & 7 & 12 & 17 & 22 & 27 & 32 & 37 \\
\hline 3 & 8 & 13 & 18 & 23 & 28 & 33 & 38 \\
\hline 4 & 9 & 14 & 19 & 24 & 29 & 34 & 39 \\
\hline 5 & 10 & 15 & 20 & 25 & 30 & 35 & 40 \\
\hline Pass & Pass & Pass & Pass & Pass & Pass & Pass & Pass \\
\hline 41 & 46 & 51 & 56 & 61 & 66 & 71 & 76 \\
\hline 42 & 47 & 52 & 57 & 62 & 67 & 72 & 77 \\
\hline 43 & 48 & 53 & 58 & 63 & 68 & 73 & 78 \\
\hline 44 & 49 & 54 & 59 & 64 & 69 & 74 & 79 \\
\hline 45 & 50 & 55 & 60 & 65 & 70 & 75 & 80 \\
\hline Pass & Pass & Pass & Pass & Pass & Pass & Pass & Pass \\
\hline 81 & 86 & 91 & 96 & 101 & 106 & 111 & 116 \\
\hline 82 & 87 & 92 & 97 & 102 & 107 & 112 & 117 \\
\hline 83 & 88 & 93 & 98 & 103 & 108 & 113 & 118 \\
\hline 84 & 89 & 94 & 99 & 104 & 109 & 114 & 119 \\
\hline 85 & 90 & 95 & 100 & 105 & 110 & 115 & 120 \\
\hline
\end{tabular}

\section{APPENDIX C}

Enclosure Efficiency and Air Flow Measurement 
Table C-1 $S F_{6}$ sampling results for enclosure efficiency evaluation of Tongil milling machining center

\begin{tabular}{|c|c|c|c|c|c|c|c|c|c|}
\hline \multirow[b]{3}{*}{ Pair } & \multicolumn{4}{|c|}{ Cut Position } & \multicolumn{4}{|c|}{ Duct Position } & \multirow{3}{*}{ Efficiency } \\
\hline & \multicolumn{2}{|c|}{ Background } & \multirow[b]{2}{*}{ Measure } & \multirow{2}{*}{$\begin{array}{l}\text { Adjusted } \\
\text { Measure }\end{array}$} & \multicolumn{2}{|c|}{ Background } & \multirow[b]{2}{*}{ Measure } & \multirow{2}{*}{$\begin{array}{l}\text { Adjusted } \\
\text { Measure }\end{array}$} & \\
\hline & Pre- & Post- & & & Pre- & Post- & & & \\
\hline 1 & 0.1145 & 0.6082 & $\begin{array}{l}15.37 \\
\end{array}$ & 15.01 & 0.6082 & 0.6548 & 15.50 & 14.87 & 101.0 \\
\hline 2 & 0.6549 & 0.8216 & 16.04 & 15.30 & 0.8216 & 0.8932 & 15.74 & 14.89 & 102.8 \\
\hline 3 & 0.7649 & 0.8383 & 14.67 & 13.87 & 0.5427 & 0.7648 & 15.41 & 14.76 & 93.97 \\
\hline 4 & 0.8383 & 1.0123 & 15.74 & 14.82 & 1.0123 & 1.0714 & 16.14 & 15.10 & 98.12 \\
\hline 5 & 1.1129 & 1.0560 & 15.07 & 13.99 & 1.0714 & 1.1129 & 15.91 & 14.82 & 94.37 \\
\hline
\end{tabular}

$$
\left(\begin{array}{l}
\text { Adjusted } \\
\text { measure }
\end{array}\right)=\text { Measure }-\left(\frac{\text { Pr e-Background }+ \text { Post }- \text { Backgorund }}{2}\right)
$$

\section{Milling Machine Enclosure Efficiency is $\mathbf{9 8 . 1 \%}$}

Table C-2. Pitot tube traverse data for milling machining center enclosure exhaust system prior to the startup of the study.

\begin{tabular}{|c|c|c|c|c|c|}
\hline \multicolumn{3}{|c|}{ X-Direction Traverse } & \multicolumn{3}{|c|}{ Y-Direction Traverse } \\
\hline $\begin{array}{c}\text { Traverse } \\
\text { Point }\end{array}$ & $\begin{array}{l}\text { Velocity } \\
\text { Pressure }\end{array}$ & Velocity & $\begin{array}{c}\text { Traverse } \\
\text { Point }\end{array}$ & $\begin{array}{l}\text { Velocity } \\
\text { Pressure }\end{array}$ & Velocity \\
\hline 1 & 0.28 & 2119 & 1 & 0.24 & 1962 \\
\hline 2 & 0.42 & 2659 & 2 & 0.46 & 2716 \\
\hline 3 & 0.45 & 2687 & 3 & 0.47 & 2746 \\
\hline 4 & 0.45 & 2687 & 4 & 0.46 & 2716 \\
\hline 5 & 0.46 & 2716 & 5 & 0.43 & 2626 \\
\hline 6 & 0.47 & 2746 & 6 & 0.42 & 2596 \\
\hline 7 & 0.42 & 2596 & 7 & 0.35 & 2369 \\
\hline \multicolumn{2}{|c|}{$\begin{array}{l}\text { Mean Velocity } \\
\text { X-Direction }\end{array}$} & 2601 & \multicolumn{2}{|c|}{$\begin{array}{l}\text { Mean Velocity } \\
\text { Y-Direction }\end{array}$} & 2533 \\
\hline \multicolumn{6}{|c|}{$\begin{array}{lr}\text { System Velocity }=2567 \mathrm{ft} / \mathrm{min} & \text { Duct Area }=0.1963 \mathrm{ft}^{2} \\
\text { System Exhaust Volume }=2567 \mathrm{ft} / \mathrm{min}^{*} 0.1963 \mathrm{ft}^{2}=504.00 \mathrm{CFM}\end{array}$} \\
\hline
\end{tabular}

Table C-3. Pitot tube traverse data for milling machining center enclosure exhaust system after completion of the startup of the study. 


\begin{tabular}{|c|c|c|c|c|c|}
\hline $\begin{array}{c}\text { Traverse } \\
\text { Point }\end{array}$ & $\begin{array}{l}\text { Velocity } \\
\text { Pressure }\end{array}$ & Velocity & $\begin{array}{c}\text { Traverse } \\
\text { Point }\end{array}$ & $\begin{array}{l}\text { Velocity } \\
\text { Pressure }\end{array}$ & Velocity \\
\hline 1 & 0.40 & 2533 & 1 & 0.38 & 2469 \\
\hline 2 & 0.48 & 2775 & 2 & 0.48 & 2775 \\
\hline 3 & 0.50 & 2832 & 3 & 0.48 & 2775 \\
\hline 4 & 0.48 & 2775 & 4 & 0.48 & 2775 \\
\hline 5 & 0.45 & 2687 & 5 & 0.48 & 2775 \\
\hline 6 & 0.41 & 2564 & 6 & 0.45 & 2687 \\
\hline 7 & 0.32 & 2266 & 7 & 0.26 & 2042 \\
\hline \multicolumn{2}{|c|}{$\begin{array}{l}\text { Mean Velocity } \\
\text { X-Direction }\end{array}$} & 2633 & \multicolumn{2}{|c|}{$\begin{array}{l}\text { Mean Velocity } \\
\text { Y-Direction }\end{array}$} & 2614 \\
\hline \multicolumn{6}{|c|}{ System Velocity $=2624 \mathrm{ft} / \mathrm{min} \quad$ Duct Area $=0.1963 f t^{2}$} \\
\hline \multicolumn{6}{|c|}{ System Exhaust Volume $=2624 \mathrm{ft} / \mathrm{min}^{*} 0.1963 \mathrm{ft}^{2}=515 \mathrm{CFM}$} \\
\hline
\end{tabular}

\section{Milling Enclosure Exhaust Airflow}

The overall enclosure exhaust airflow on the Tongil milling machine during the milling study is the average of the exhaust airflow before the startup of the study and after completion of the study.

$$
\begin{aligned}
\text { Exhaust airflow }= & (\mathrm{C} 2 \text { airflow }+\mathrm{C} 3 \text { airflow }) / 2 \\
& =(504 \mathrm{cfm}+515 \mathrm{cfm}) / 2 \\
& =(1019) / 2 \\
& =509.5 \mathrm{cfm} \\
& =\underline{\mathbf{5 1 0} \mathbf{c f m} .}
\end{aligned}
$$

Table C-4 $\mathrm{SF}_{6}$ sampling results for enclosure efficiency evaluation of Hardinge turning machining center

\begin{tabular}{|l|l|l|l|}
\hline & Cut Position & Duct Position & \\
\hline
\end{tabular}




\begin{tabular}{|c|c|c|c|c|c|c|c|c|c|}
\hline \multirow{2}{*}{ Pair } & \multicolumn{2}{|c|}{ Background } & \multirow{2}{*}{ Measure } & \multirow{2}{*}{$\begin{array}{l}\text { Adjusted } \\
\text { Measure }\end{array}$} & \multicolumn{2}{|c|}{ Background } & \multirow{2}{*}{ Measure } & \multirow{2}{*}{$\begin{array}{l}\text { Adjusted } \\
\text { Measure }\end{array}$} & \multirow[t]{2}{*}{ Efficiency } \\
\hline & Pre- & Post- & & & Pre- & Post- & & & \\
\hline 1 & $\mathrm{~N} / \mathrm{A}$ & N/A & 17.5 & 17.5 & $\mathrm{~N} / \mathrm{A}$ & N/A & 16.5 & 16.5 & 106.0 \\
\hline 2 & $\mathrm{~N} / \mathrm{A}$ & N/A & 17.1 & 17.1 & N/A & N/A & 16.7 & 16.7 & 102.0 \\
\hline 3 & $\mathrm{~N} / \mathrm{A}$ & N/A & 17.0 & 17.0 & $\mathrm{~N} / \mathrm{A}$ & N/A & 16.9 & 16.9 & 101.0 \\
\hline 4 & $\mathrm{~N} / \mathrm{A}$ & N/A & 17.4 & 17.4 & $\mathrm{~N} / \mathrm{A}$ & N/A & 16.9 & 16.9 & 103.0 \\
\hline 5 & $\mathrm{~N} / \mathrm{A}$ & N/A & 15.6 & 15.6 & N/A & N/A & 17.5 & 17.5 & 89.1 \\
\hline
\end{tabular}

N/A = Not measured

Milling Machine Enclosure Efficiency is $\mathbf{1 0 0 . 2 \%}$

Table C-5. Pitot tube traverse data for turning machining center enclosure exhaust system.

\begin{tabular}{|c|c|c|c|c|c|}
\hline \multicolumn{3}{|c|}{ X-Direction Traverse } & \multicolumn{3}{|c|}{ Y-Direction Traverse } \\
\hline $\begin{array}{l}\text { Traverse } \\
\text { Point }\end{array}$ & $\begin{array}{l}\text { Velocity } \\
\text { Pressure }\end{array}$ & Velocity & $\begin{array}{l}\text { Traverse } \\
\text { Point }\end{array}$ & $\begin{array}{l}\text { Velocity } \\
\text { Pressure }\end{array}$ & Velocity \\
\hline 1 & 0.35 & 2369 & 1 & 0.38 & 2469 \\
\hline 2 & 0.44 & 2657 & 2 & 0.47 & 2646 \\
\hline 3 & 0.50 & 2832 & 3 & 0.52 & 2888 \\
\hline 4 & 0.50 & 2832 & 4 & 0.51 & 2860 \\
\hline 5 & 0.47 & 2746 & 5 & 0.47 & 2746 \\
\hline 6 & 0.45 & 2687 & 6 & 0.45 & 2687 \\
\hline 7 & 0.36 & 2403 & 7 & 0.27 & 2081 \\
\hline \multicolumn{2}{|c|}{$\begin{array}{l}\text { Mean Velocity } \\
\text { X-Direction }\end{array}$} & 2647 & \multicolumn{2}{|c|}{$\begin{array}{c}\text { Mean Velocity } \\
\text { Y-Direction }\end{array}$} & 2640 \\
\hline \multicolumn{6}{|c|}{ System Velocity $=2644 \mathrm{ft} / \mathrm{min} \quad$ Duct Area $=0.1963 \mathrm{ft}^{2}$} \\
\hline \multicolumn{6}{|c|}{ System Exhaust Volume $=2644 \mathrm{ft} / \mathrm{min}^{*} 0.1963 f t^{2}=519 \mathrm{CFM}$} \\
\hline
\end{tabular}

\section{APPENDIX D}

Enclosure and Background Aerosol Generation Plots 


\section{Milling EPA Fluid Enclosure Run 1 7/19/04}

틀

हᄐ

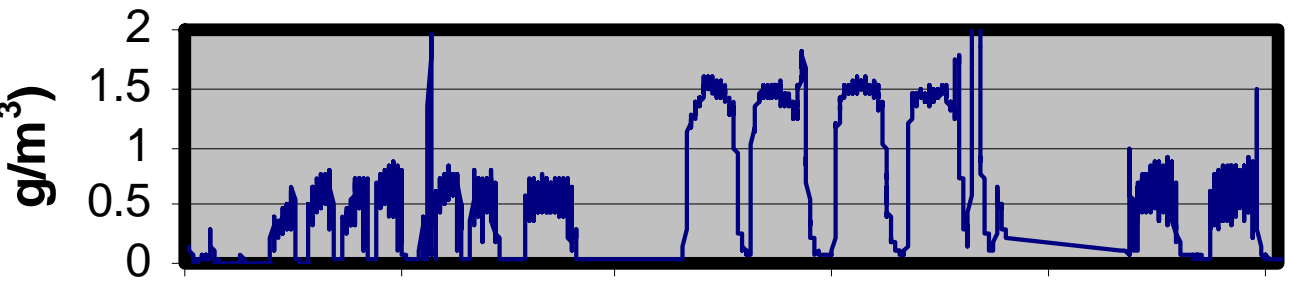

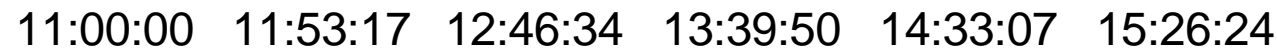

Time (hh:mm:ss)

\section{Milling EPA Fluid \\ Background Run $1 \quad 7 / 19 / 04$}

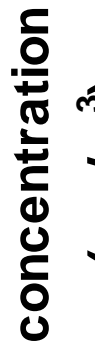

0.2

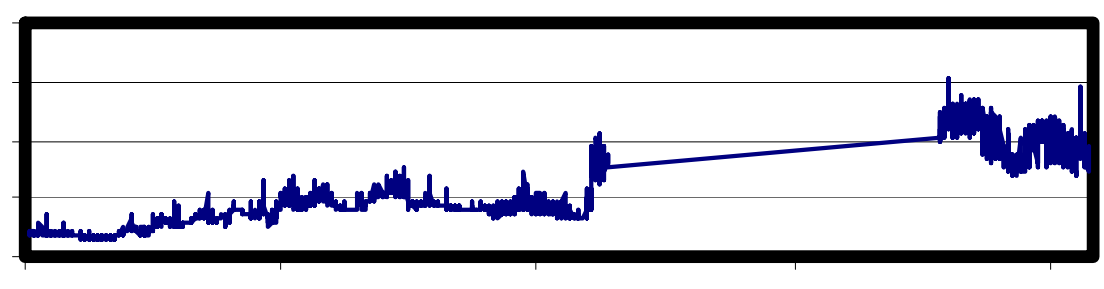

10:00:00 $\quad 11: 04: 48 \quad 12: 09: 36 \quad 13: 14: 24 \quad 14: 19: 12$

time (hh:mm:ss) 


\section{Milling EPA Fluid \\ Enclosure Run 2 7/26/04}

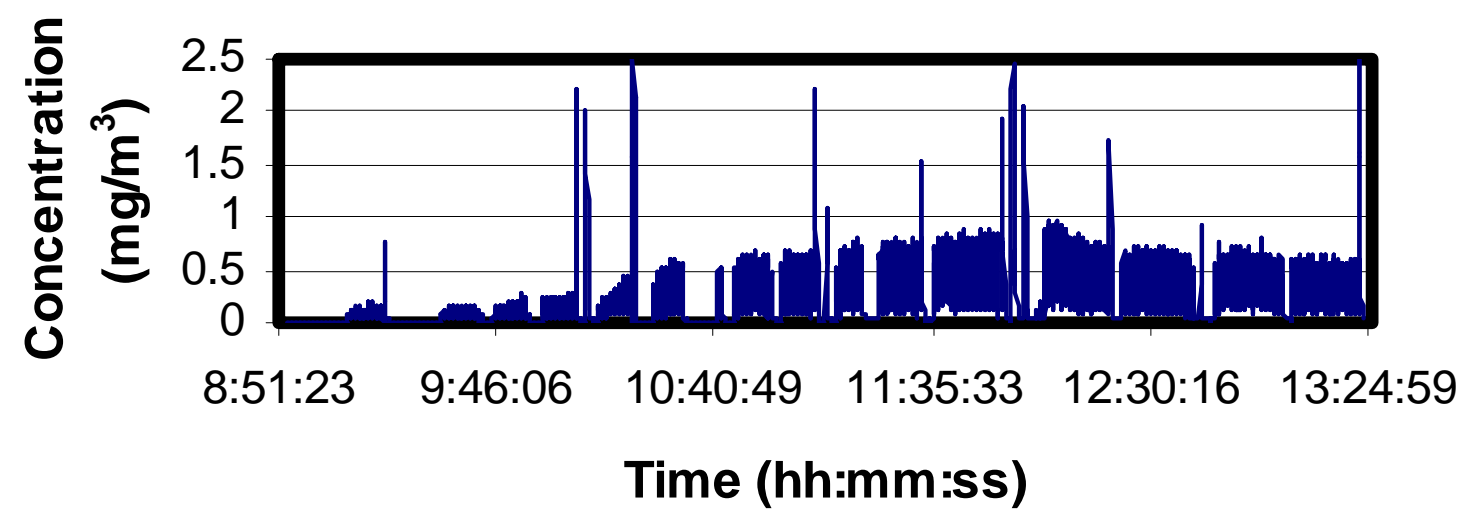

\section{Milling EPA Fluid \\ Background Run $2 \quad 7 / 26 / 04$}

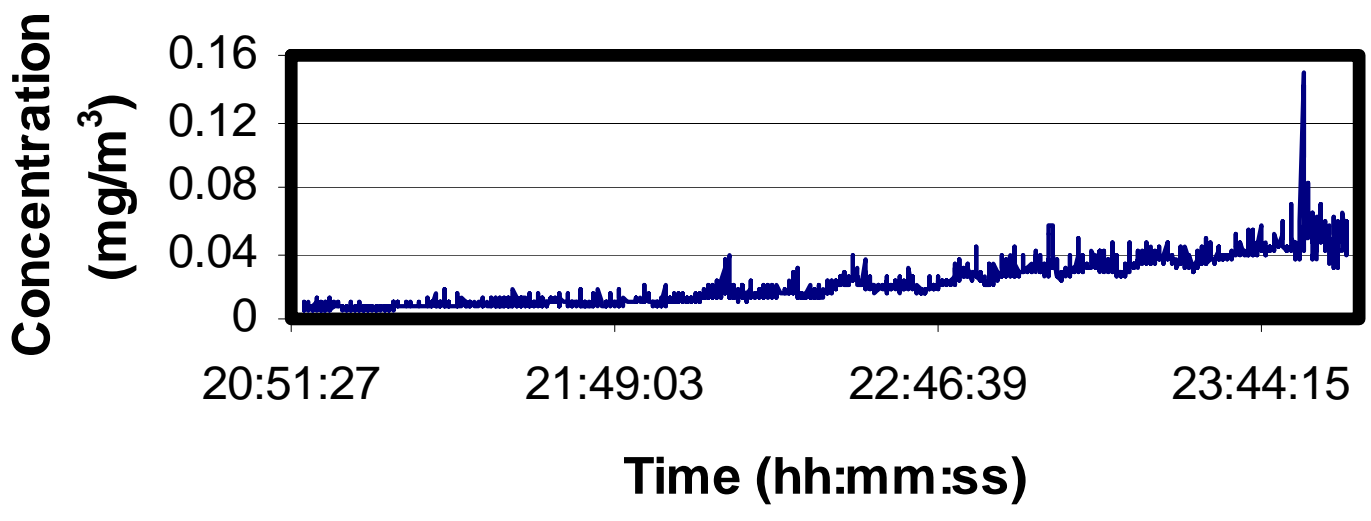




\section{Milling EPA Fluid \\ Enclosure Run 3 7/27/04}

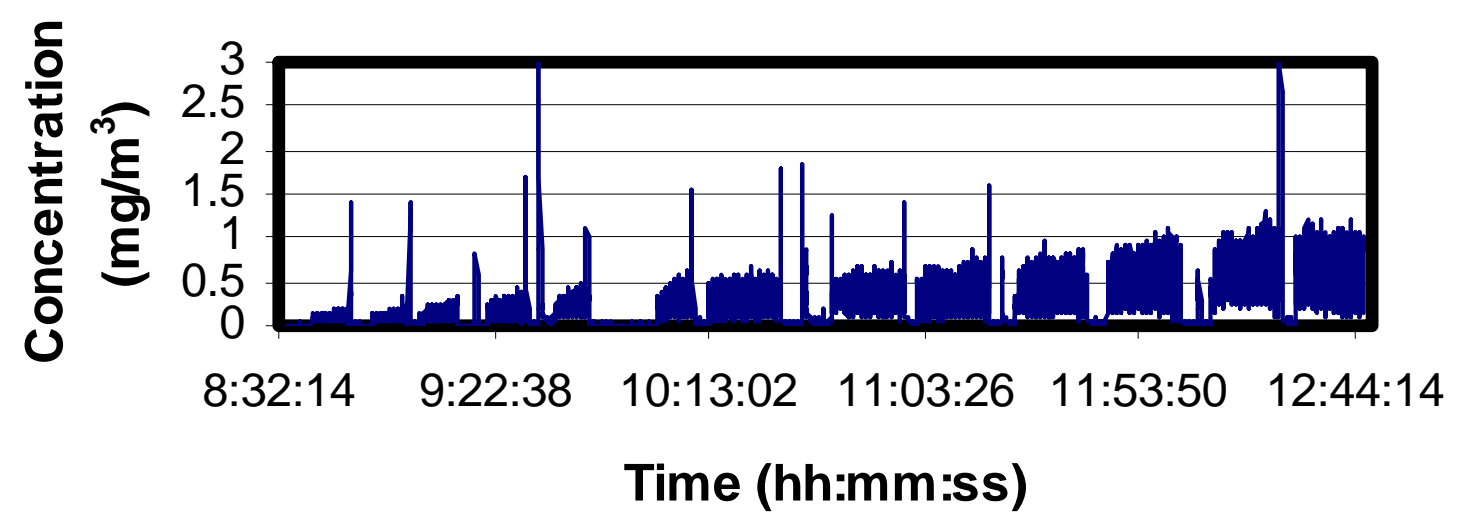

\section{Milling EPA Fluid Background Run 3 7/27/04}

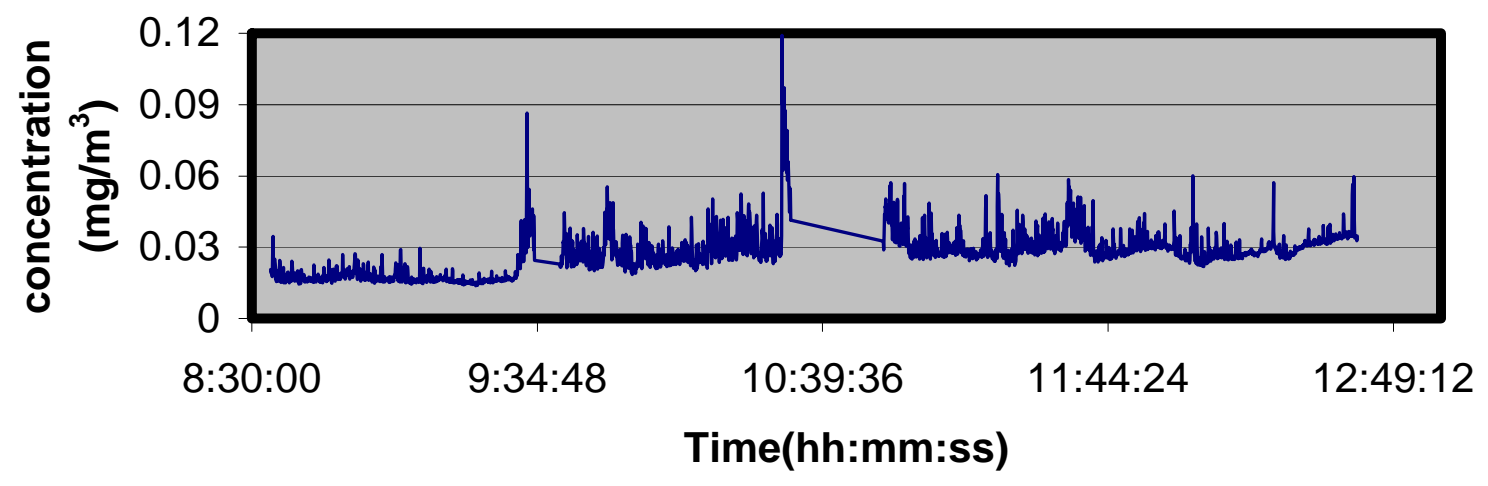




\section{Milling EPA Fluid \\ Enclosure Run 4 7/28/04}

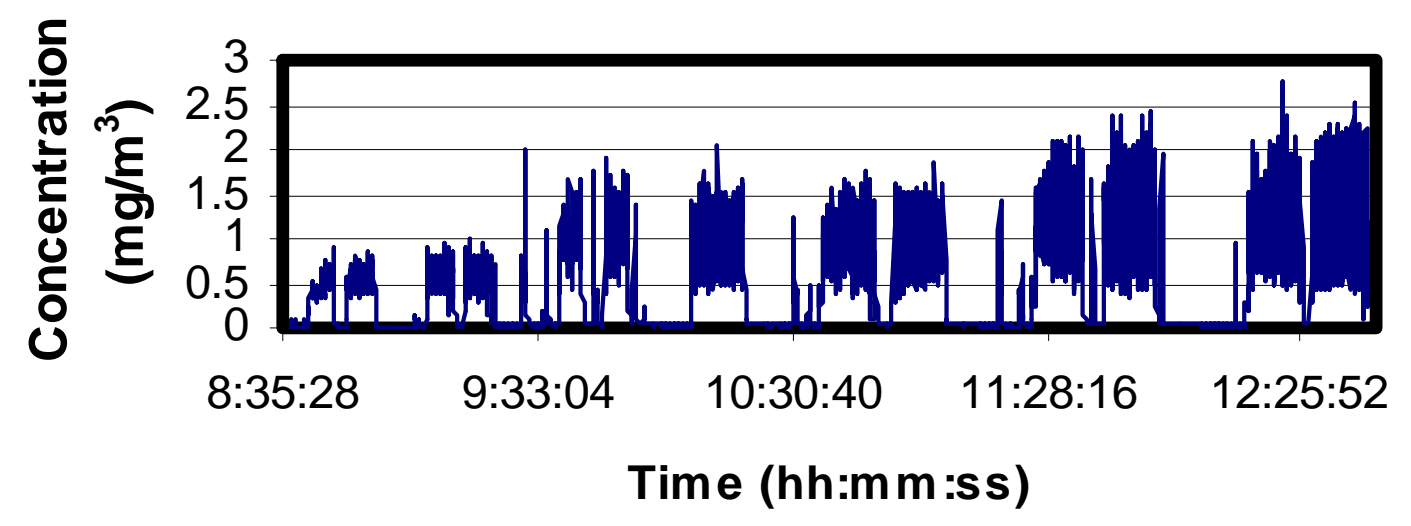

\section{Milling EPA Fluid \\ Background Run $4 \quad 7 / 28 / 04$}

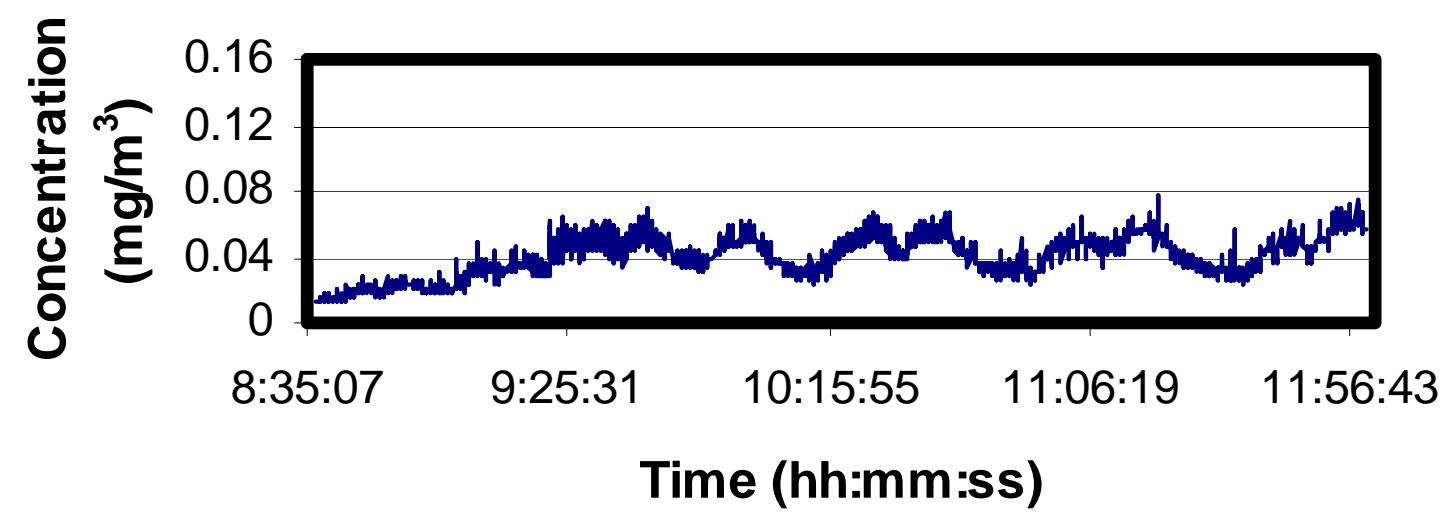




\section{Milling EPA Fluid \\ Enclosure Run 5 7/29/04}

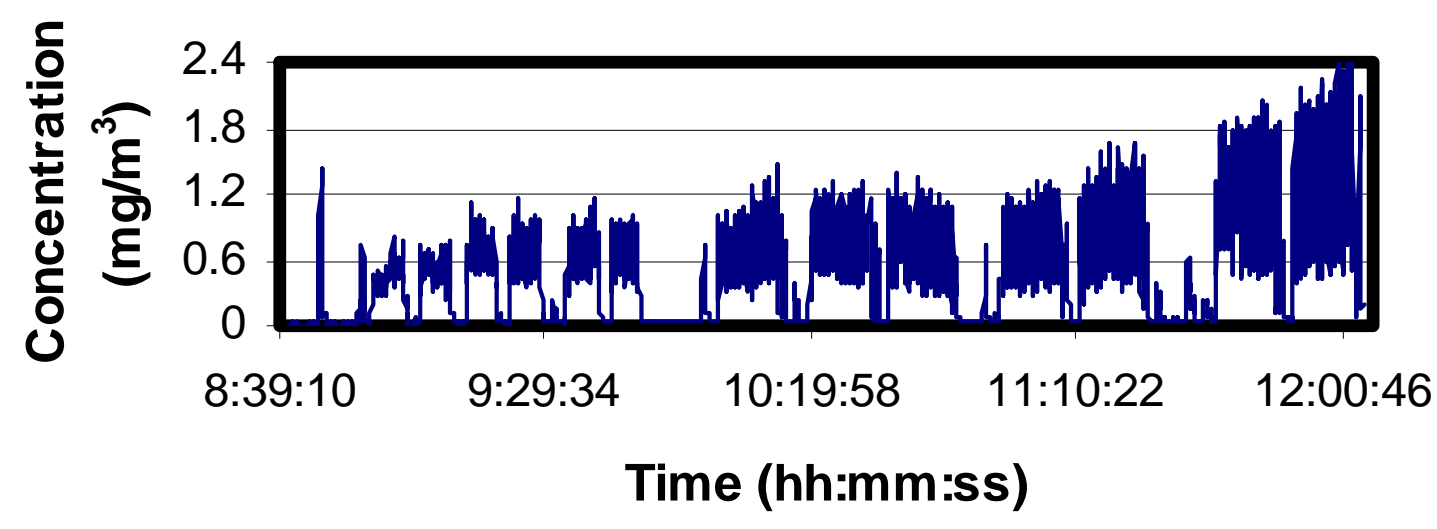

\section{Milling EPA Fluid \\ Background Run 5 7/29/04}

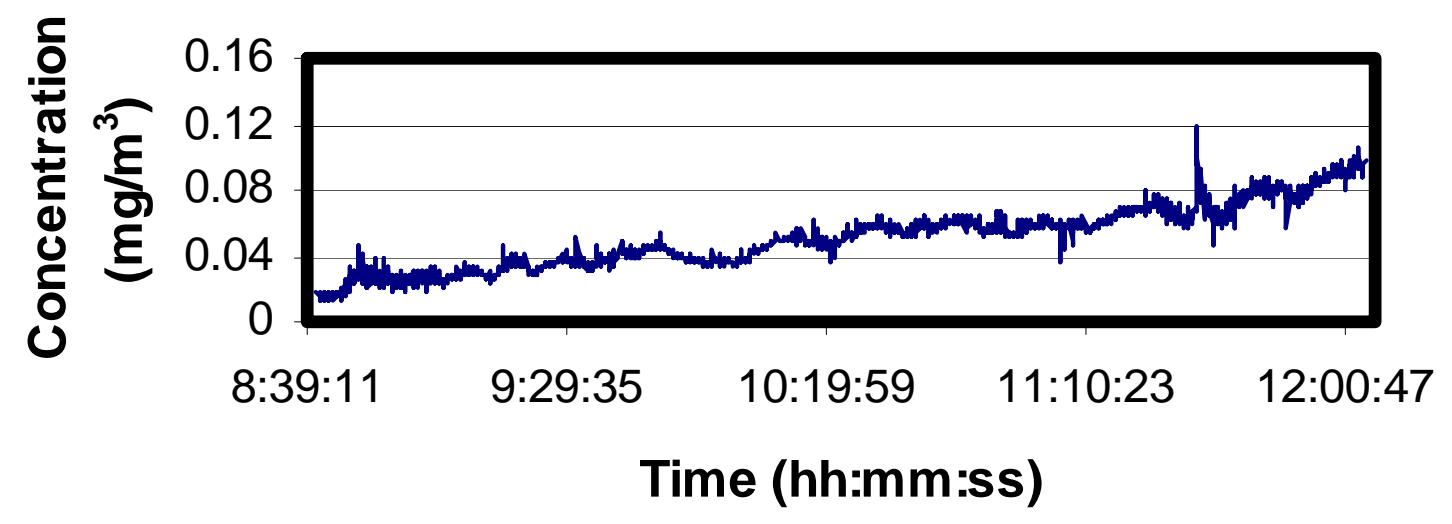




\section{Milling EPA Fluid \\ Enclosure Run 6 7/30/04}

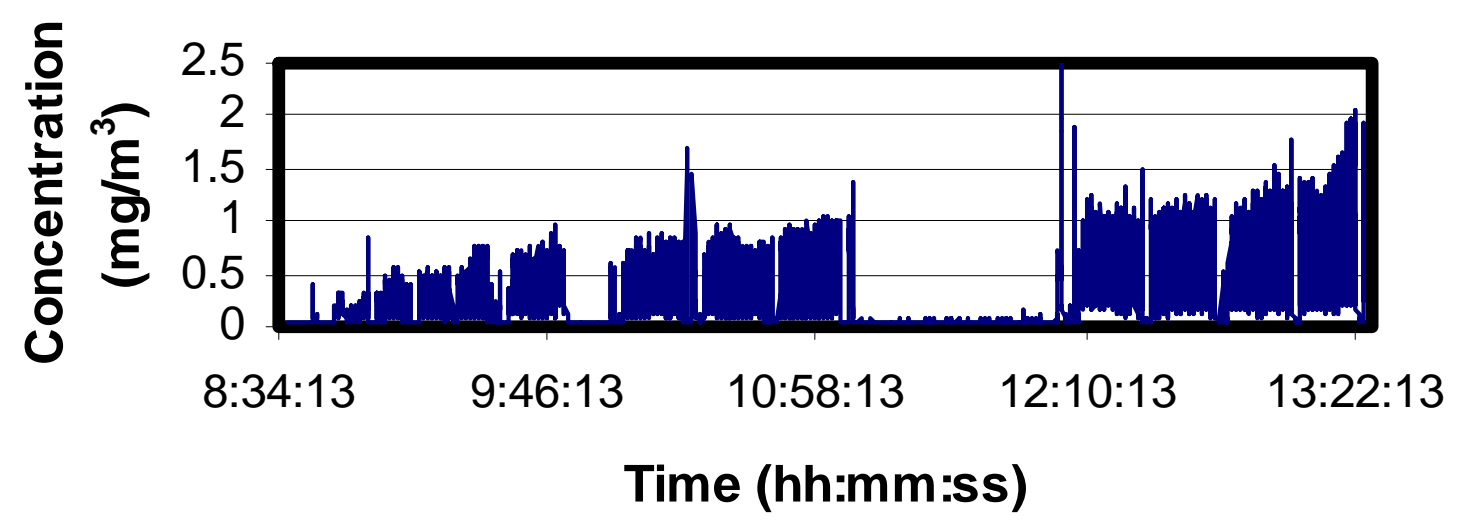

\section{Milling EPA Fluid \\ Background Run 6 7/30/04}

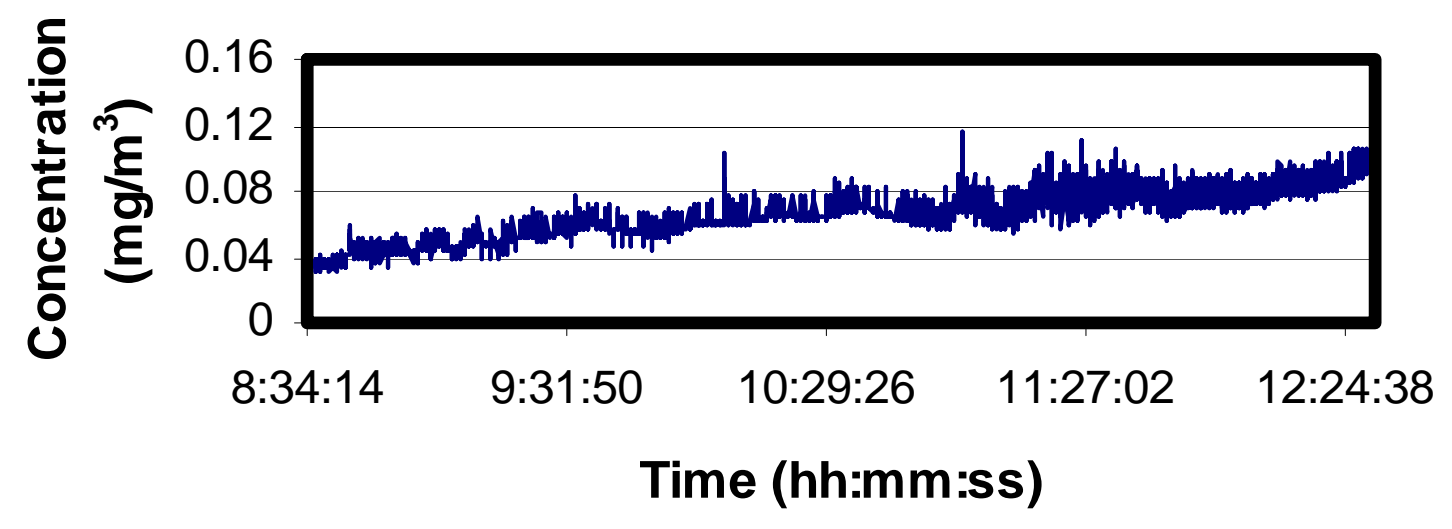




\section{Milling EPA Fluid \\ Enclosure Run $7 \quad 8 / 2 / 04$}

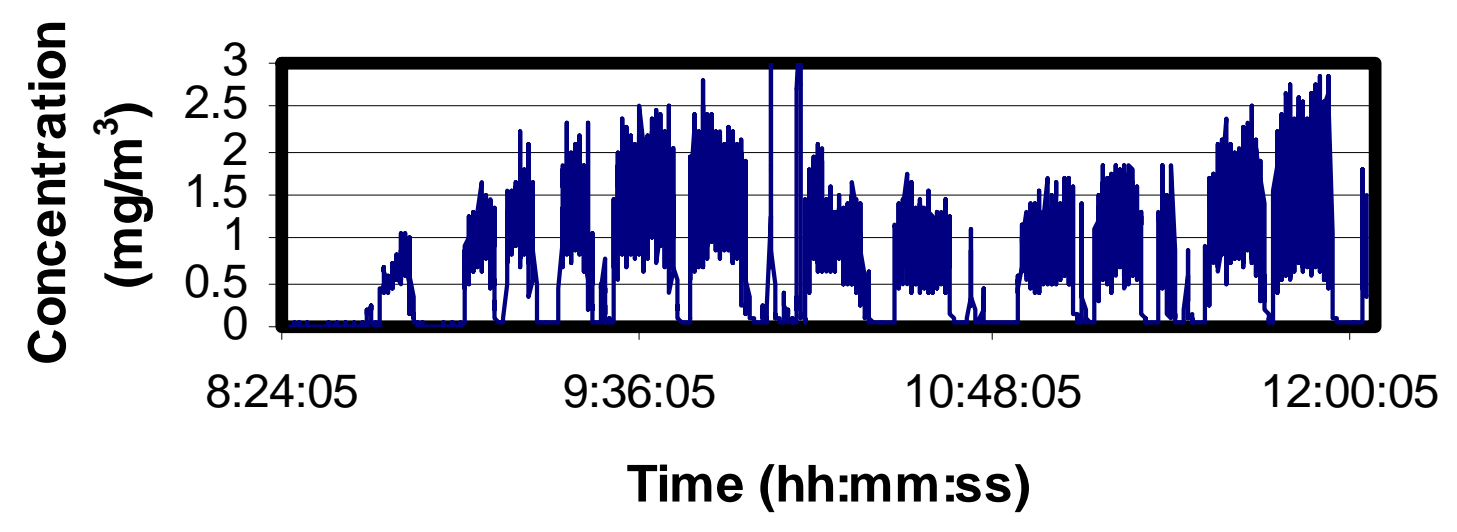

\section{Milling EPA Fluid Background Run 7 8/2/04}

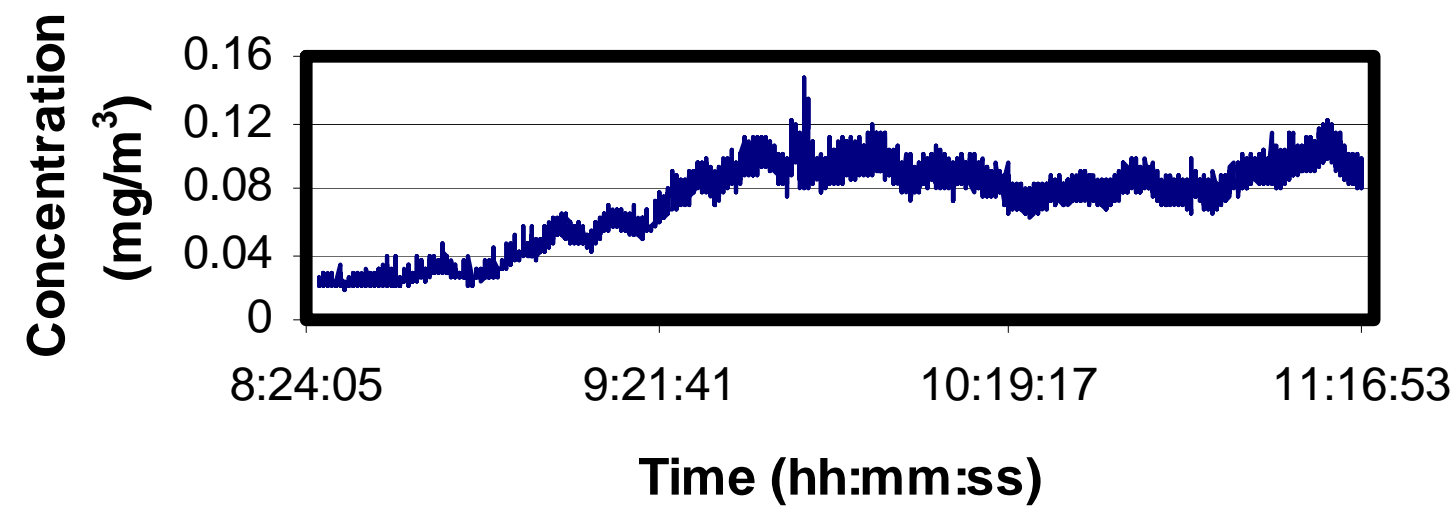




\section{Milling EPA Fluid \\ Enclosure Run 8 8/4/04}

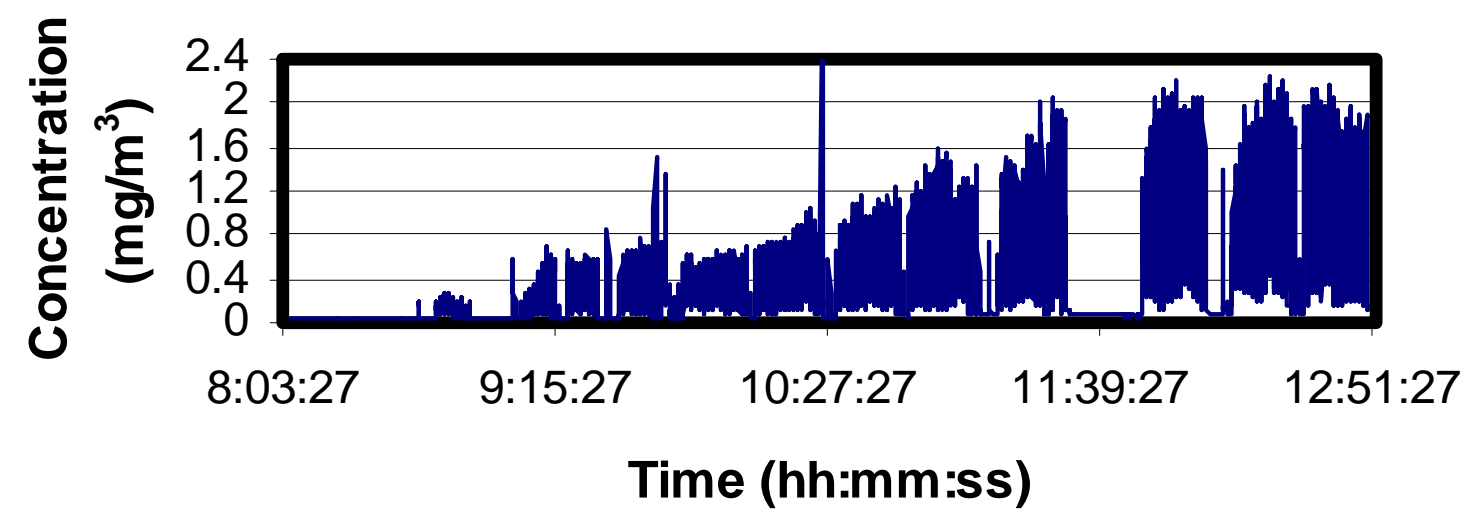

\section{Milling EPA Fluid \\ Background Run 8 8/4/04}

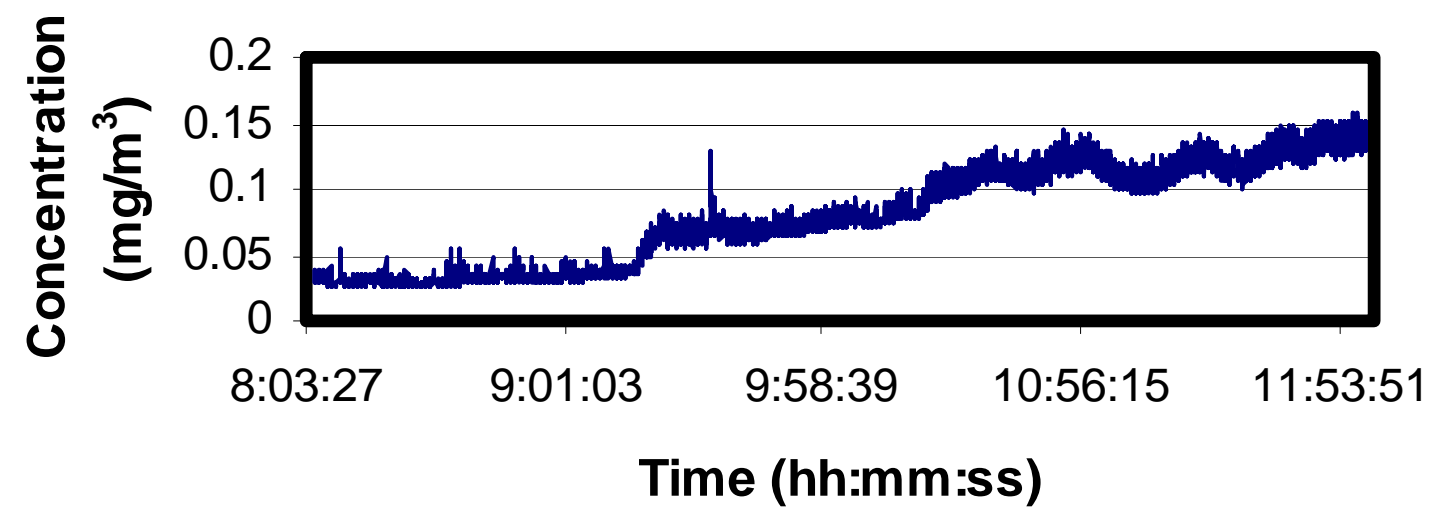




\section{Milling EPA Fluid \\ Enclosure Run 9 8/5/04}

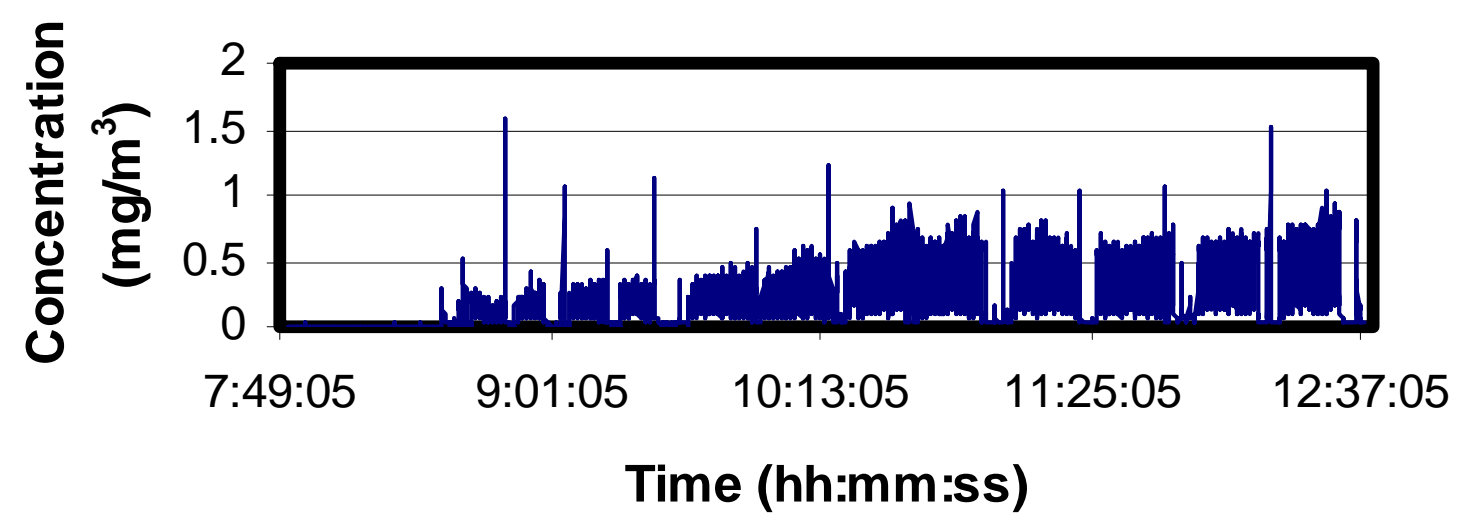

\section{Milling EPA Fluid \\ Background Run 9 8/5/04}

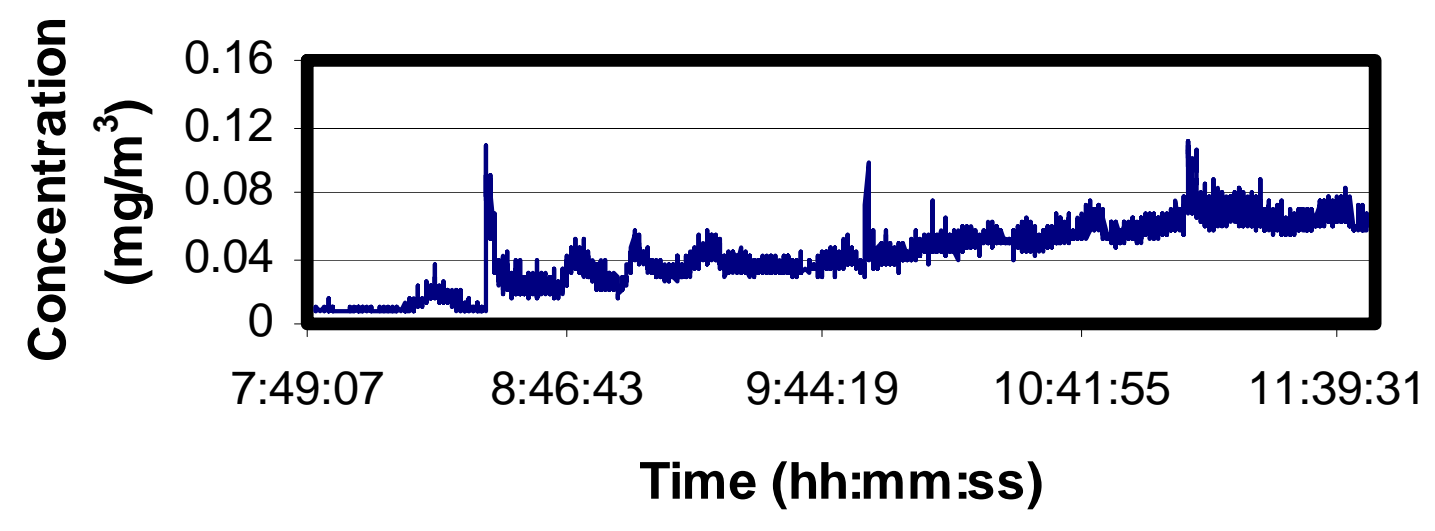




\section{Milling EPA Fluid \\ Enclosure Run 10 8/6/04}

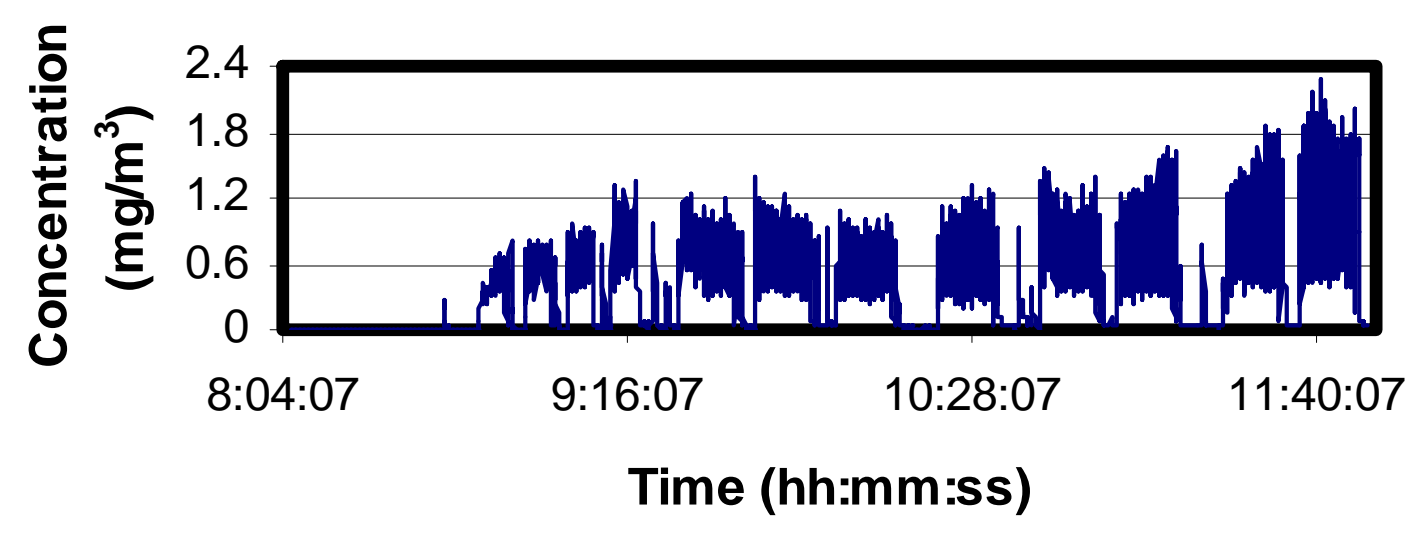

\section{Milling EPA Fluid Background Run 10 8/6/04}

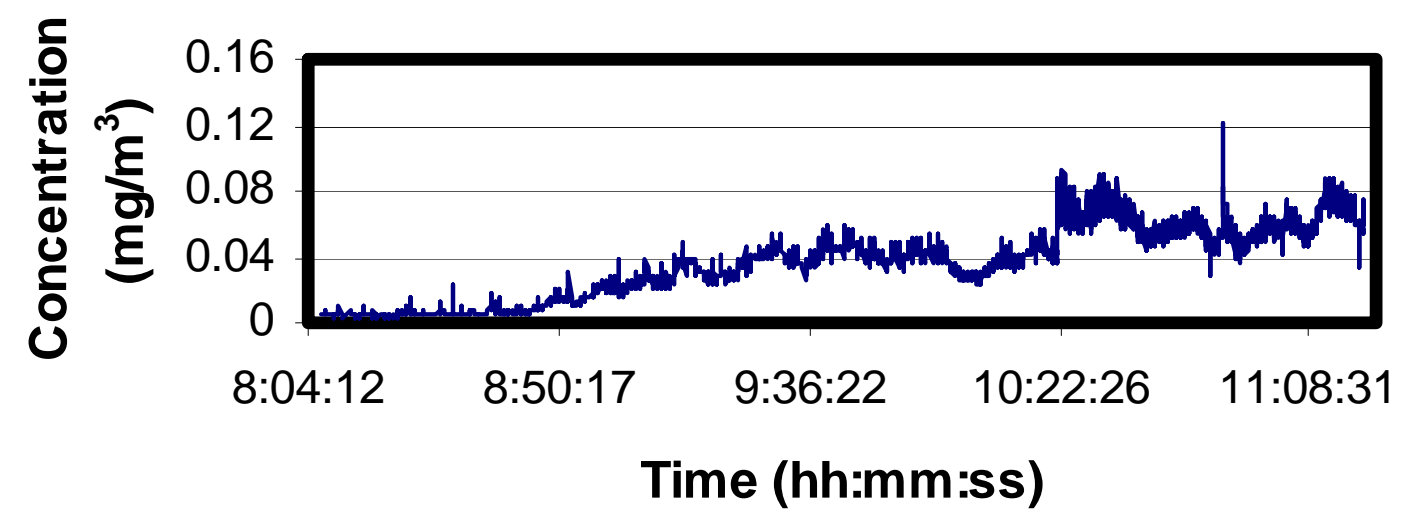




\section{Milling Baseline Fluid \\ Enclosure Run 1 8/18/04}

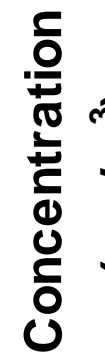

0.2

ल 0.16

0.12

0.08

0.04

0

8:15:11

8:58:23

$9: 41: 35$

$10: 24: 47$

Time (hh:mm:ss)

\section{Milling Baseline Fluid}

Background Run1 8/18/04

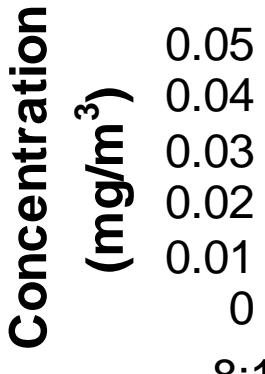

$\begin{array}{llllll}\text { 8:15:10 } & 8: 43: 58 & 9: 12: 46 & 9: 41: 34 & 10: 10: 22 & 10: 39: 10\end{array}$

Time (hh:mm:ss) 


\section{Milling Baseline Fluid \\ Enclosure Run 2 8/18/04}

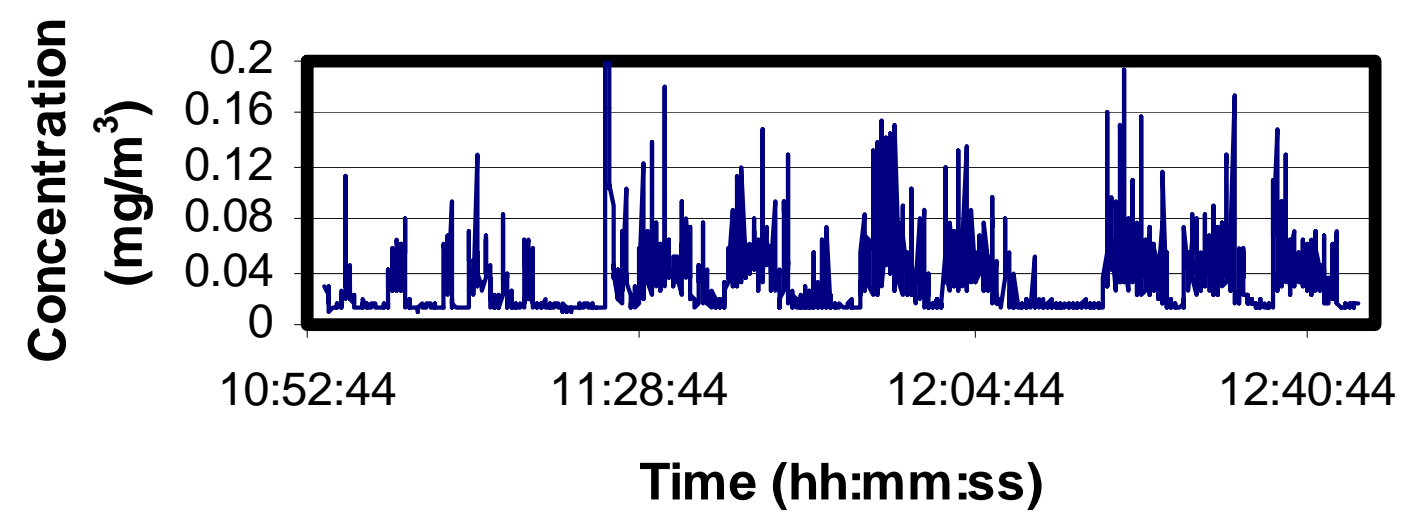

\section{Milling Baseline Fluid}

Background Run 2 8/18/04

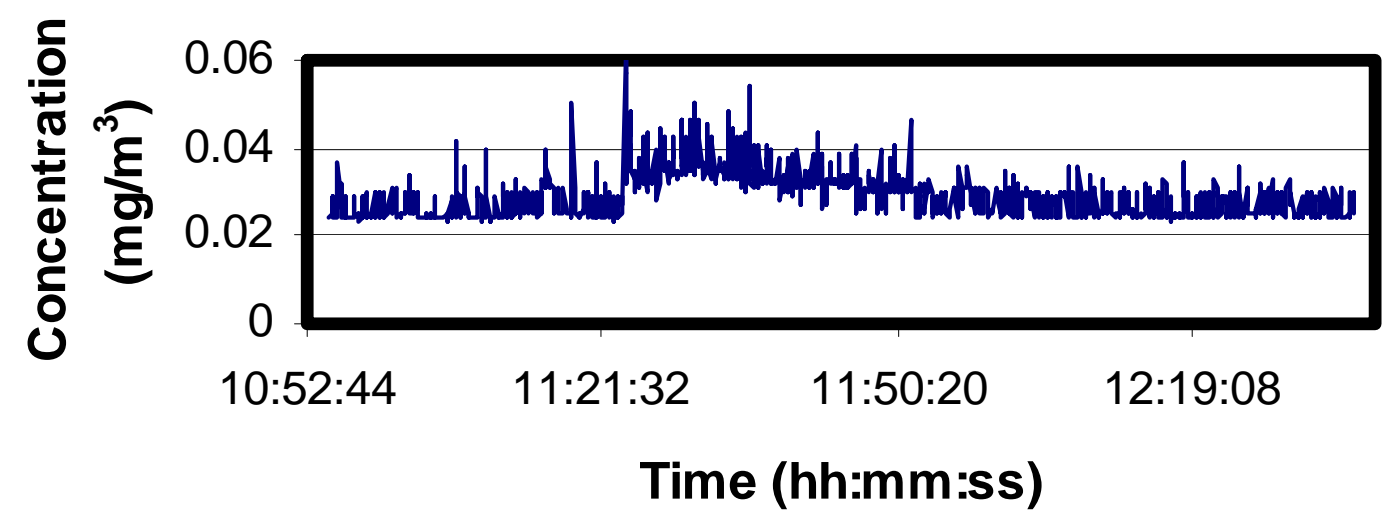




\section{Milling Baseline Fluid \\ Enclosure Run 3 8/19/04}

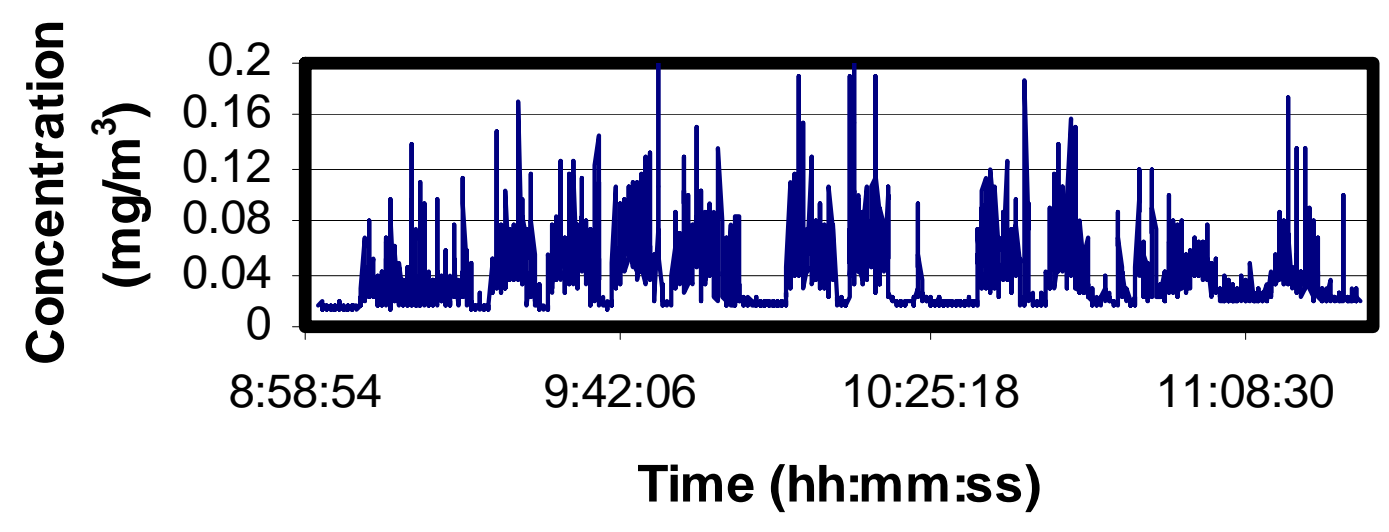

Milling Baseline Fluid Background Run 3 8/19/04

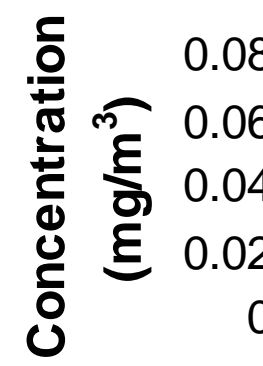

$\begin{array}{lllll}\text { 8:59:01 } & 9: 27: 49 & 9: 56: 37 & 10: 25: 25 & 10: 54: 13\end{array}$

Time (hh:mm:ss) 


\section{Milling Baseline Fluid \\ Enclosure Run 4 8/19/04}

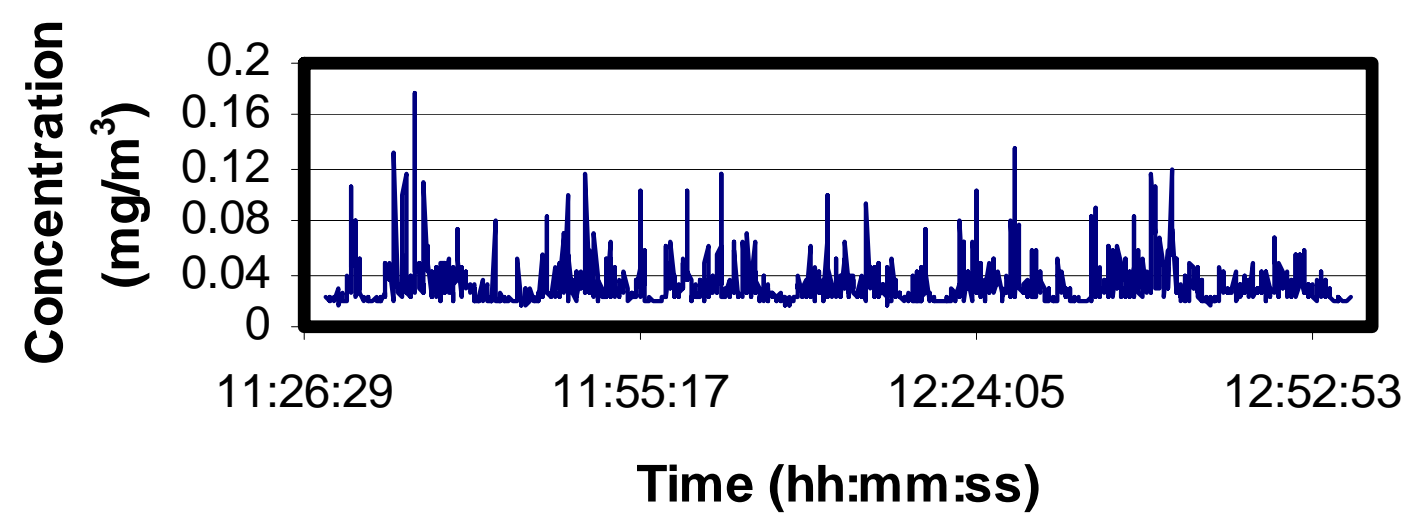

\section{Milling Baseline Fluid Background Run 4 8/19/04}

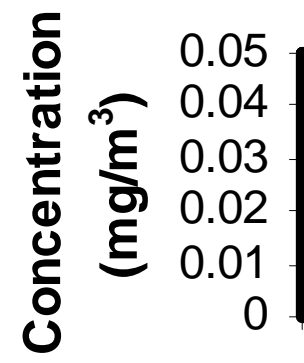

11:26:36 $\quad 11: 48: 12 \quad 12: 09: 48 \quad 12: 31: 24$

Time (hh:mm:ss) 


\section{Milling Baseline Fluid \\ Enclosure Run 5 8/20/05}

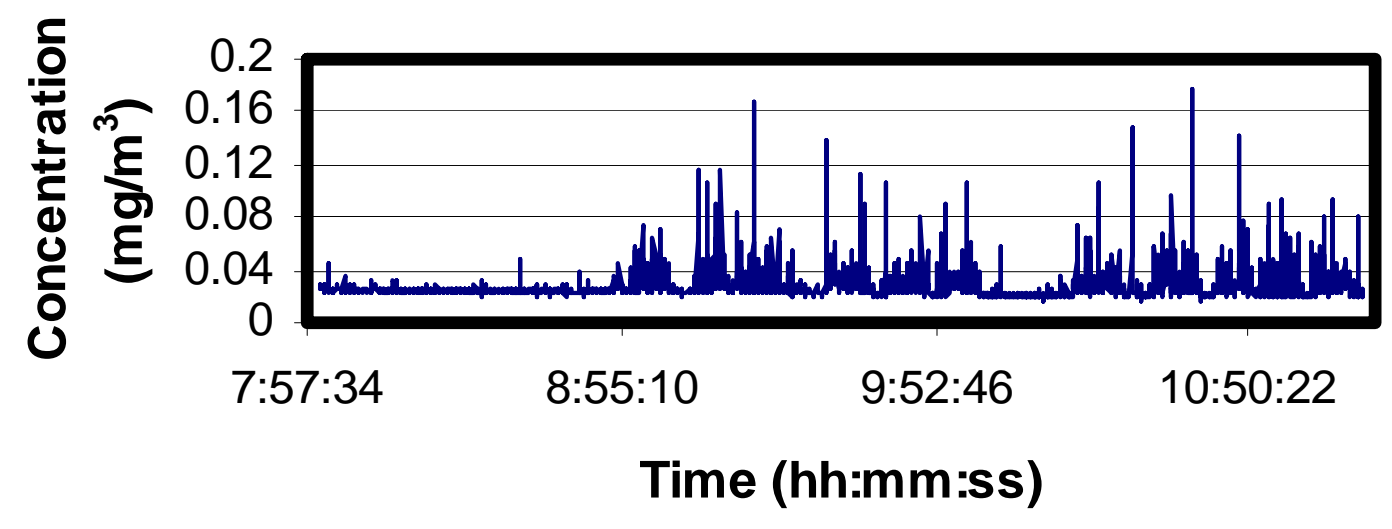

\section{Milling Baseline Fluid}

Background Run 5 8/20/04

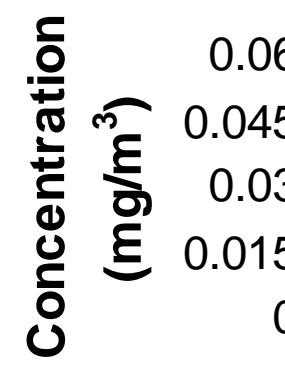

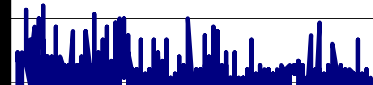

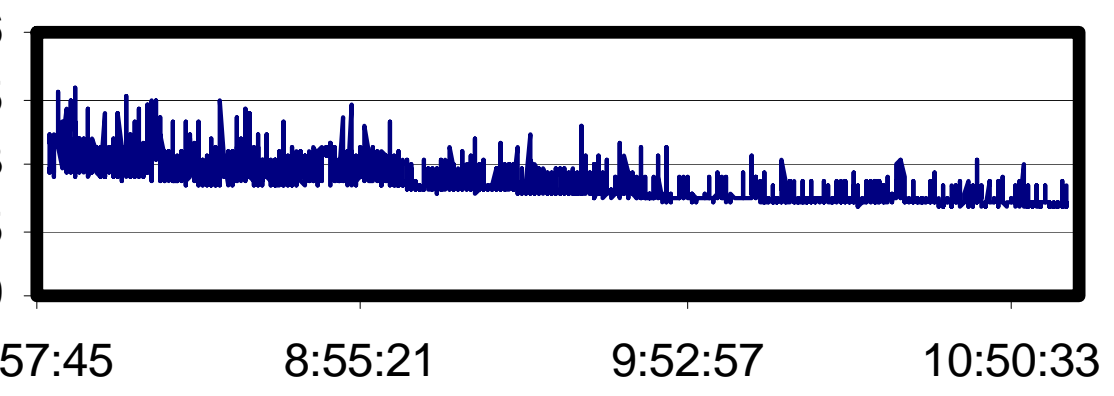

Time (hh:mm:ss) 


\section{Milling Baseline Fluid \\ Enclosure Run 6 8/20/04}

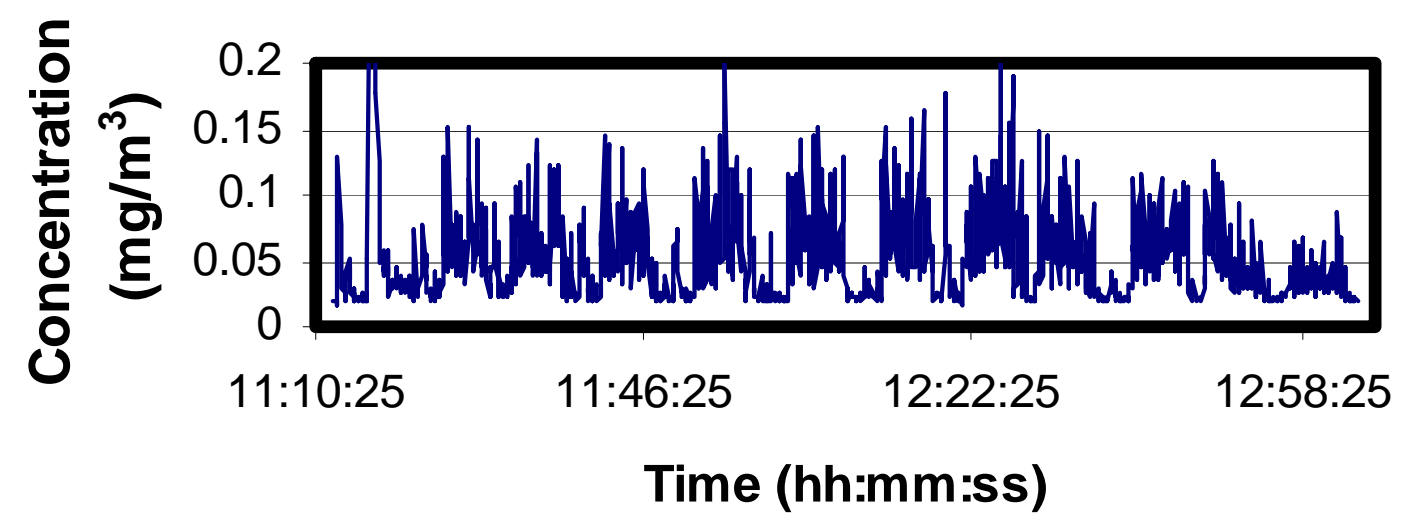

Milling Baseline Fluid Background Run 6 8/20/04

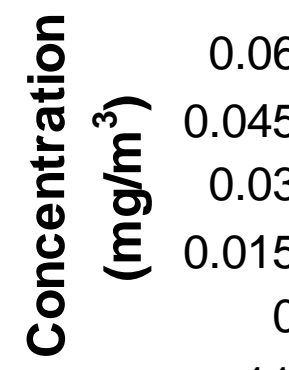

11:10:25

11:39:13

12:08:01

$12: 36: 49$

Time (hh:mm:ss) 


\section{Milling Baseline Fluid \\ Enclosure Run 7 8/25/04}

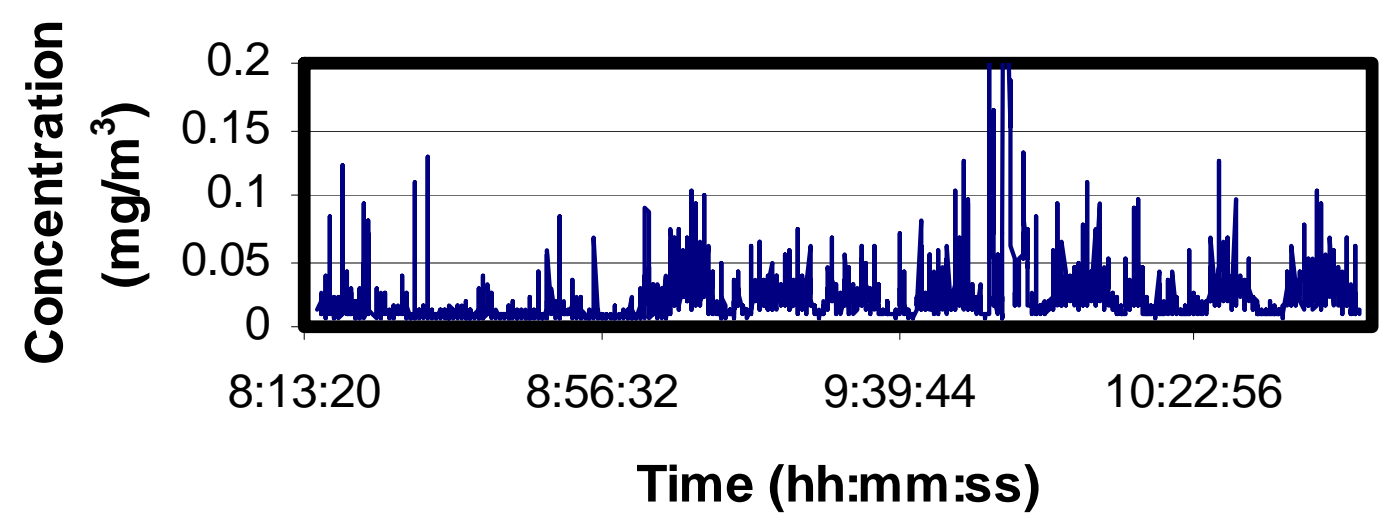

Milling baseline Fluid

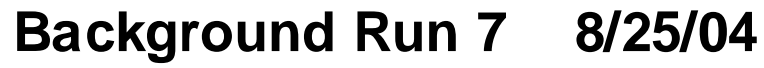

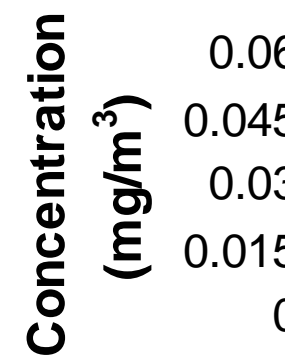

8:13:42

8:42:30

9:11:18

9:40:06

10:08:54

Time (hh:mm:ss) 


\section{Milling Baseline Fluid Enclosure Run 8 8/25/04}

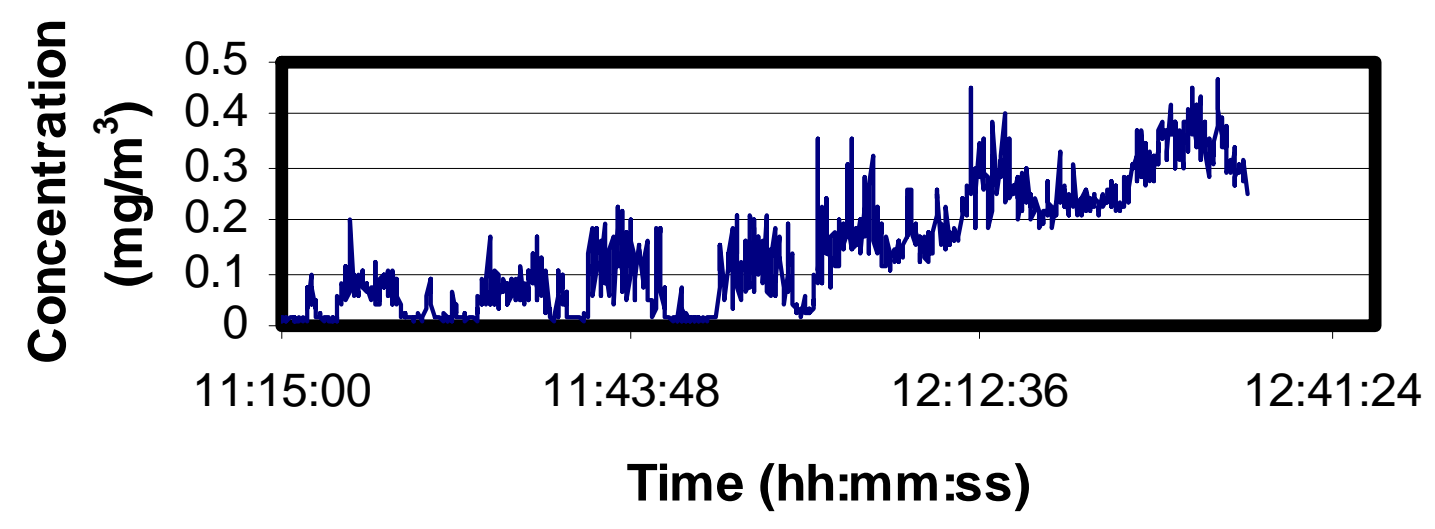

Milling Baseline Fluid Background Run 8 8/25/04

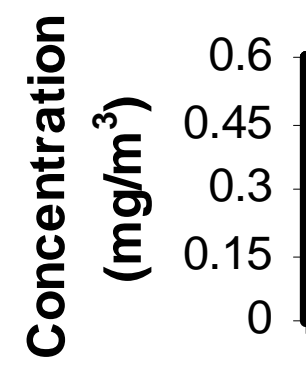

$11: 12: 39 \quad 11: 27: 03 \quad 11: 41: 27 \quad 11: 55: 51 \quad 12: 10: 15$

Time (hh:mm:ss) 


\section{Milling Baseline Fluid \\ Enclosure Run 9 8/26/04}

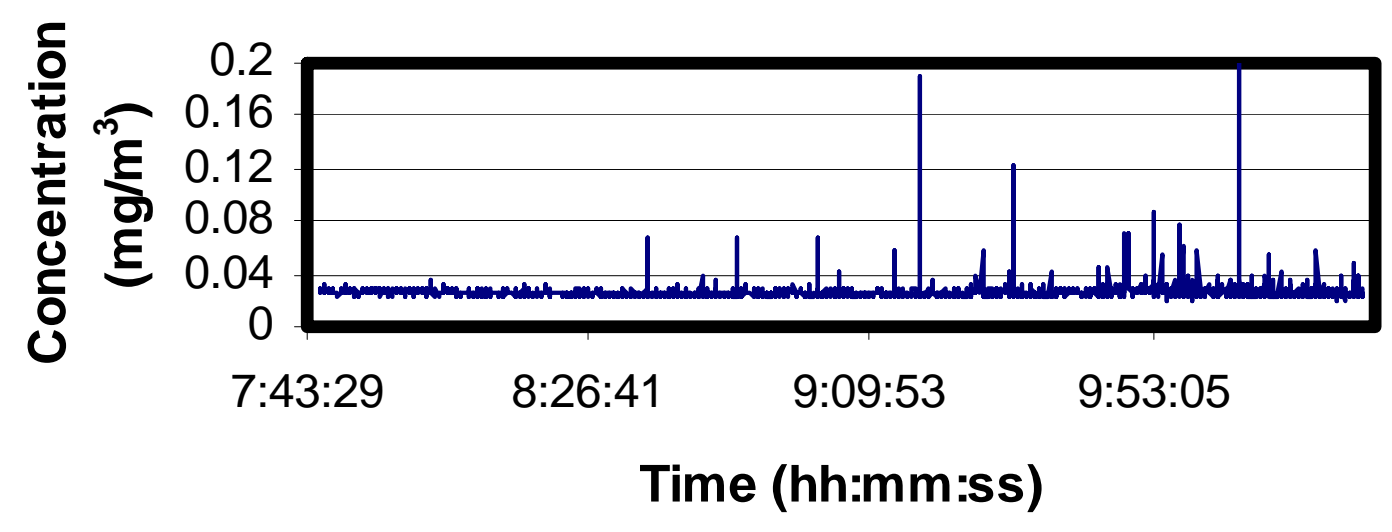

\section{Milling Baseline Fluid}

Background Run 9 8/26/04

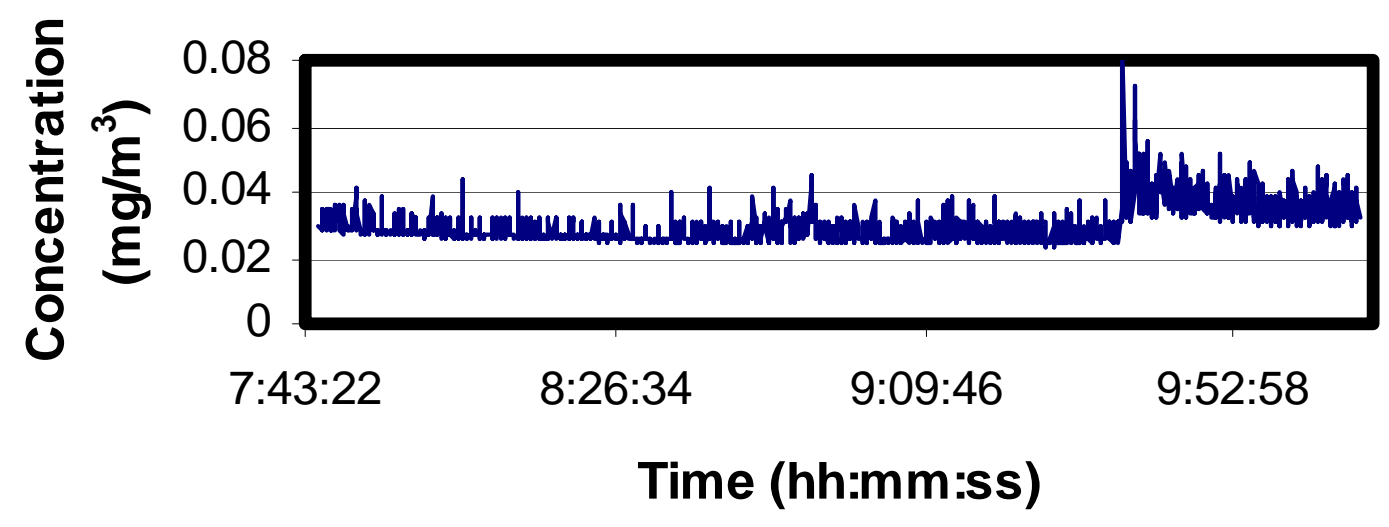




\section{Milling Baseline Fluid Enclosure Run 10 8/26/04}

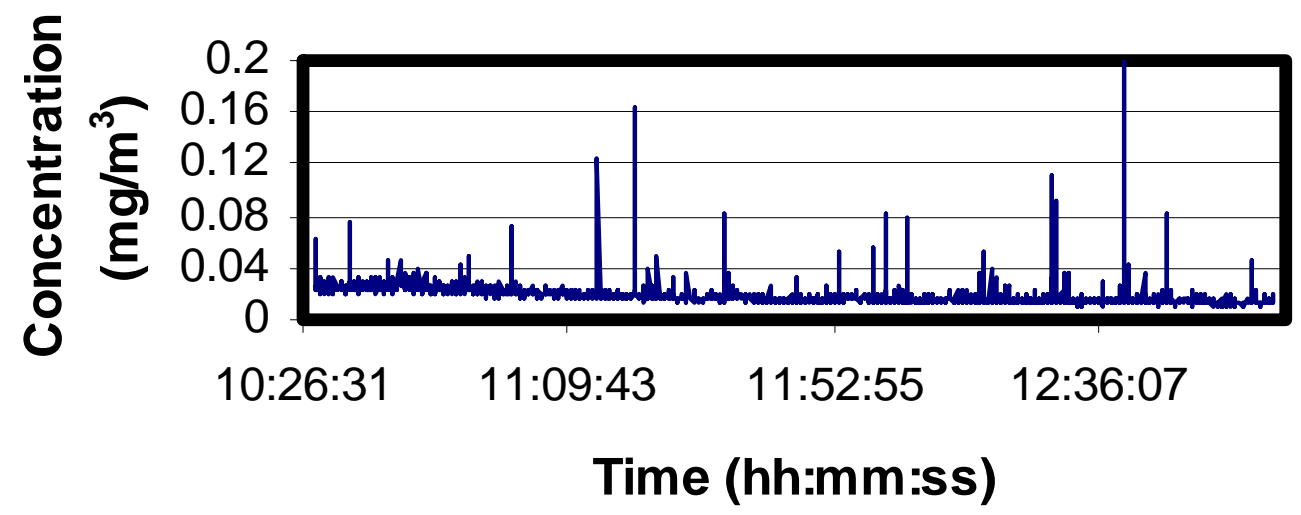

\section{Milling Baseline Fluid Background Run 10 8/26/04}

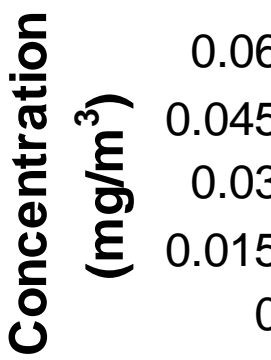

10:26:27

11:09:39

$11: 52: 51$

$12: 36: 03$

Time (hh:mm:ss) 


\section{Turning Baseline Fluid Enclosure Run 1 9/1/04}

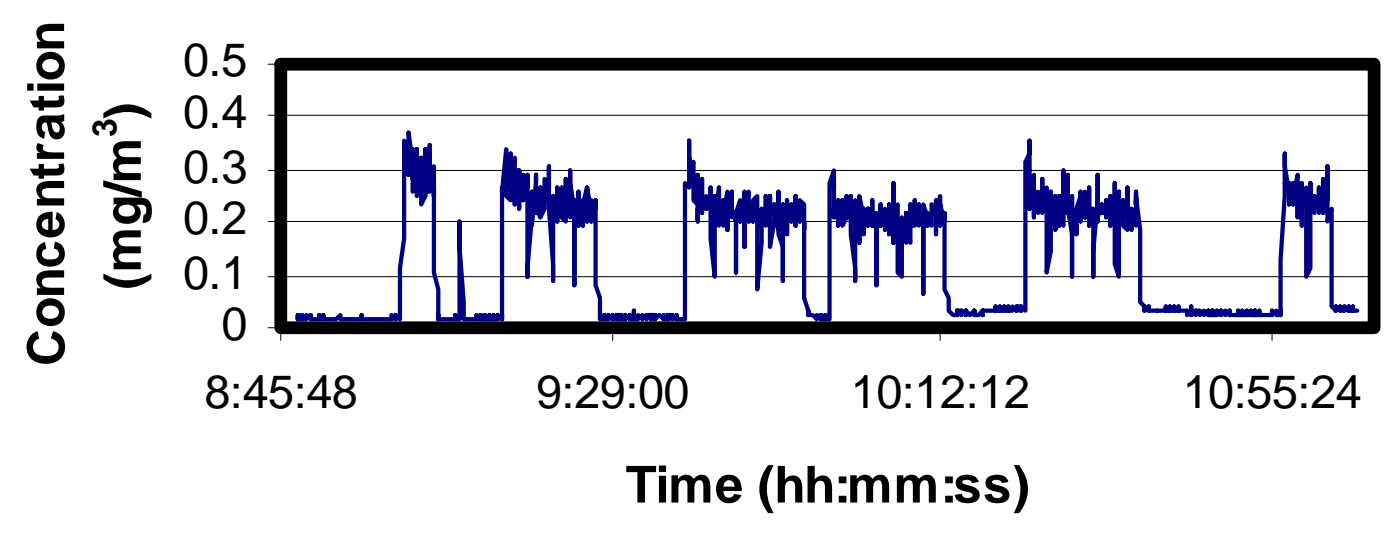

Turning Baseline Fluid
Background Run $1 \quad 9 / 1 / 04$

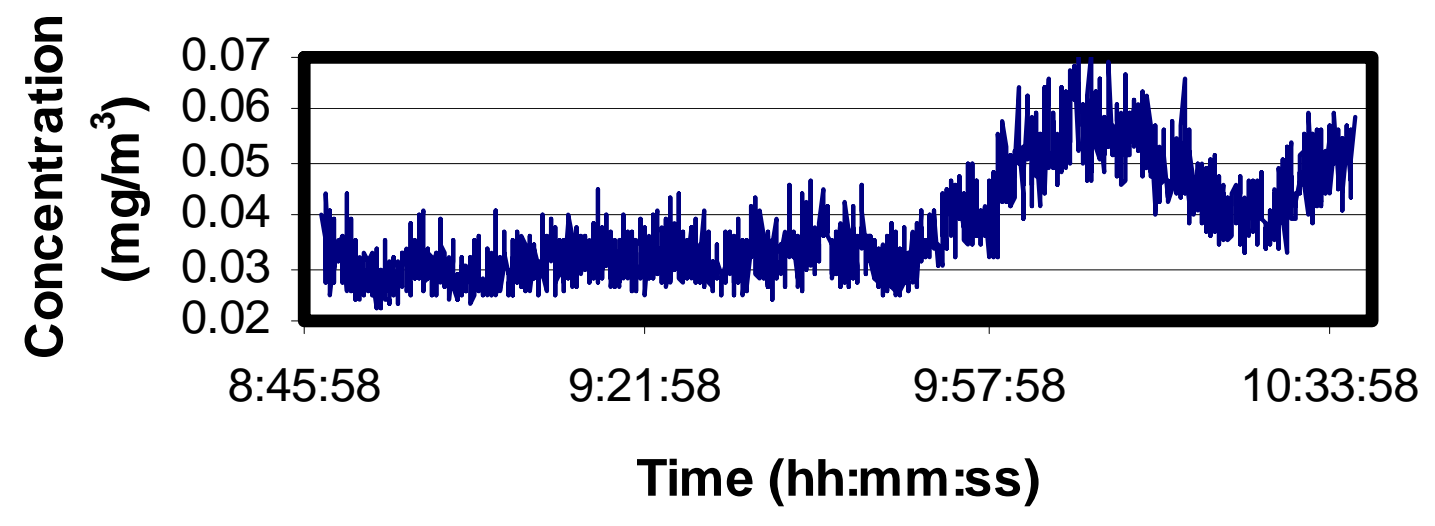




\section{Turning Baseline Fluid Enclosure Run 2 9/1/04}

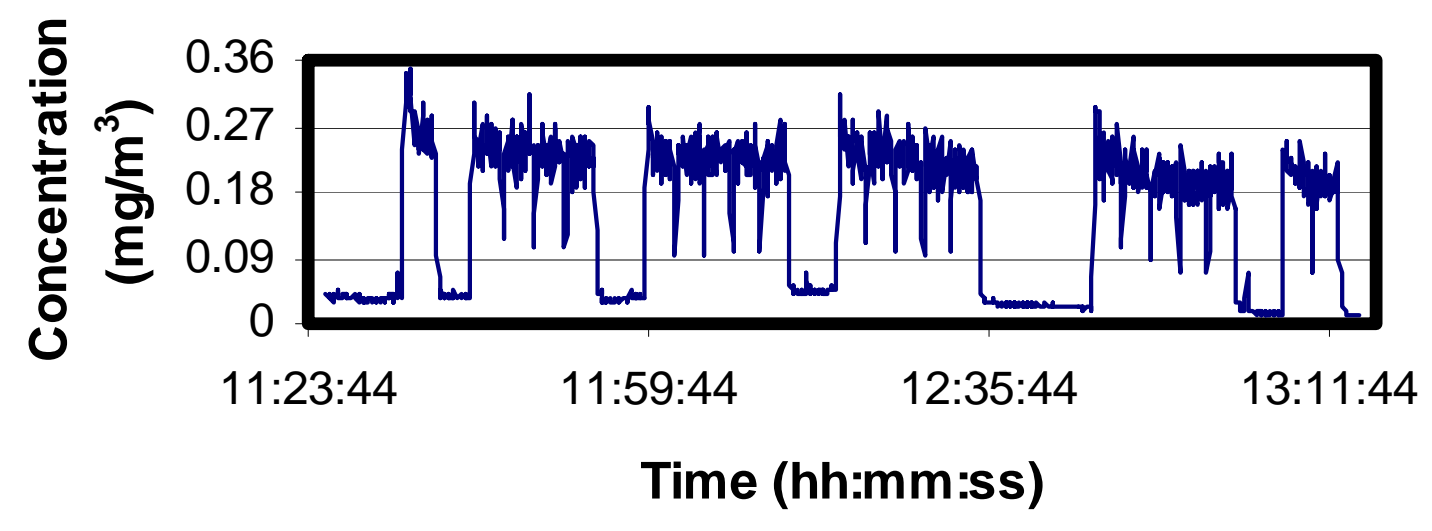

Turning Baseline Fluid Background Run 2 9/1/04

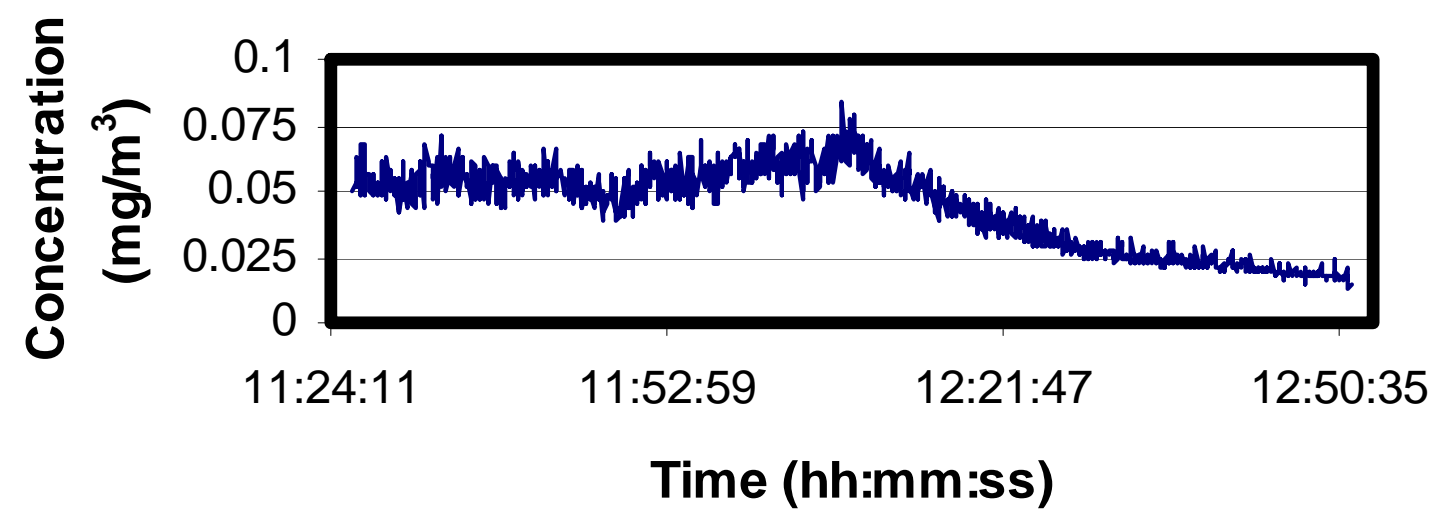




\section{Turning Baseline Fluid Enclosure Run 3 9/2/04}

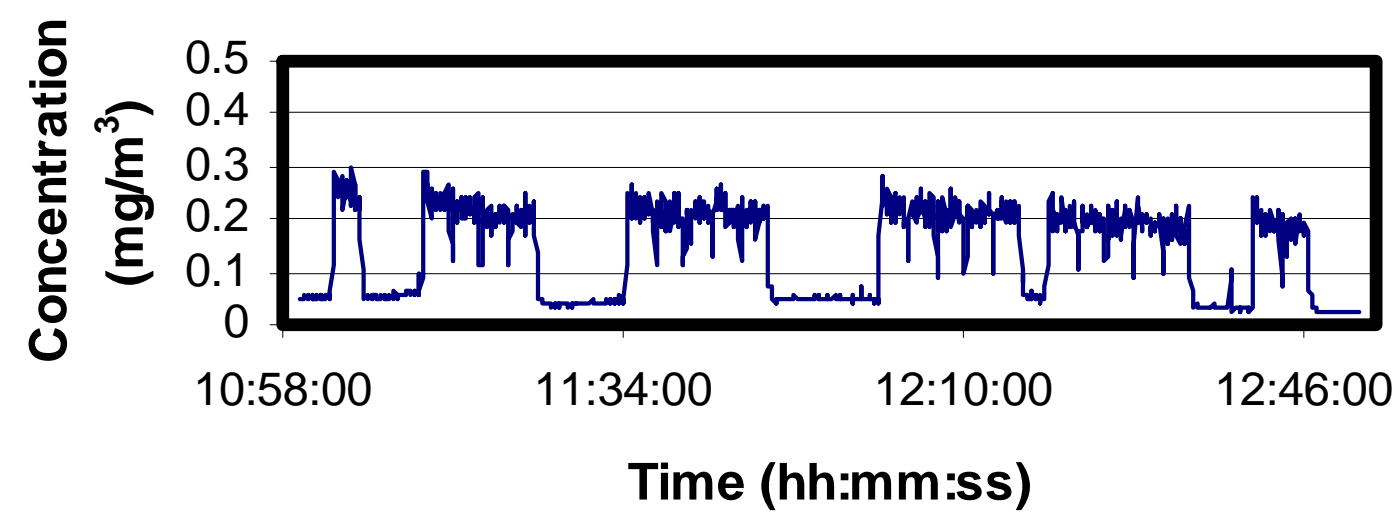

\section{Turning baseline Fluid Background Run 3 9/2/04}

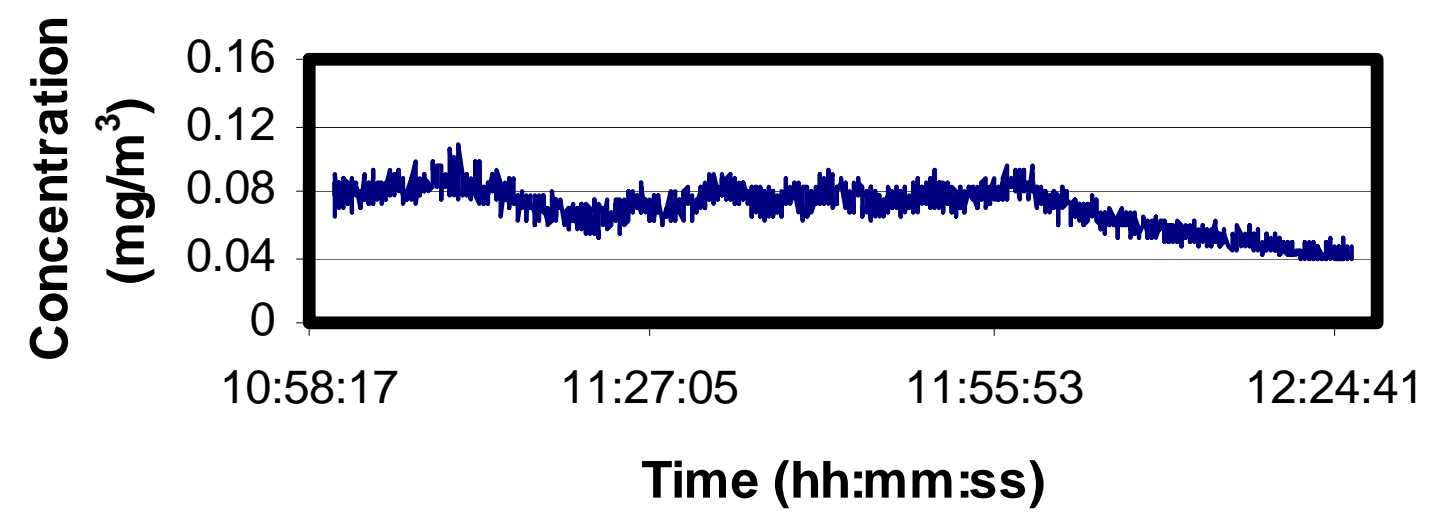




\section{Turning Baseline Fluid Enclosure Run 4 9/7/04}

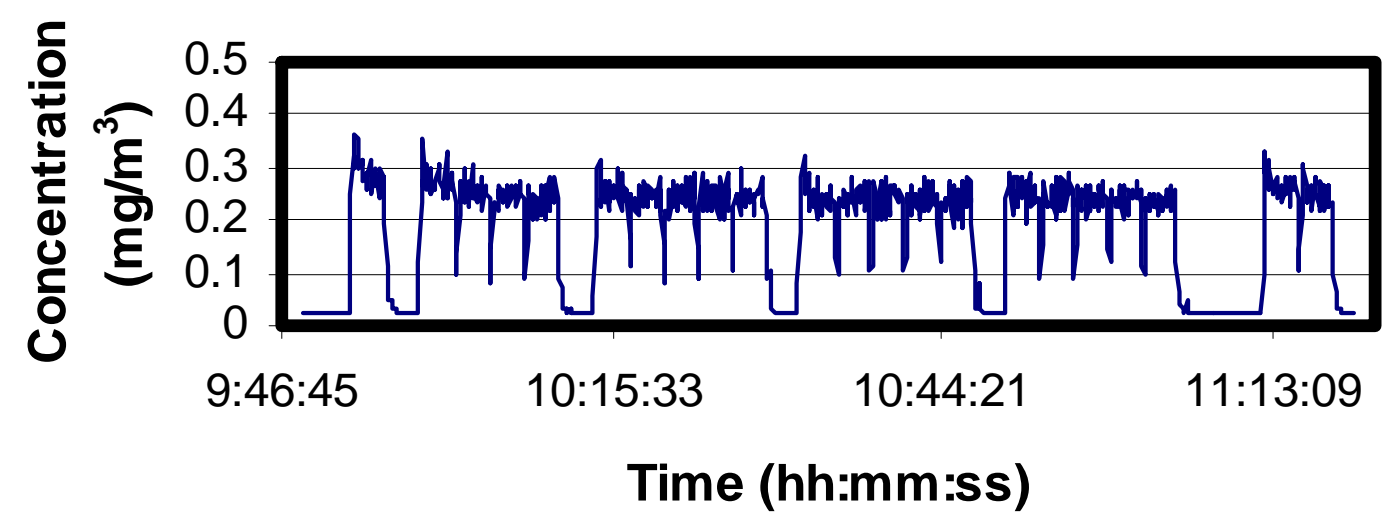

\section{Turning Baseline Fluid}

Background Run 4 9/7/04

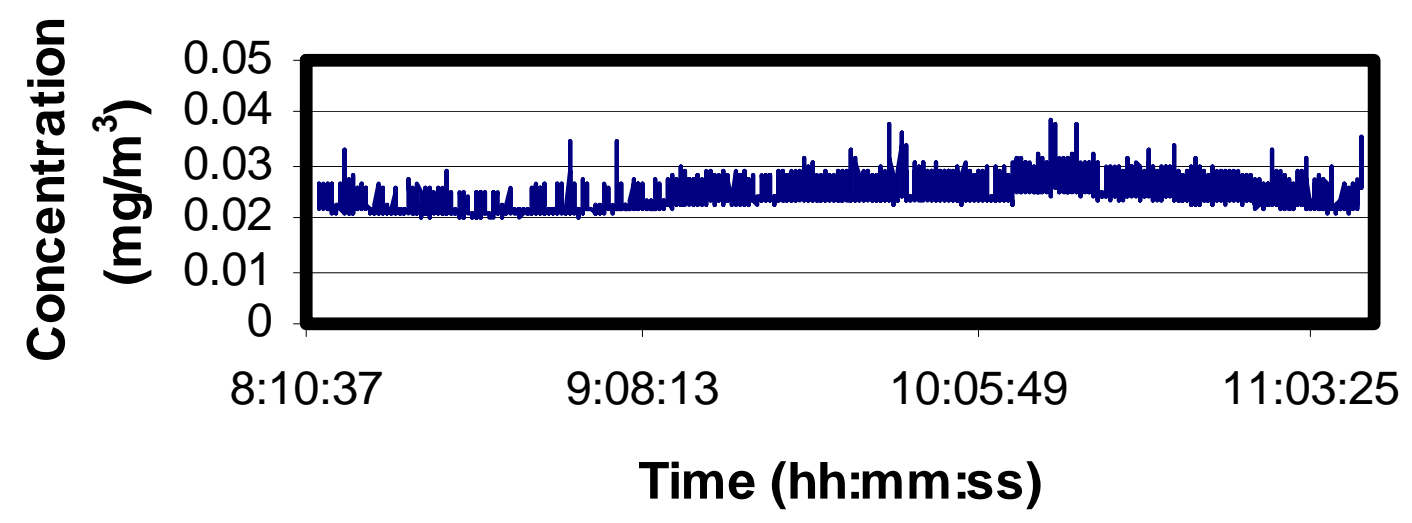




\section{Turning Baseline Fluid \\ Enclosure Run 5 9/7/04}

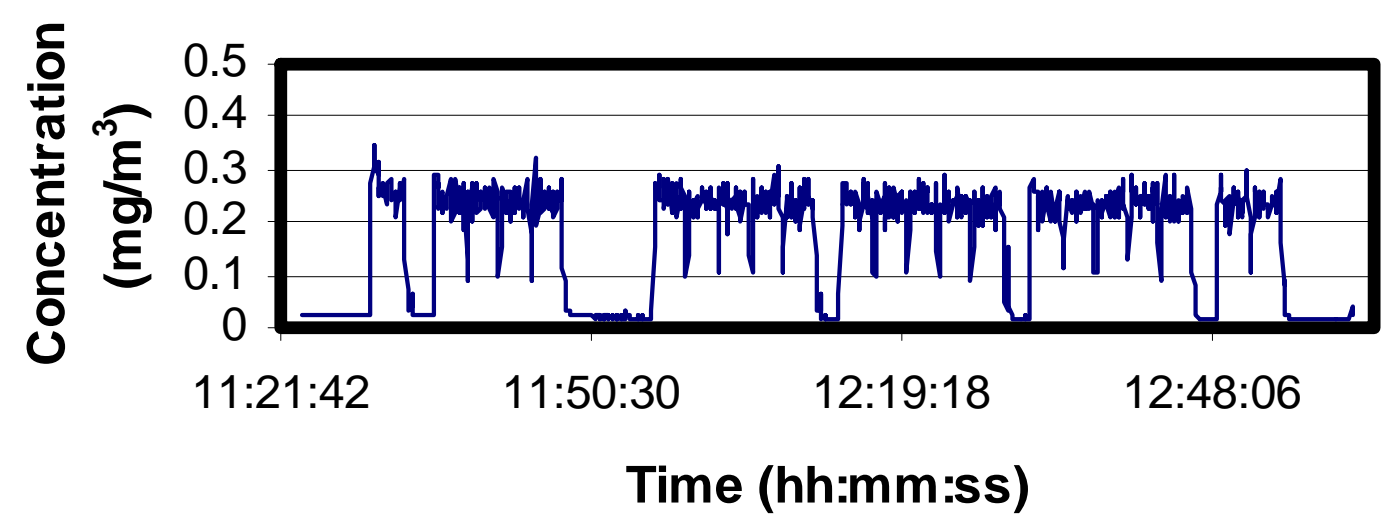

Turning Baseline Fluid

Background Run 5 9/7/04

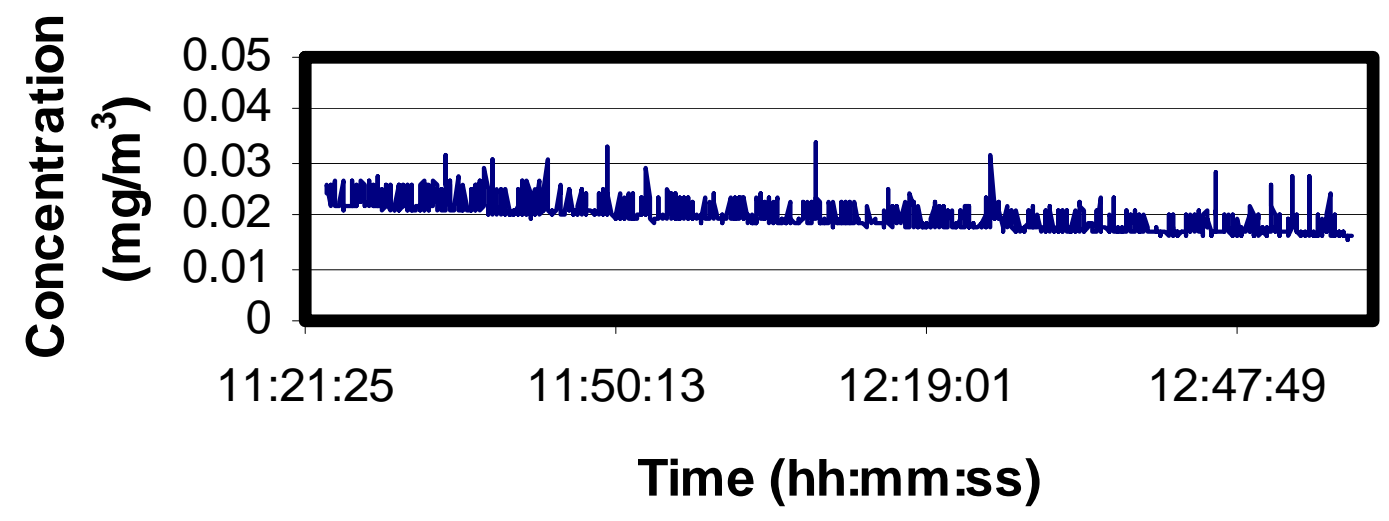




\section{Turning EPA Fluid \\ Enclosure Run 1 9/14/04}

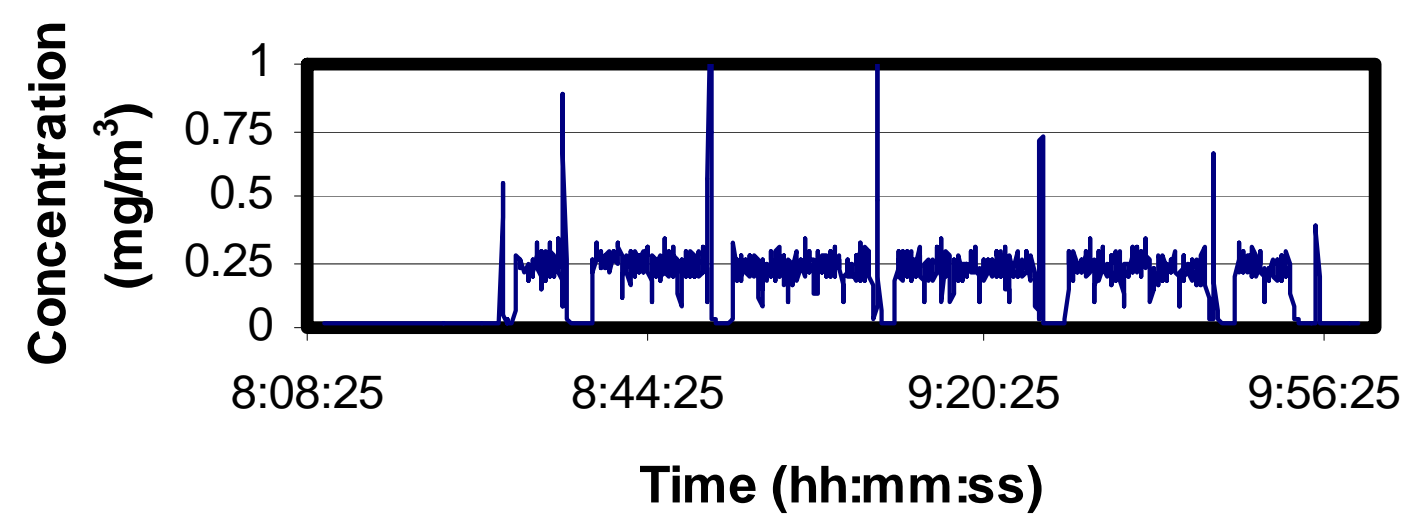

\section{Turning EPA Fluid Background Run 1 9/14/04}

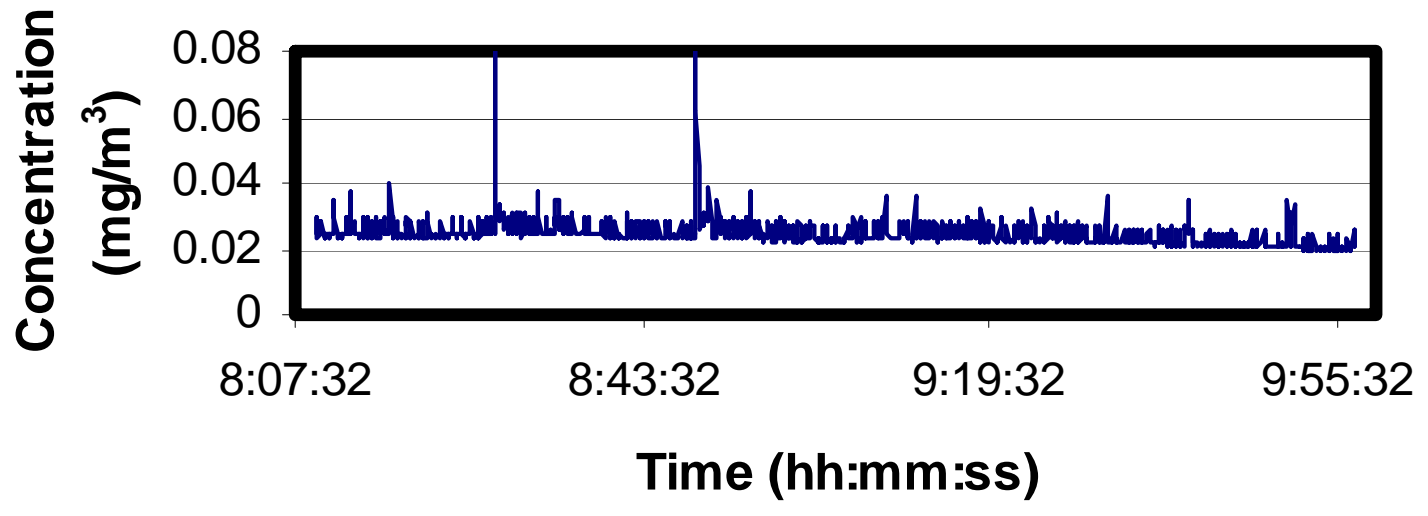




\section{Turning EPA Fluid \\ Enclosure Run 2 9/14/04}

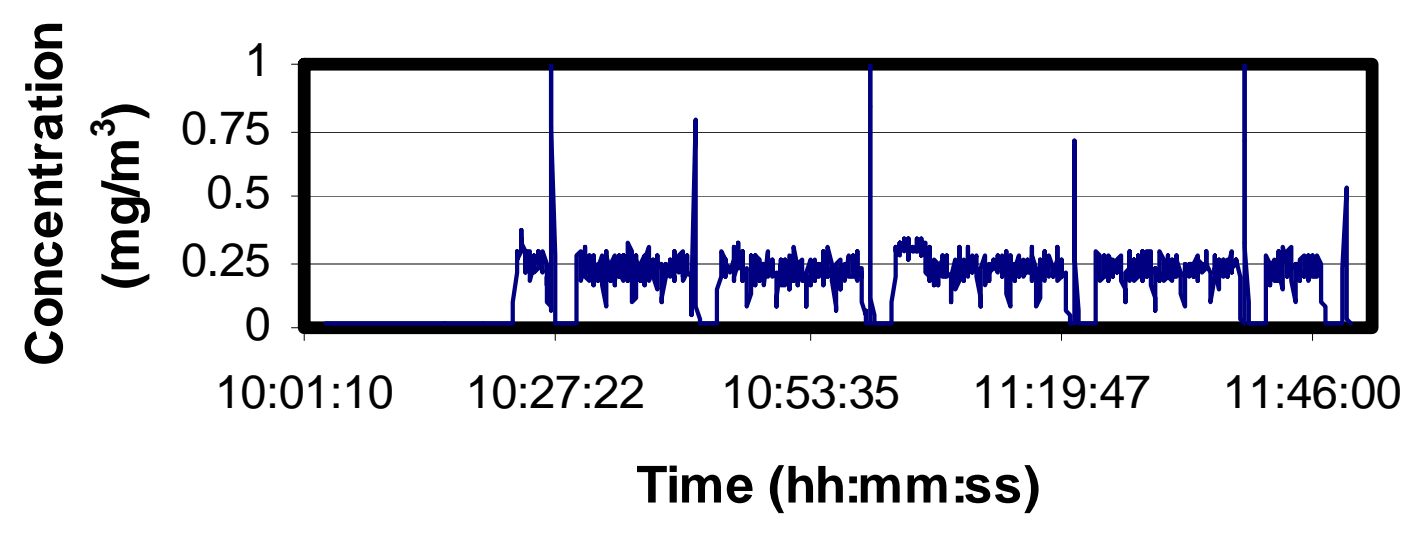

Turning EPA Fluid Background Run 2 9/14/04

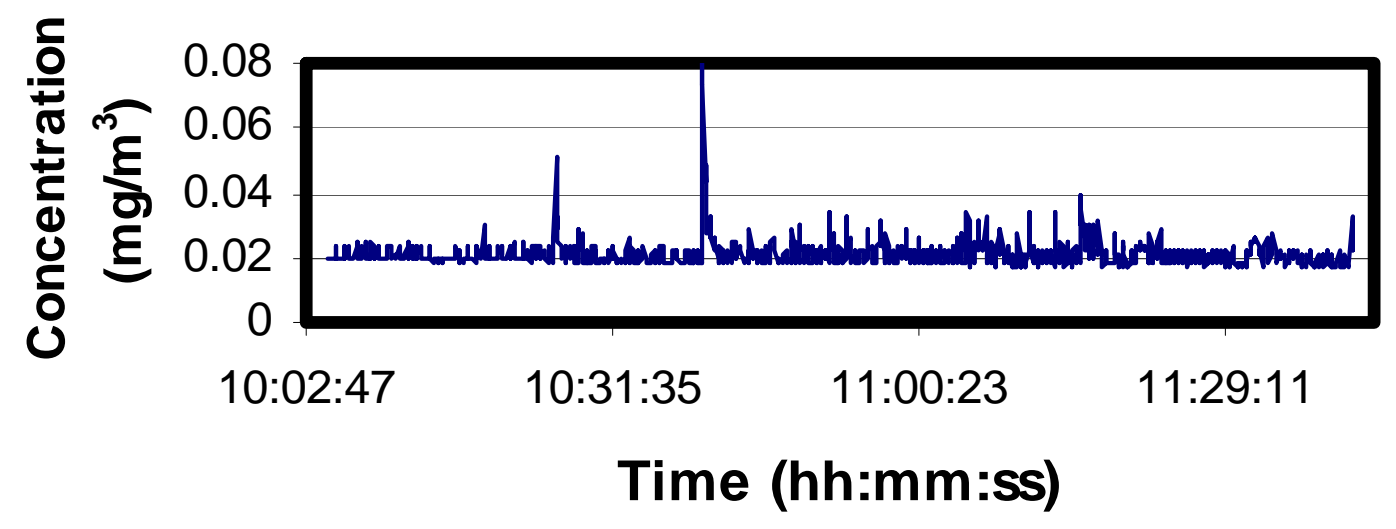




\section{Turning EPA Fluid Enclosure Run 3 9/15/04}

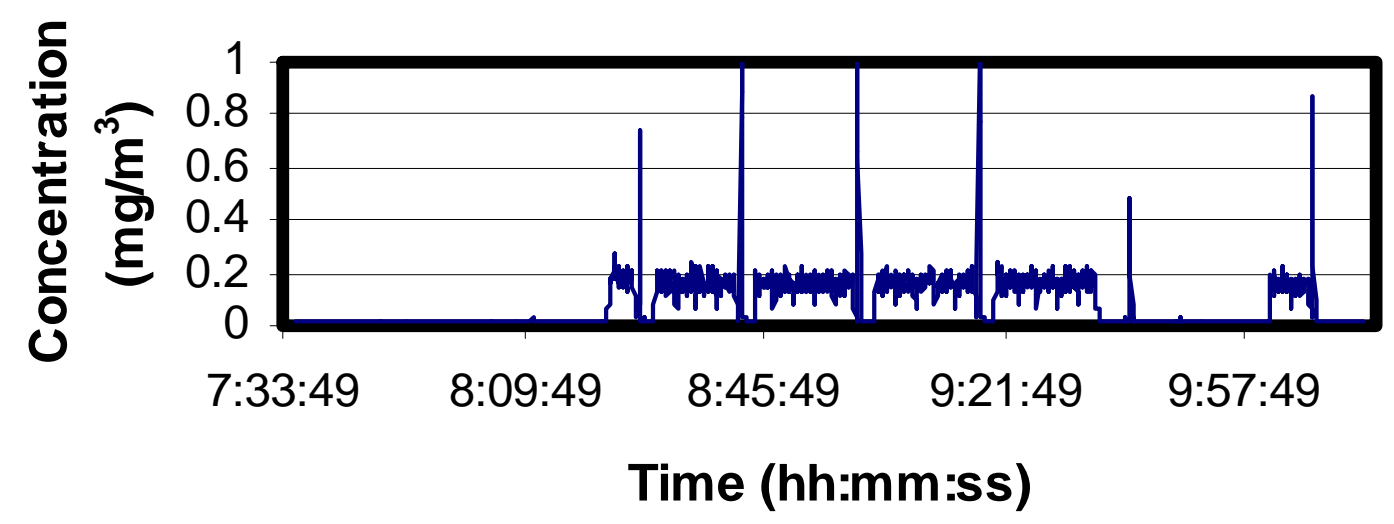

\section{Turning EPA Fluid Background Run 3 9/15/04}

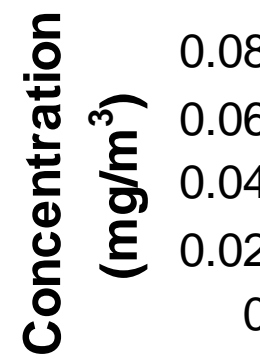

7:31:31

8:07:31

8:43:31

9:19:31

9:55:31

Time (hh:mm:ss) 


\section{Turning EPA Fluid Enclosure Run 4 9/15/04}

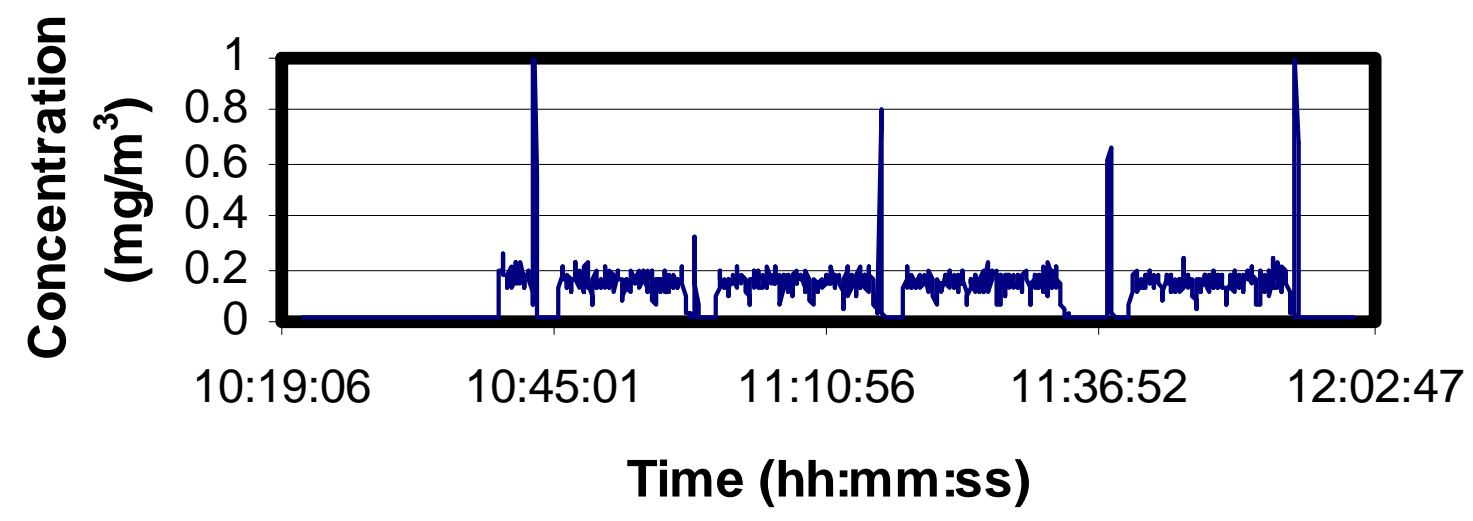

\section{Turning EPA Fluid Background Run 4 9/15/04}

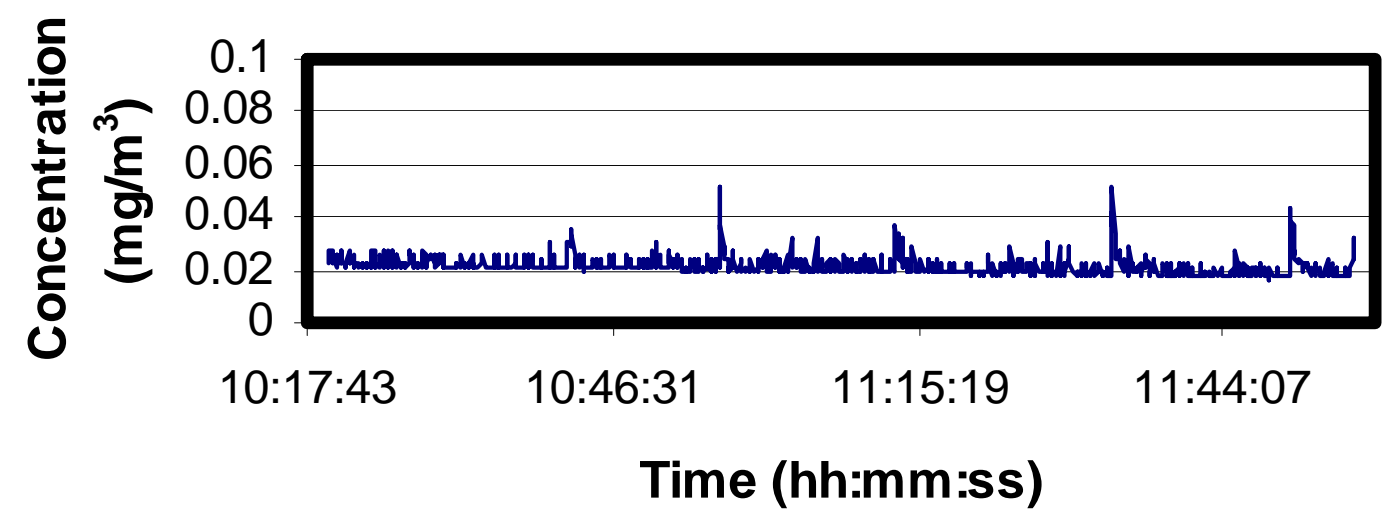




\section{Turning EPA Fluid Enclosure Run 5 9/16/04}

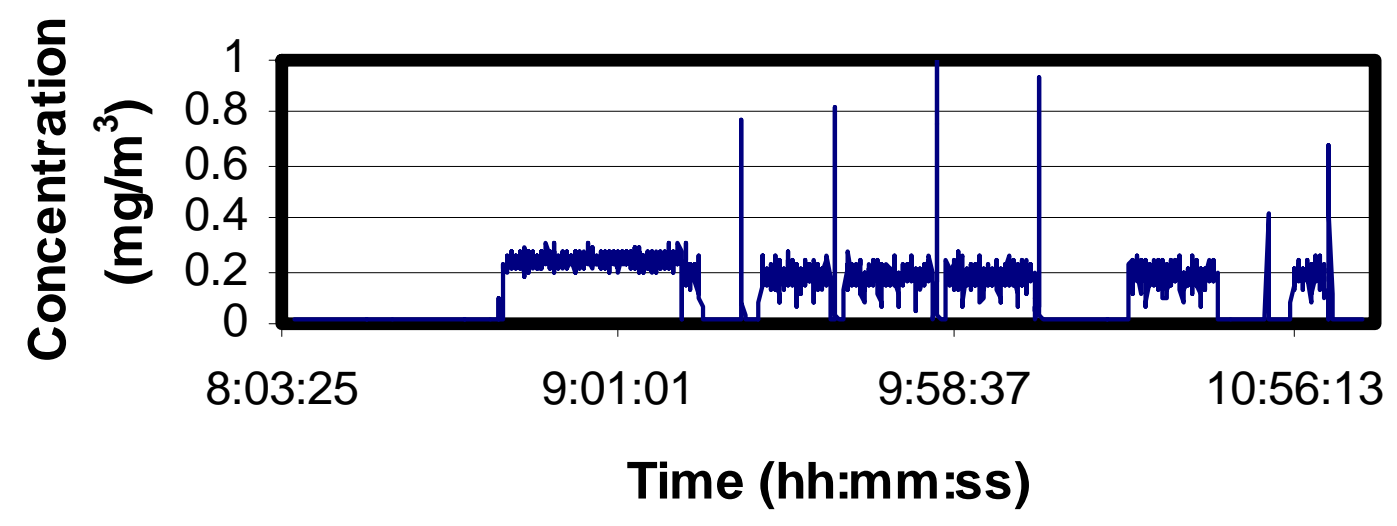

\section{Turning EPA Fluid Background Run 5 9/16/04}

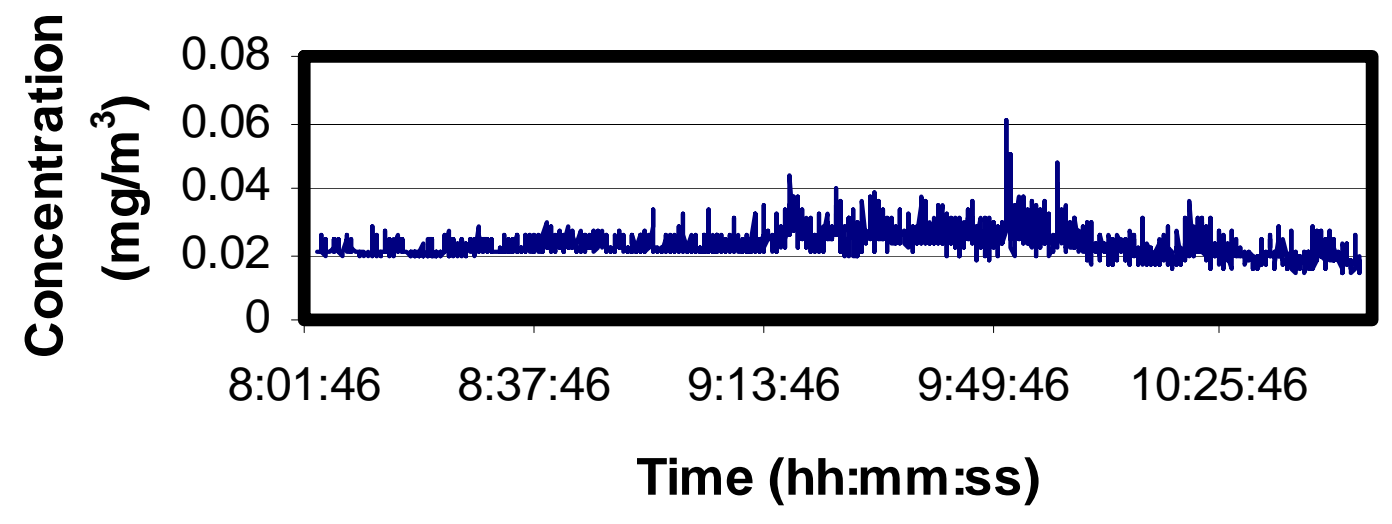




\section{APPENDIX E}

Calculated Generation Rates

\begin{tabular}{|c|c|c|c|c|c|c|c|}
\hline $\begin{array}{c}\text { Run } \\
\text { No. }\end{array}$ & Process & Date & Fluid & $\begin{array}{l}\text { Application } \\
\text { Method } \\
\text { (rpm) }\end{array}$ & $\begin{array}{c}\text { Temp } \\
\text { ( F) }\end{array}$ & $\begin{array}{c}\text { Relative } \\
\text { Humidity } \\
\text { (\%) }\end{array}$ & $\begin{array}{c}\text { Generation } \\
\text { Rate } \\
\text { (mg/min) }\end{array}$ \\
\hline 1 & Milling & 7/19/04 & EPA & Flood (2292) & 75 & 52 & 10.047 \\
\hline 2 & Milling & $7 / 26 / 04$ & EPA & Flood (1528) & 72.2 & 64 & 7.035 \\
\hline 3 & Milling & $7 / 27 / 04$ & EPA & Flood (1528) & 72.3 & 65 & 5.501 \\
\hline 4 & Milling & $7 / 28 / 04$ & EPA & Flood (2292) & 75.5 & 67 & 13.821 \\
\hline 5 & Milling & $7 / 29 / 04$ & EPA & Flood (2292) & 73.2 & 61 & 9.027 \\
\hline 6 & Milling & 7/30/04 & EPA & Flood (1528) & 73.6 & 70 & 6.895 \\
\hline 7 & Milling & $8 / 2 / 04$ & EPA & Flood (2292) & 74.8 & 57 & 12.182 \\
\hline 8 & Milling & $8 / 4 / 04$ & EPA & Flood (1528) & 73.9 & 52 & 9.11 \\
\hline 9 & Milling & $8 / 5 / 04$ & EPA & Flood (1528) & 73 & 58 & 6.668 \\
\hline 10 & Milling & $8 / 6 / 04$ & EPA & Flood (2292) & 73 & 48 & 9.147 \\
\hline 1 & Milling & $8 / 18 / 04$ & Baseline & Flood (1528) & 73 & 57 & 0.024 \\
\hline 2 & Milling & $8 / 18 / 04$ & Baseline & Flood (2292) & 72.2 & 56 & 0.463 \\
\hline 3 & Milling & $8 / 19 / 04$ & Baseline & Flood (2292) & 72.5 & 61 & 0.648 \\
\hline 4 & Milling & $8 / 19 / 04$ & Baseline & Flood (1528) & 73.2 & 62 & 0.102 \\
\hline 5 & Milling & $8 / 20 / 04$ & Baseline & Flood (1528) & 72.2 & 63 & 0.152 \\
\hline 6 & Milling & $8 / 20 / 04$ & Baseline & Flood (2292) & 72 & 61 & 0.754 \\
\hline 7 & Milling & $8 / 25 / 04$ & Baseline & Flood (1528) & 71.8 & 56 & 0.229 \\
\hline 8 & Milling & $8 / 25 / 04$ & Baseline & Flood (2292) & 72.3 & 52 & 1.405 \\
\hline 9 & Milling & $8 / 26 / 04$ & Baseline & Flood (2292) & 72.9 & 52 & 0.039 \\
\hline 10 & Milling & $8 / 26 / 04$ & Baseline & Flood (1528) & 71.6 & 56 & 0.041 \\
\hline 1 & Turning & $9 / 1 / 04$ & Baseline & Flood (700) & 73.8 & 54 & 3.170 \\
\hline 2 & Turning & $9 / 1 / 04$ & Baseline & Flood (700) & 77.1 & 49 & 2.508 \\
\hline 3 & Turning & $9 / 2 / 04$ & Baseline & Flood (700) & 76.3 & 51 & 2.090 \\
\hline 4 & Turning & $9 / 7 / 04$ & Baseline & Flood (700) & 74 & 57 & 3.411 \\
\hline 5 & Turning & $9 / 7 / 04$ & Baseline & Flood (700) & 73 & 61 & 3.214 \\
\hline 1 & Turning & $9 / 14 / 04$ & EPA & Flood (700) & 73.2 & 58 & 2.932 \\
\hline 2 & Turning & $9 / 14 / 04$ & EPA & Flood (700) & 72.3 & 55 & 2.975 \\
\hline 3 & Turning & $9 / 15 / 04$ & EPA & Flood (700) & 74.7 & 58 & 1.894 \\
\hline 4 & Turning & 9/15/04 & EPA & Flood (700) & 72.7 & 54 & 1.958 \\
\hline 5 & Turning & $9 / 17 / 04$ & EPA & Flood (700) & 75 & 61 & 2.318 \\
\hline
\end{tabular}




\section{APPENDIX F}

Enclosure Temperature and Relative Humidity Measurements

\section{Milling EPA Fluid \\ Enclosure Temperature and Relative Humidity \\ Run 2 7/26/04}

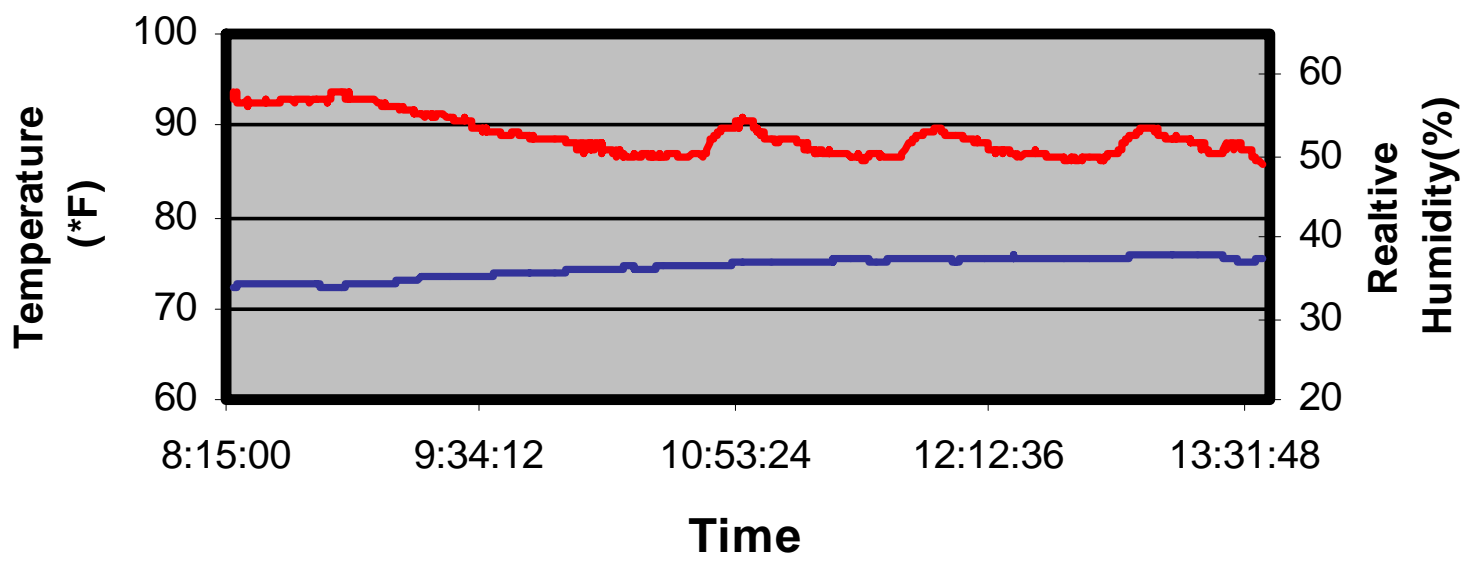




\section{Milling EPA Fuid}

\section{Enclosure Temperature and Relative Humidity}

Run 3 7/27/04

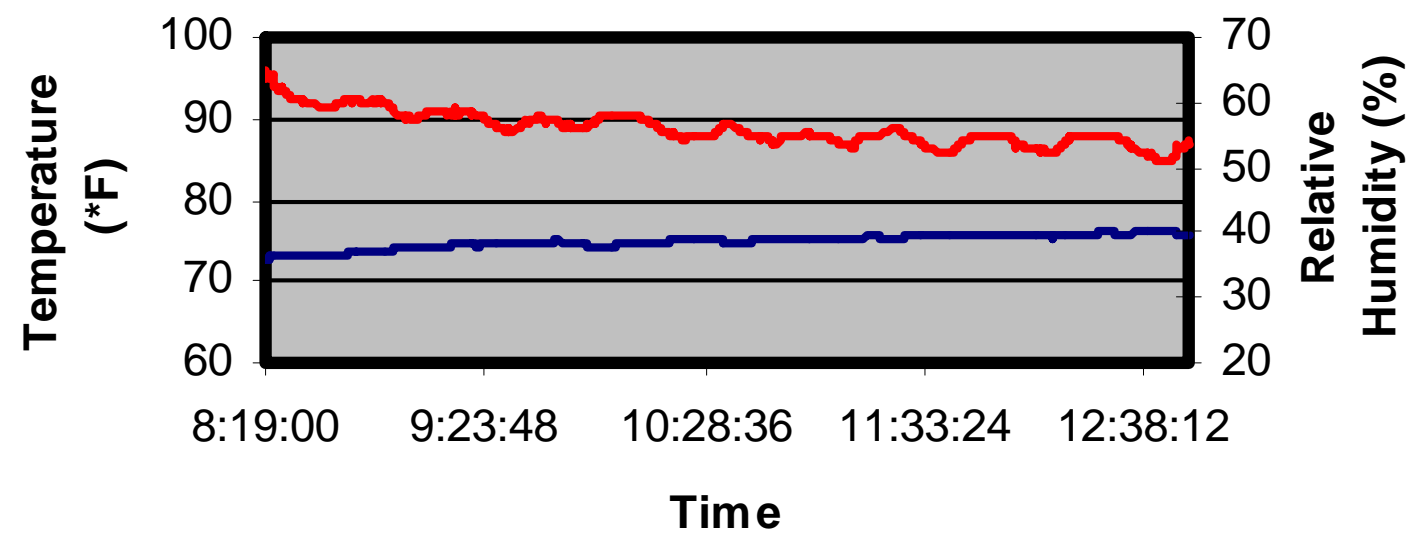

Temperature ( $\left.{ }^{*} \mathrm{~F}\right)$

Ralative Humidity (\%)

\section{Milling EPA Fluid}

Enclosure Temperature and Relative Humidity

Run 4 7/28/04
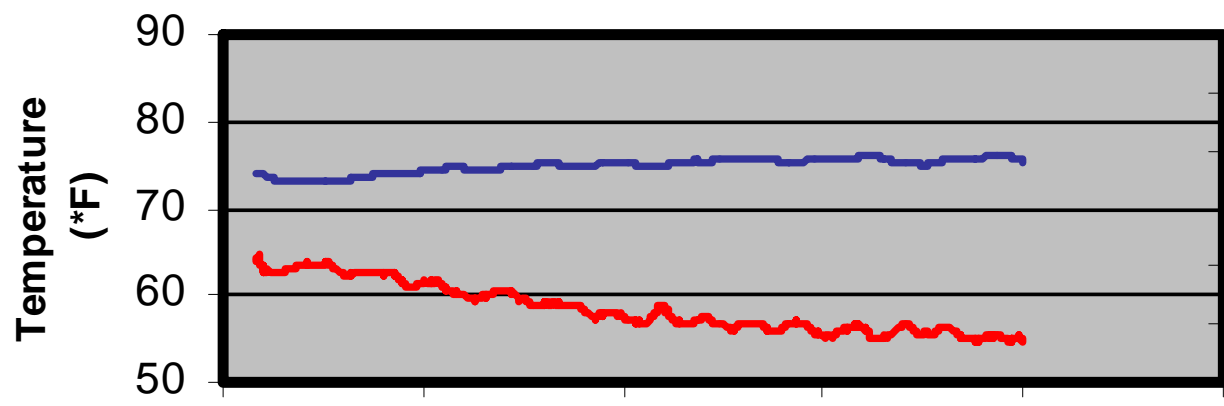

100

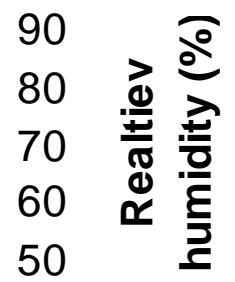

8:00:00

9:12:00

10:24:00 11:36:00 12:48:00 14:00:00

Time

Temperature $\left({ }^{*} \mathrm{~F}\right) \longrightarrow$ Relative Humidity $(\%)$ 


\section{Milling EPA Fuid \\ Enclosure Temperature and Realative Humidity Run $5 \quad 7 / 29 / 04$}

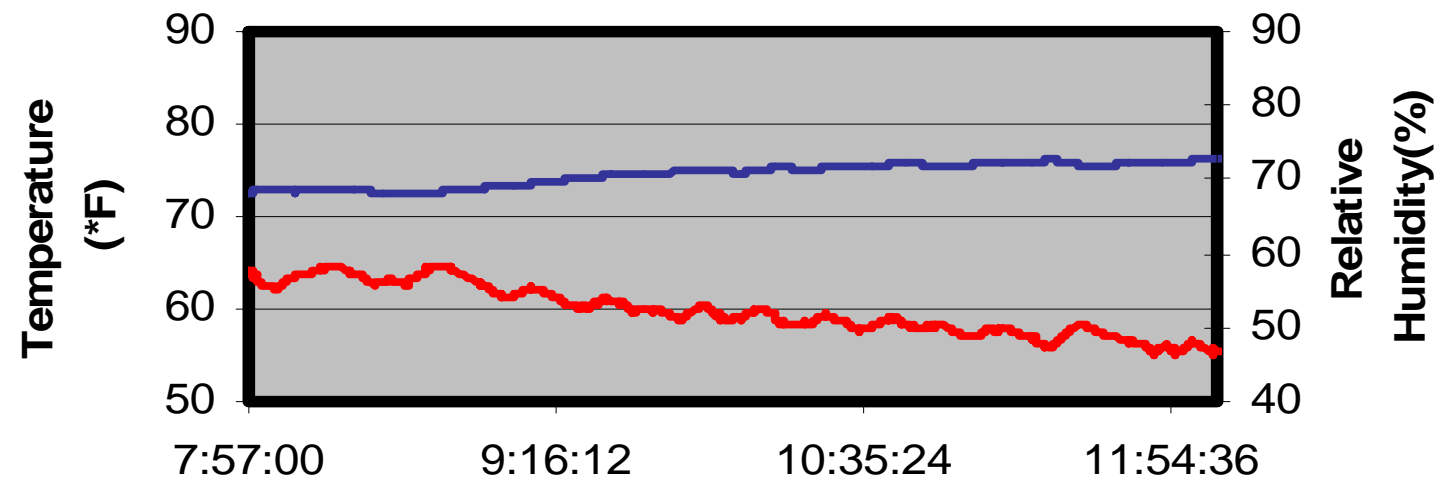

Time

Temperature ( $\left.{ }^{*} \mathrm{~F}\right)$

Relative Humidity (\%)

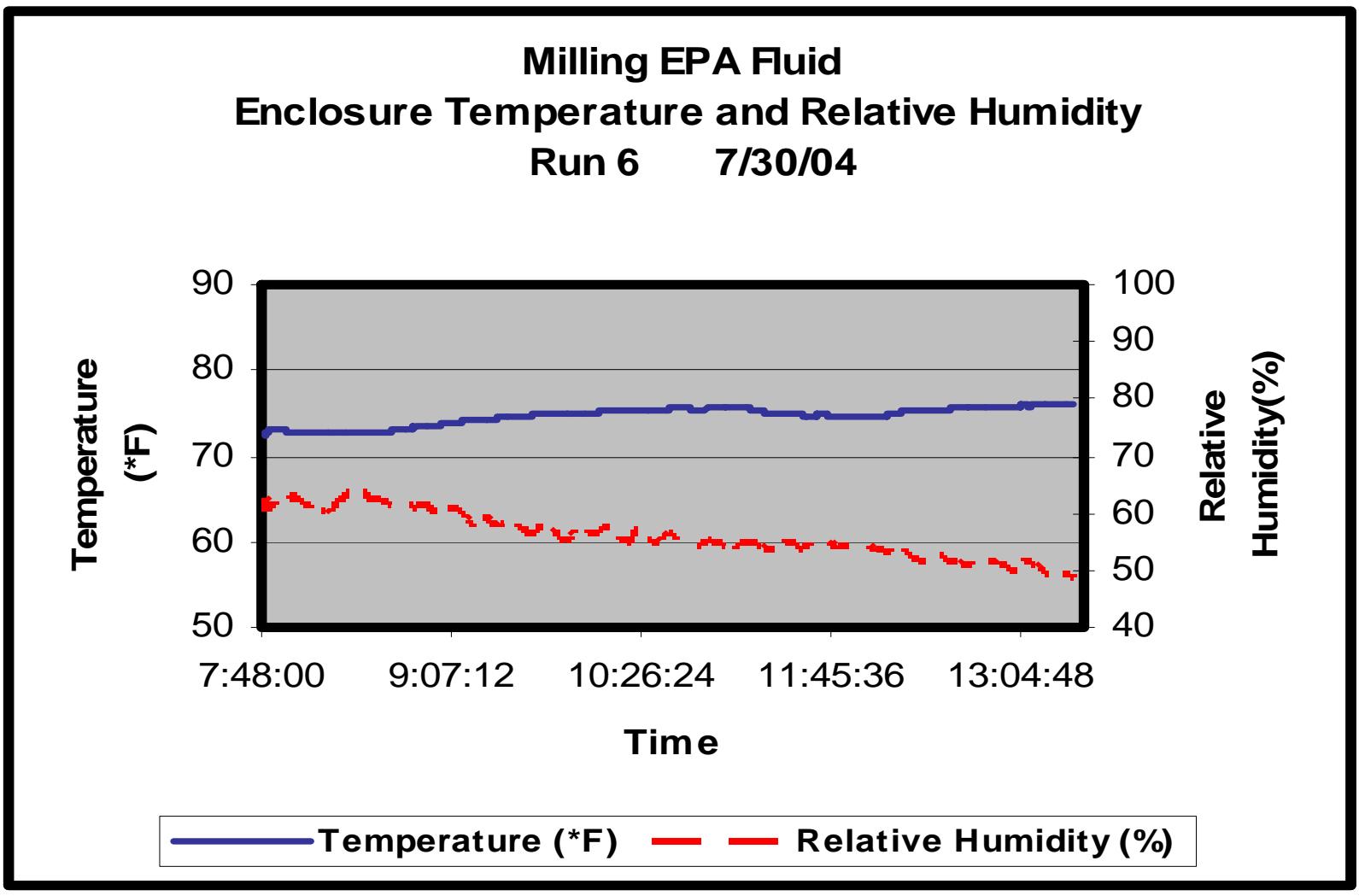




\section{Milling EPA Fuid}

\section{Enclosure Temperature and Relative Humidity \\ Run $7 \quad 8 / 2 / 04$}

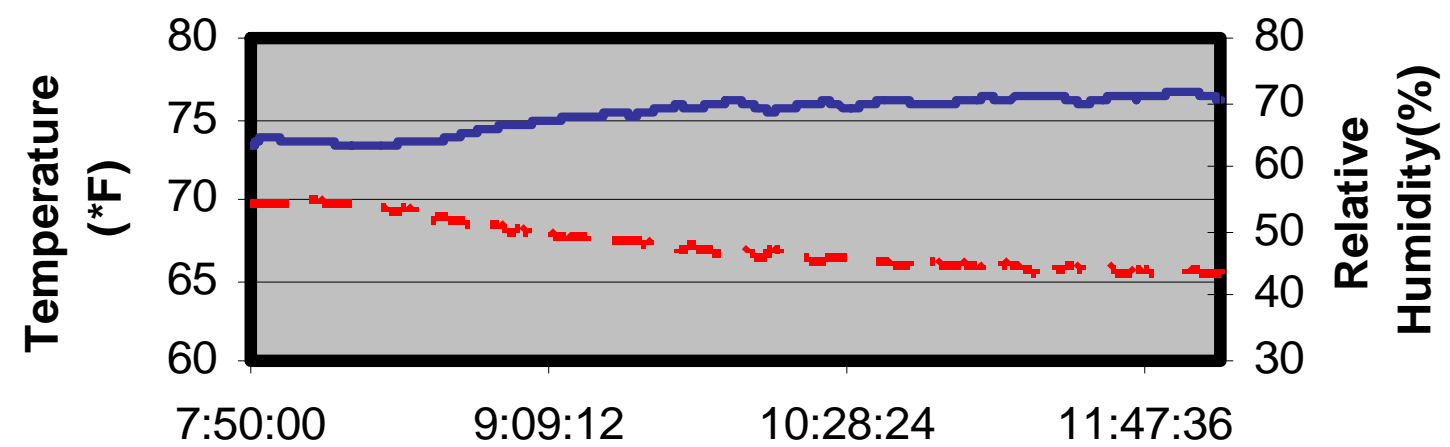

Time

Temperature ( $\left.{ }^{*} \mathrm{~F}\right)$ - Relative Humidity (\%)

Milling EPA Fluid

Enclosure Temperature and Relative Humidity

Run $8 \quad 8 / 4 / 04$

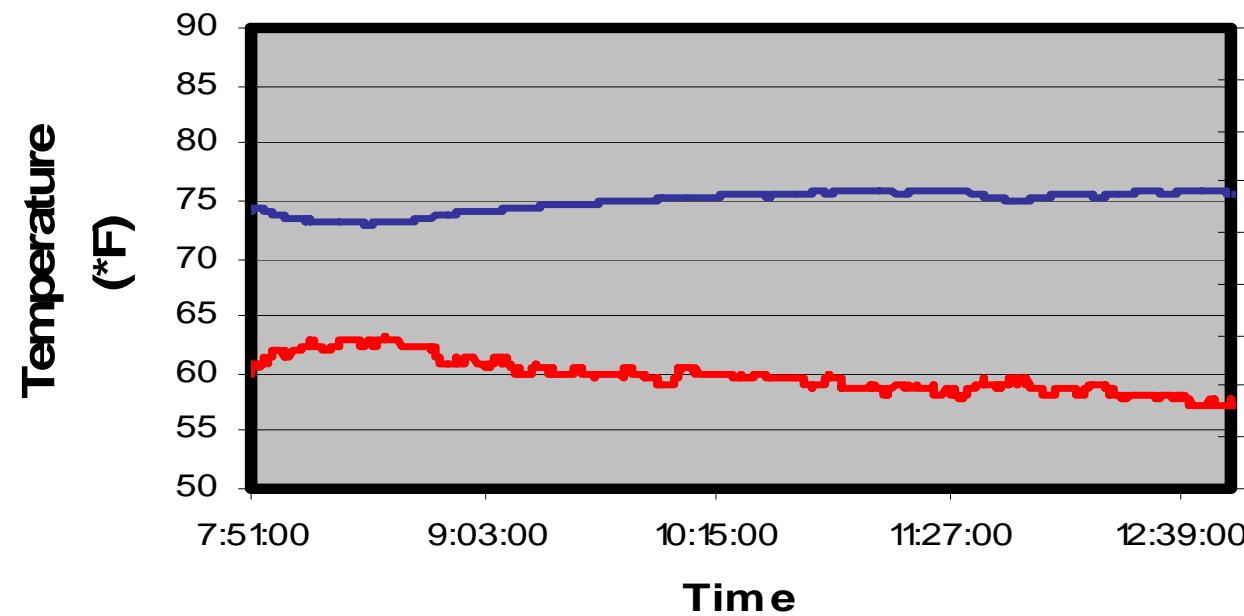

Temperature (*F)

Time 


\section{Milling EPA Fuid \\ Enclosure Temperature and Relative Humidity Run 9 8/5/04}

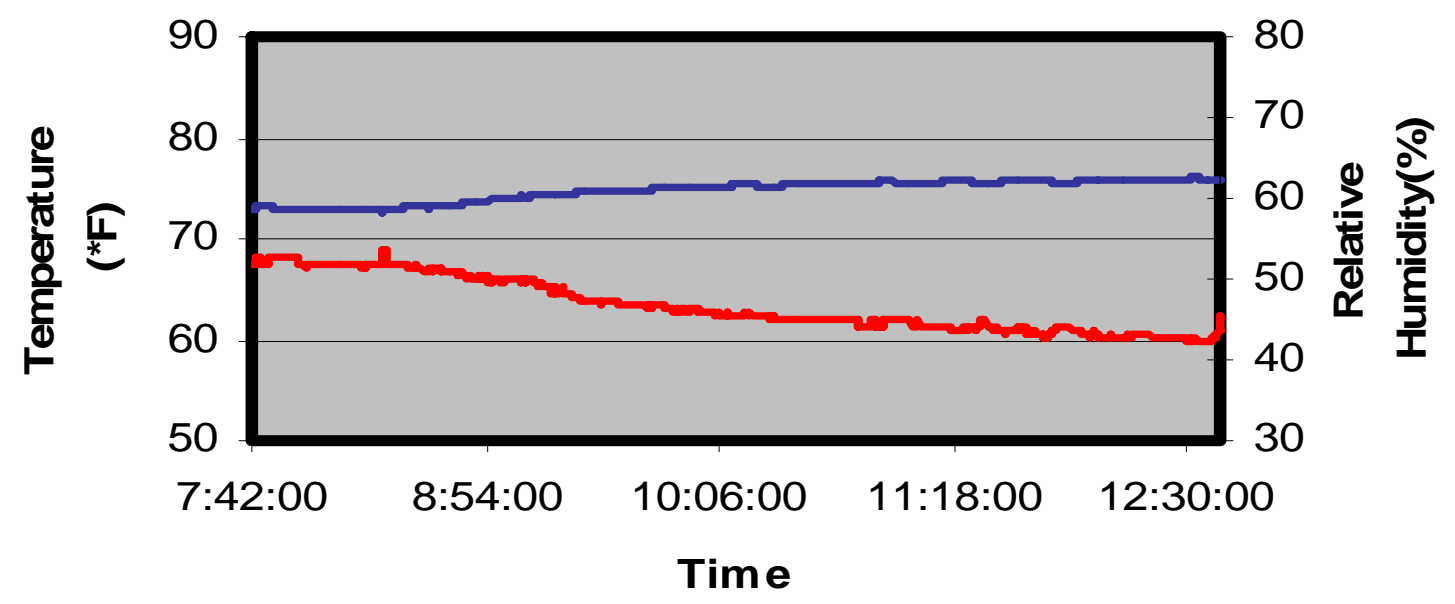

Temperature $\left({ }^{*} \mathrm{~F}\right)$

Relative Humidity (\%)

\section{Milling EPA Fuid}

Enclosure Temperature and Relative Humidity

Run $10 \quad 8 / 6 / 04$

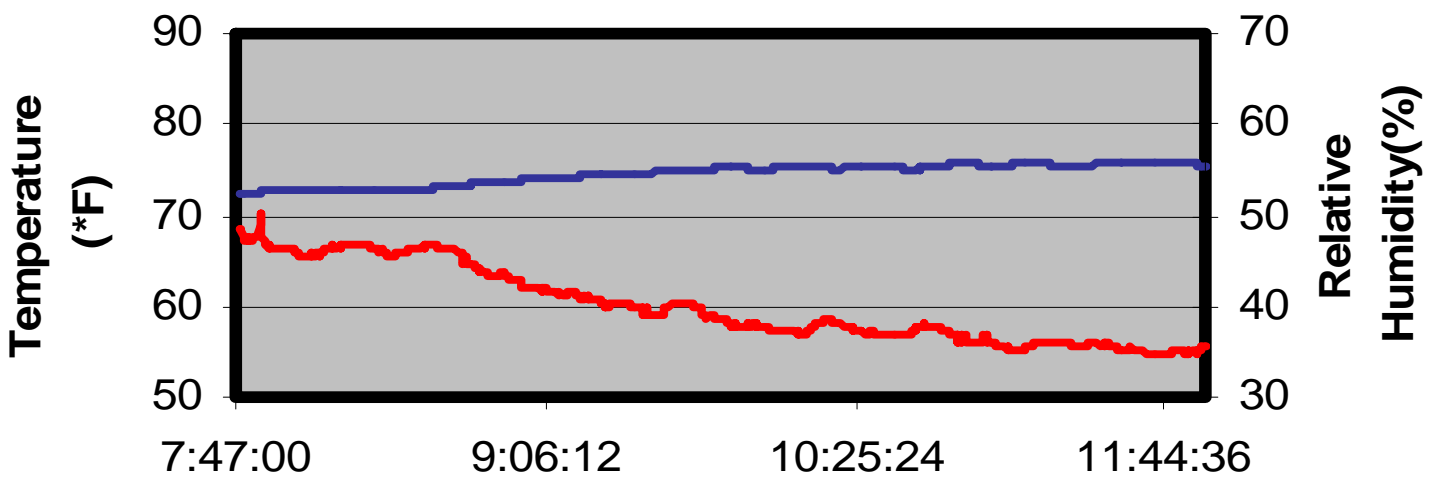

Time 
Turning Baseline Fluid

Enclosure Temperature and Relative Humidity

Runs 1,2 9/1/04

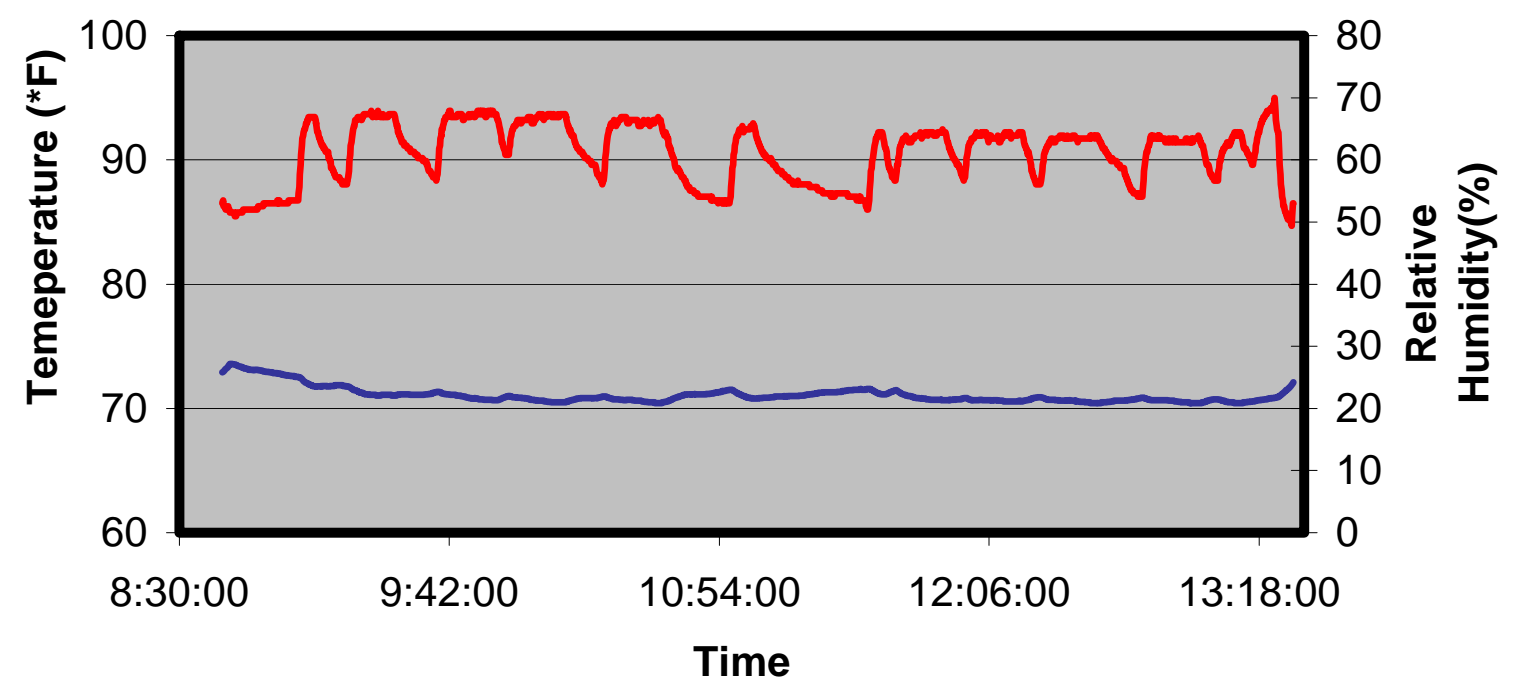

— Temperature (*F) — Relative Humidity(\%)

Turning Baseline Fluid

Enclosure Temperature and Relative Humidiity

Run 3 9/2/04

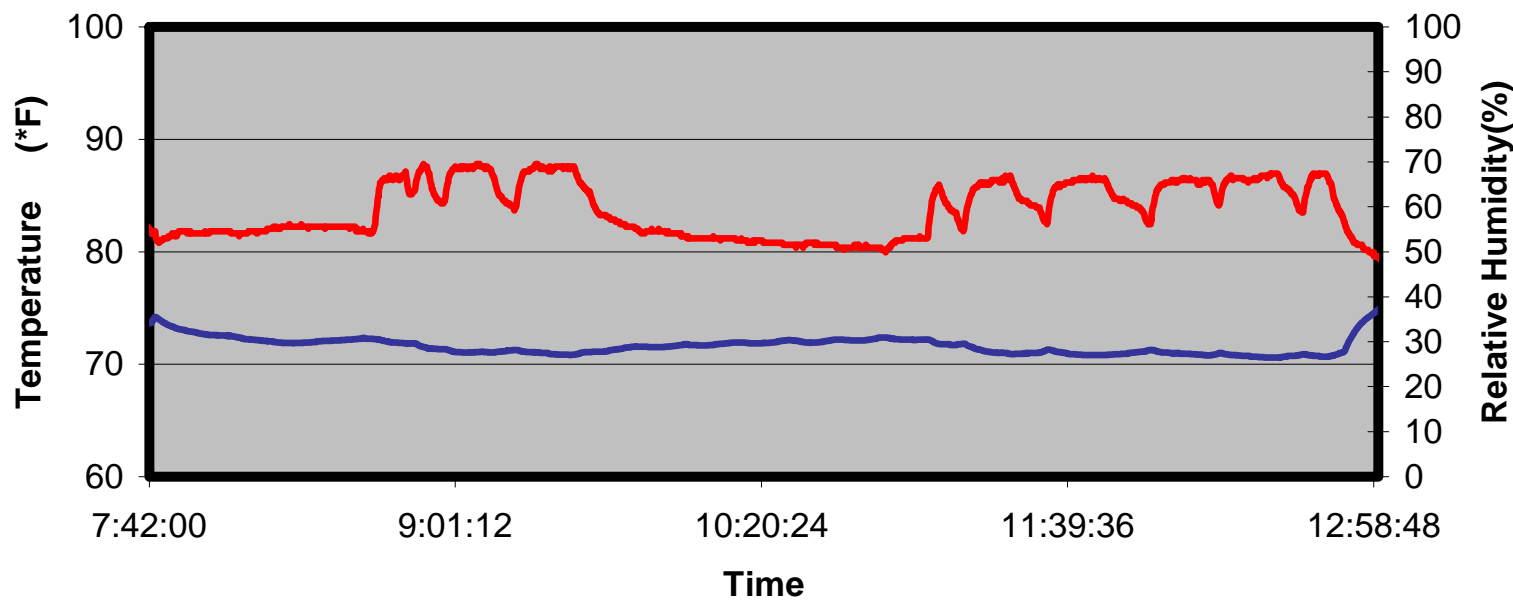

Temperature ( $\left.{ }^{*} \mathrm{~F}\right)$ Relative Humidity (\%) 

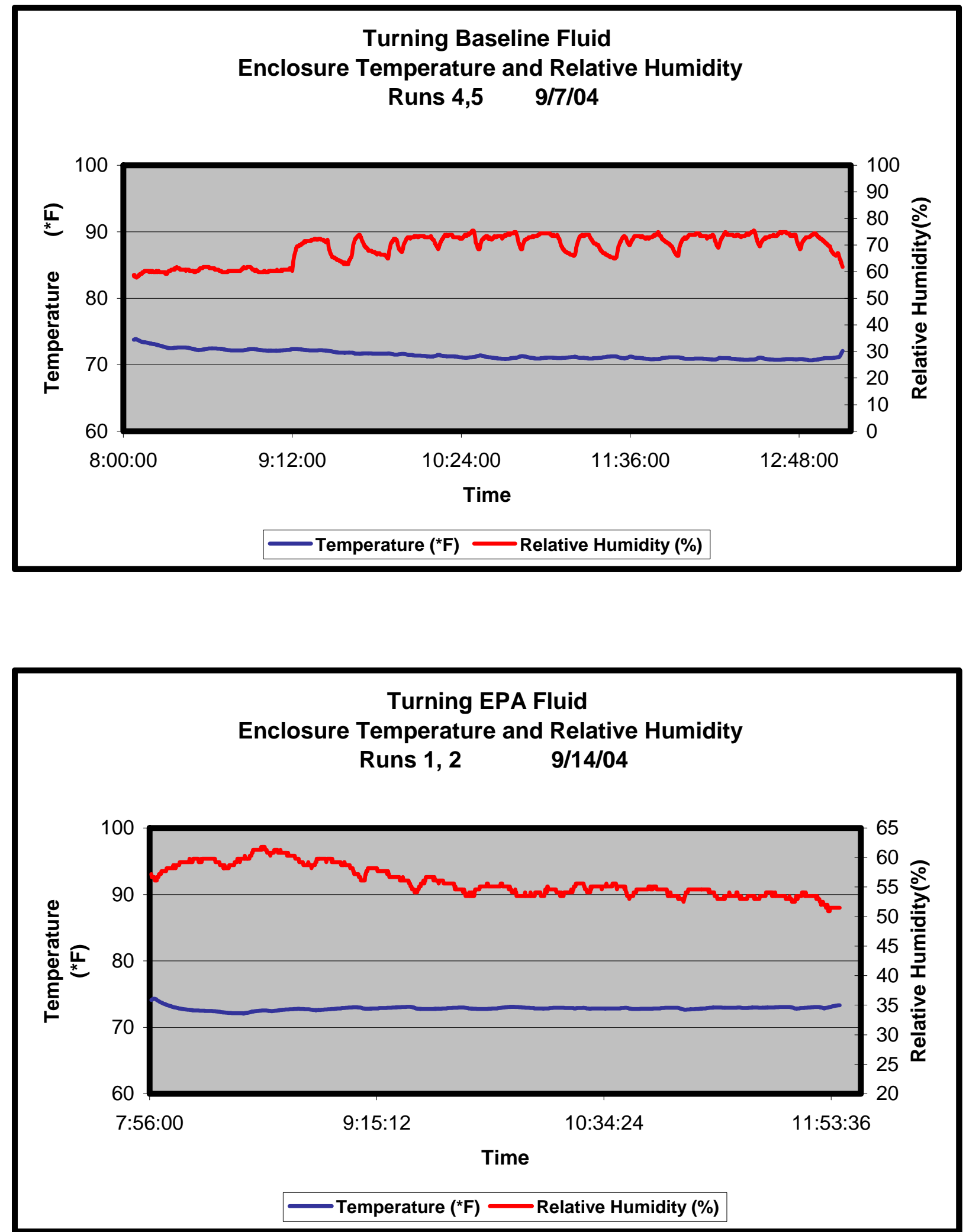

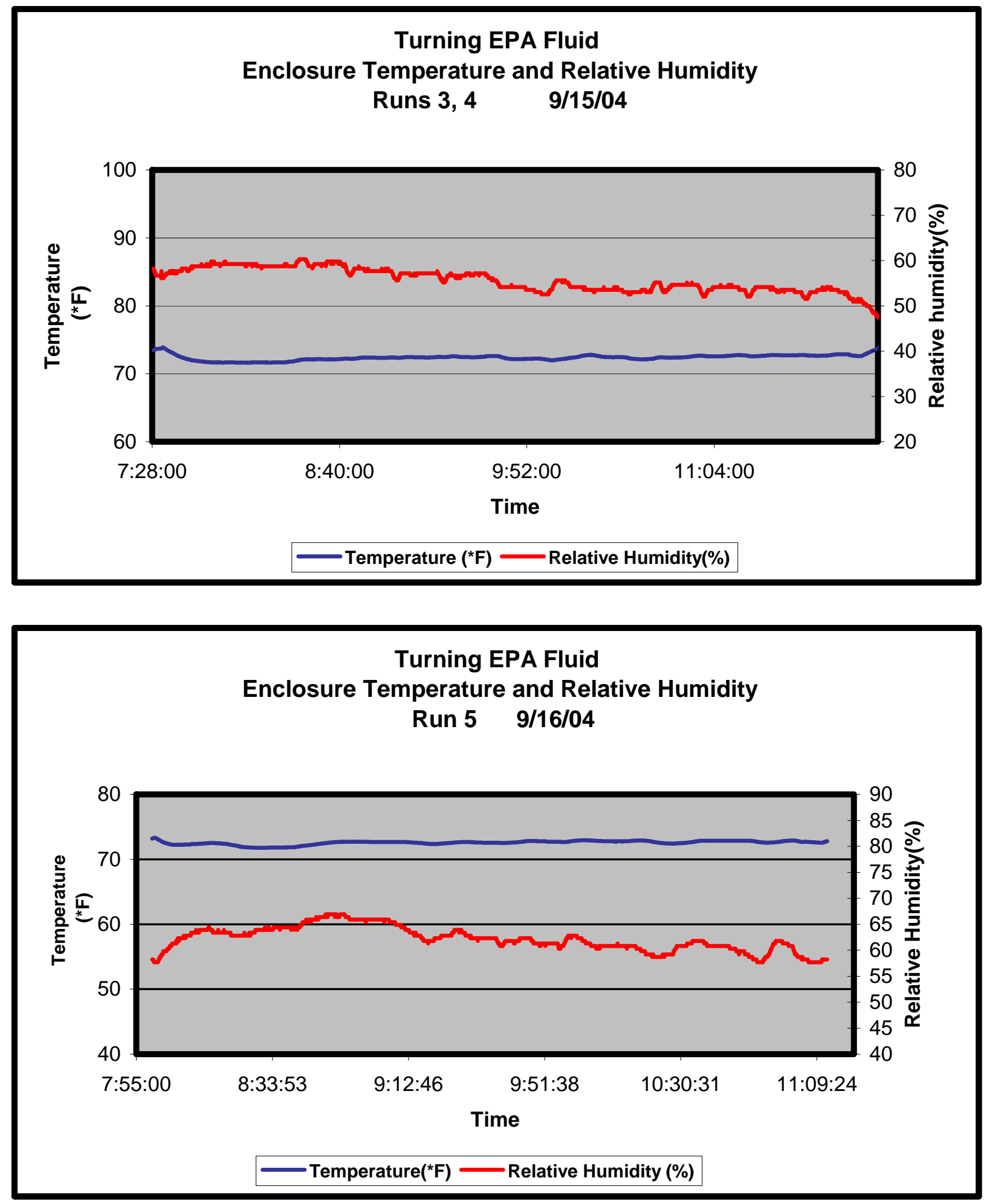


\section{APPENDIX G}

Background Temperature and Relative Humidity Measurements

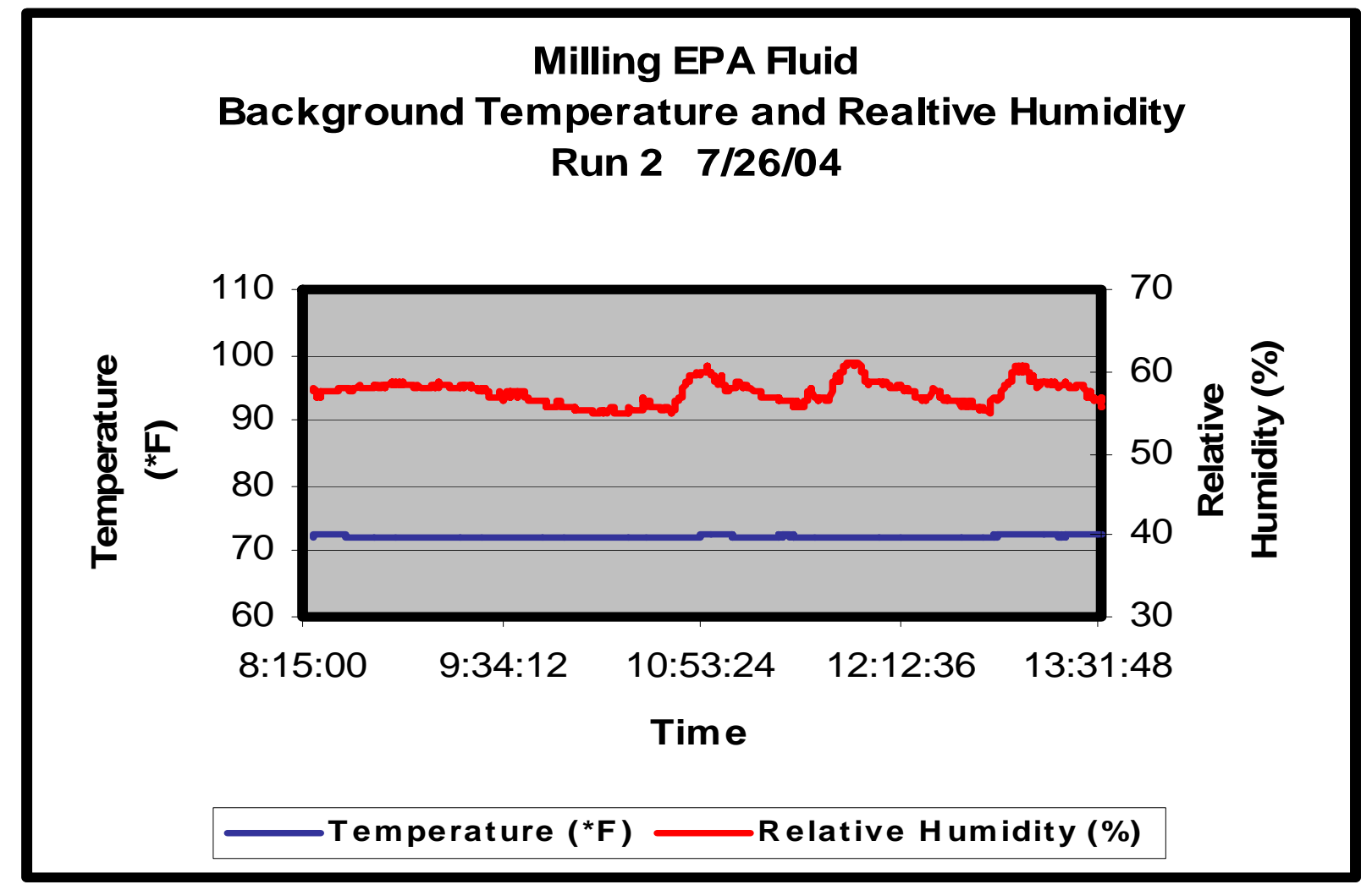




\section{Milling EPA Fluid \\ Background Temperature and Relative Humidity Run 3 7/27/04}

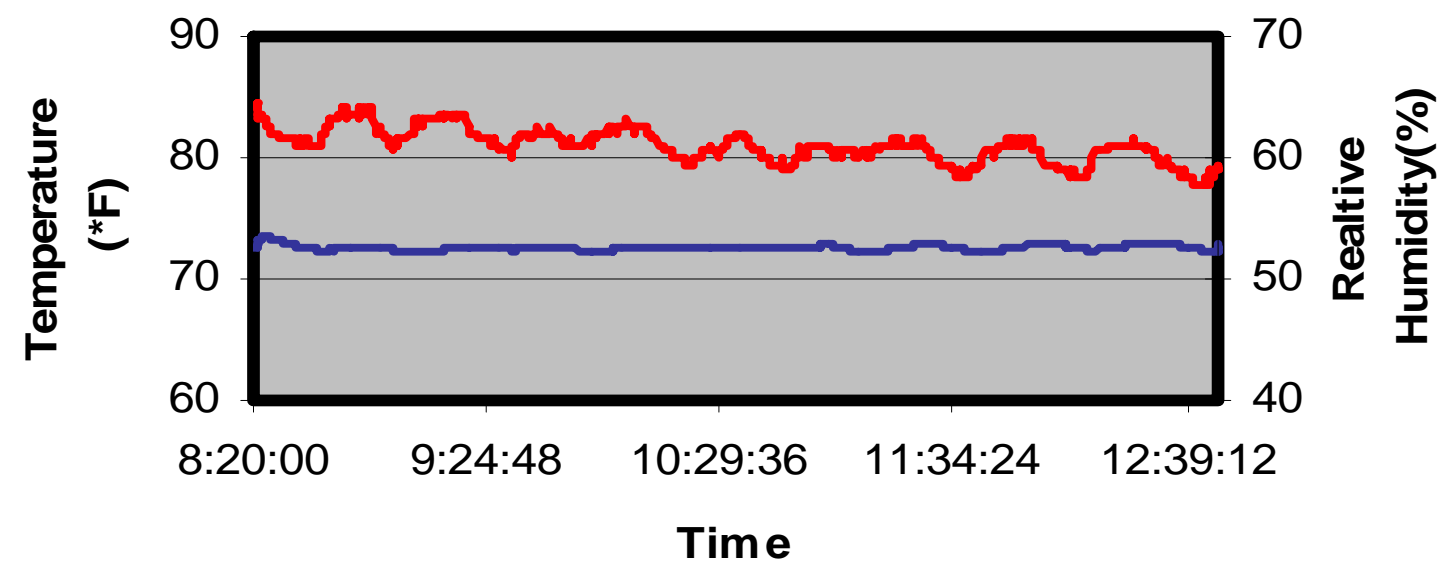

Milling EPA Fuid

Background Temperature and Relative Humidity Run 4 7/28/04

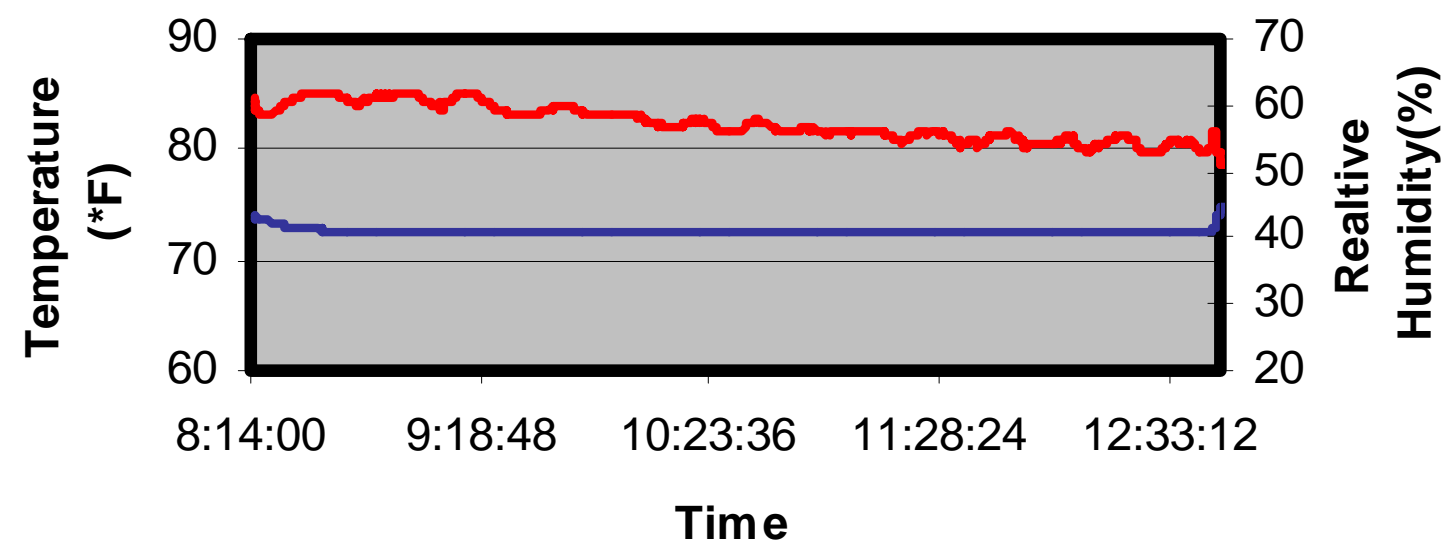




\section{Milling EPA Fuid}

Background Temperature and Relative Humidity

Run 5 7/29/04

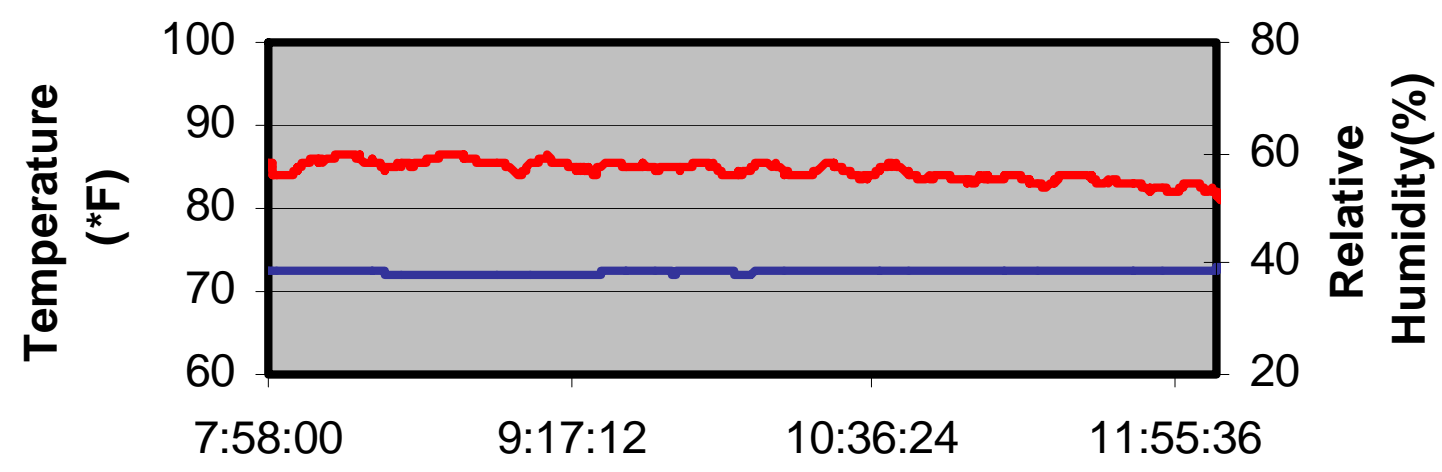

Time

\section{Milling EPA Fuid}

Background Temperature and Relative Humidity

Run 6 7/30/04

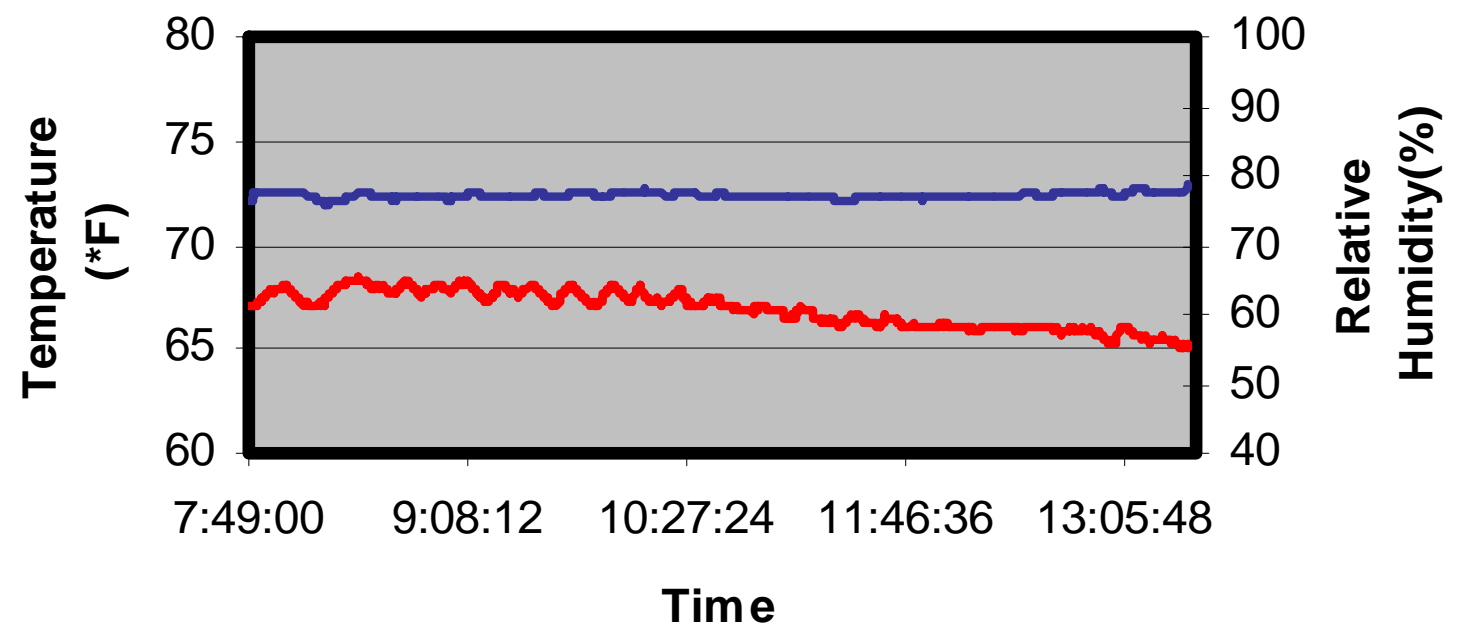

Temperature( $\left.{ }^{*} \mathrm{~F}\right) \longrightarrow$ Relative Humidity (\%) 


\section{Milling EPA Fuid \\ Background Temperature and Relative Humidity \\ Run $7 \quad 8 / 2 / 04$}

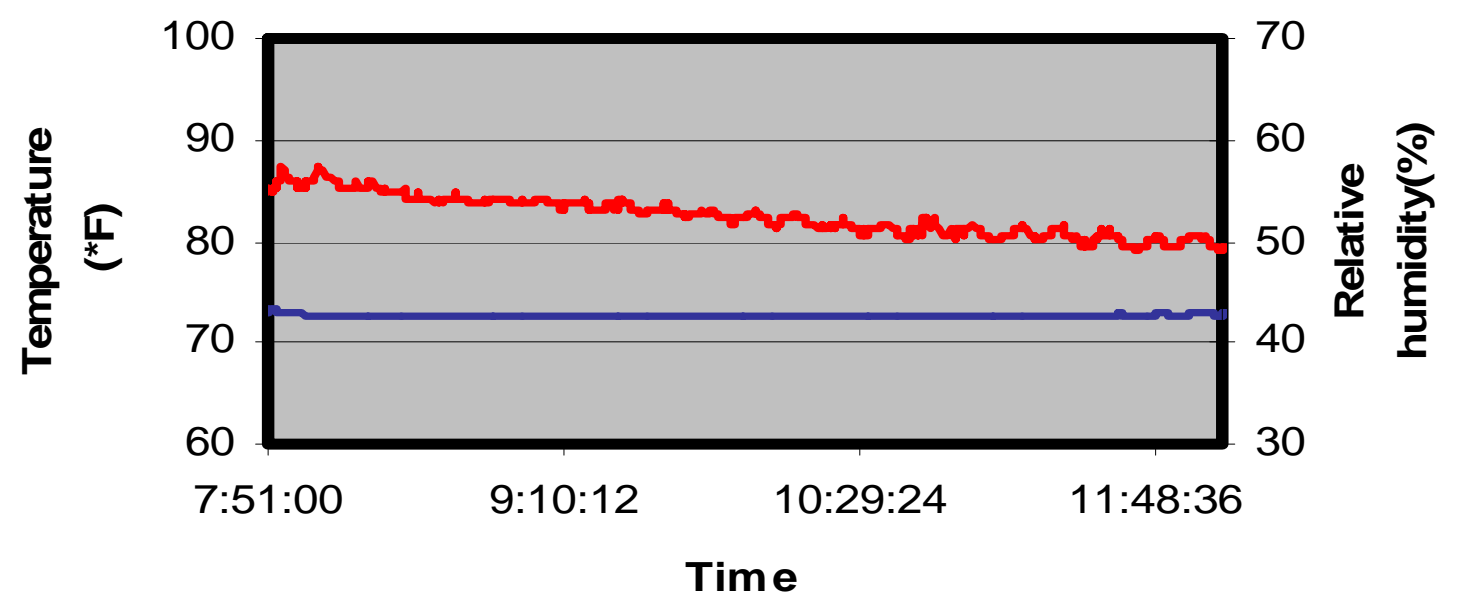

\section{Temperature ( $\left.{ }^{\star} \mathrm{F}\right) \quad$ Relative Humidity (\%)}

\section{Milling EPA Ruid}

Background Temperature and Relative Humidity

Run 9 8/5/04

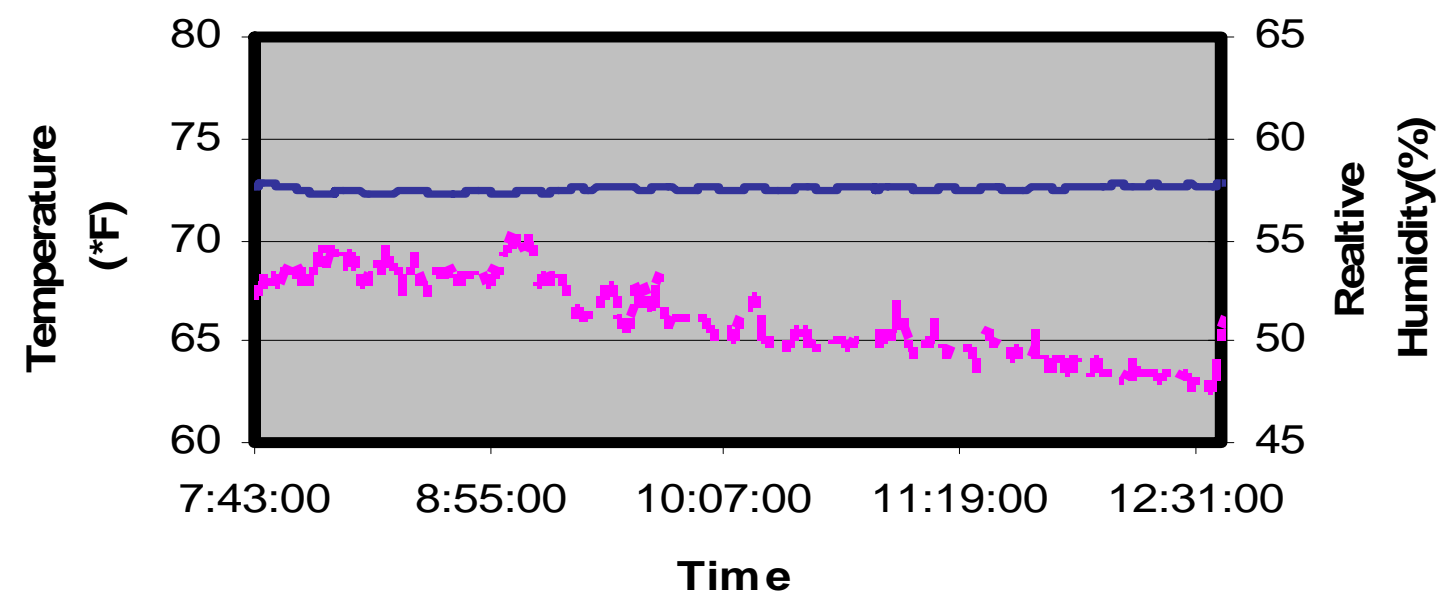

Temperature ( $\left.{ }^{*} F\right)=$ Relative Humidity (\%) 


\section{Milling EPA Fuid \\ Background Temperature and Relative Humidity Run $10 \quad 8 / 6 / 04$}
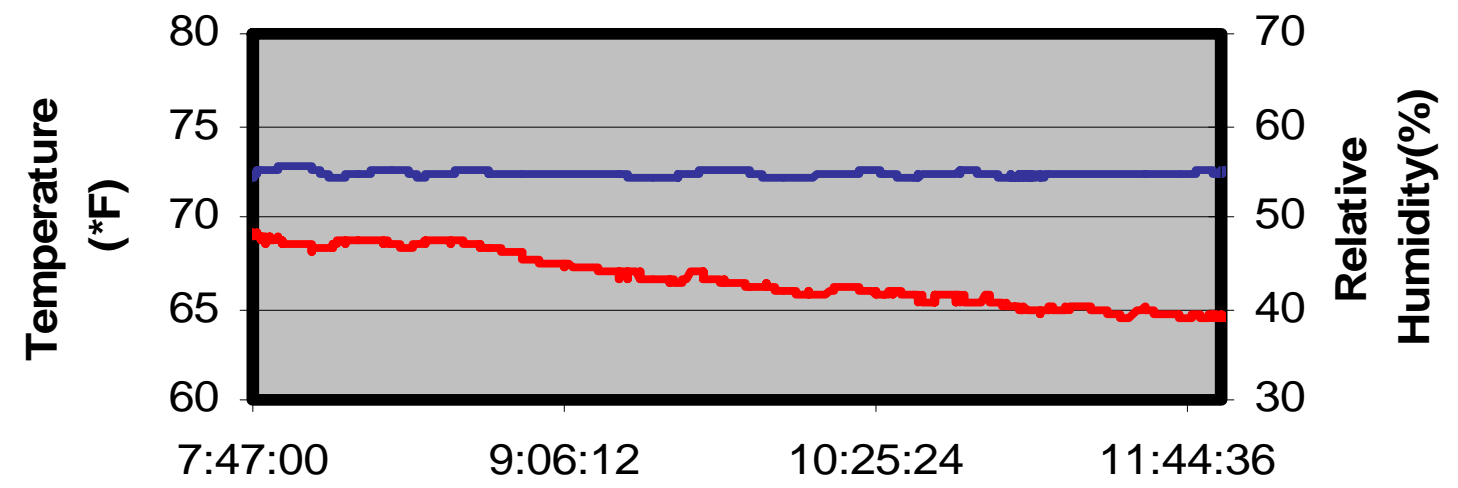

Time

Temperature $\left({ }^{*} \mathrm{~F}\right) \longrightarrow$ Relative Humidity (\%)

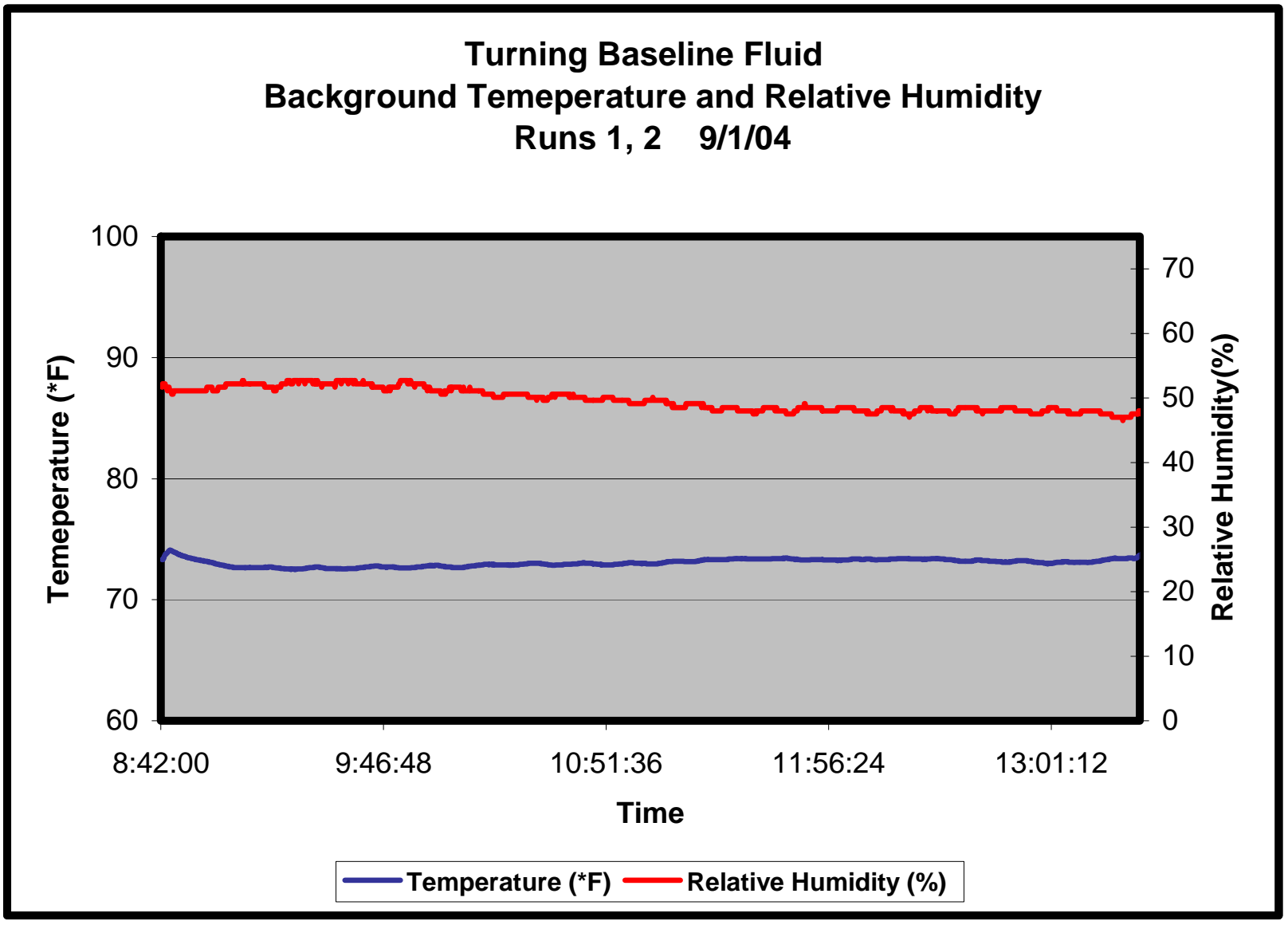




\section{Turning Baseline Fluid \\ Background Temperature and Relative Humidity}

Run 3 9/2/04

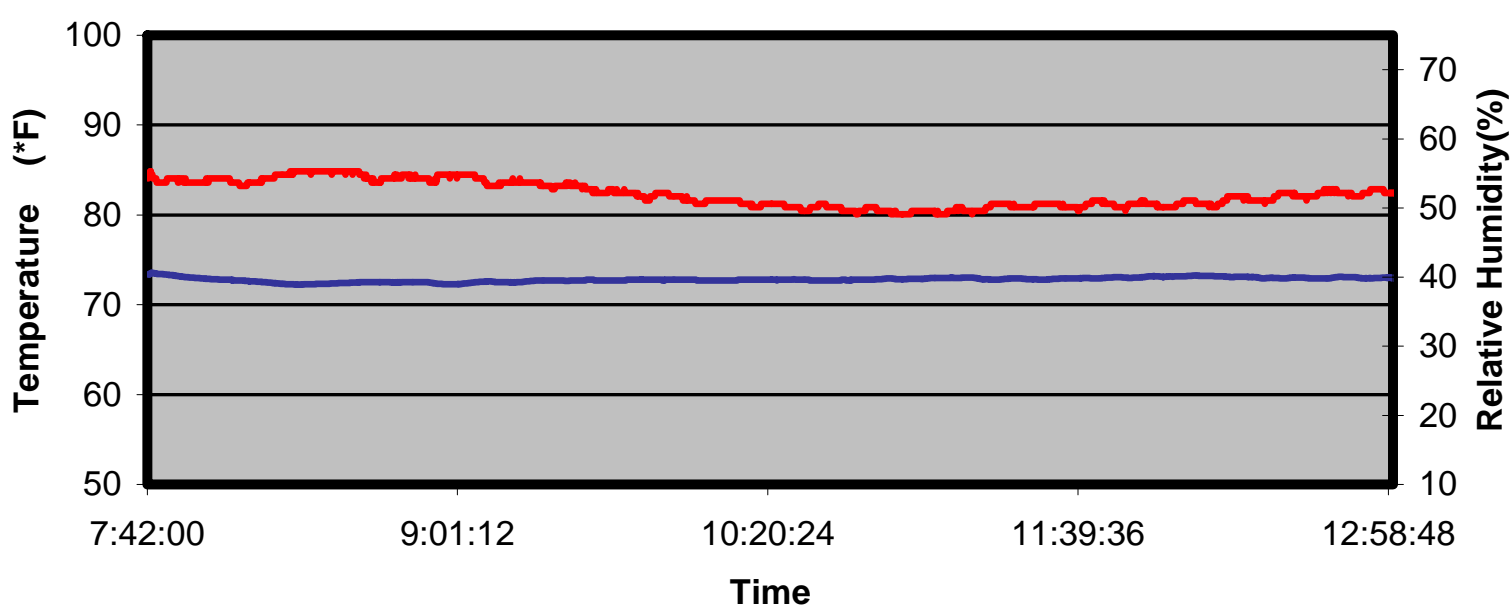

Temperature (*F) $\longrightarrow$ Relative Humidity (\%)

\section{Turning Baseline Fluid \\ Background Temperature and Relative Humidity \\ Runs 4,5 9/7/04}

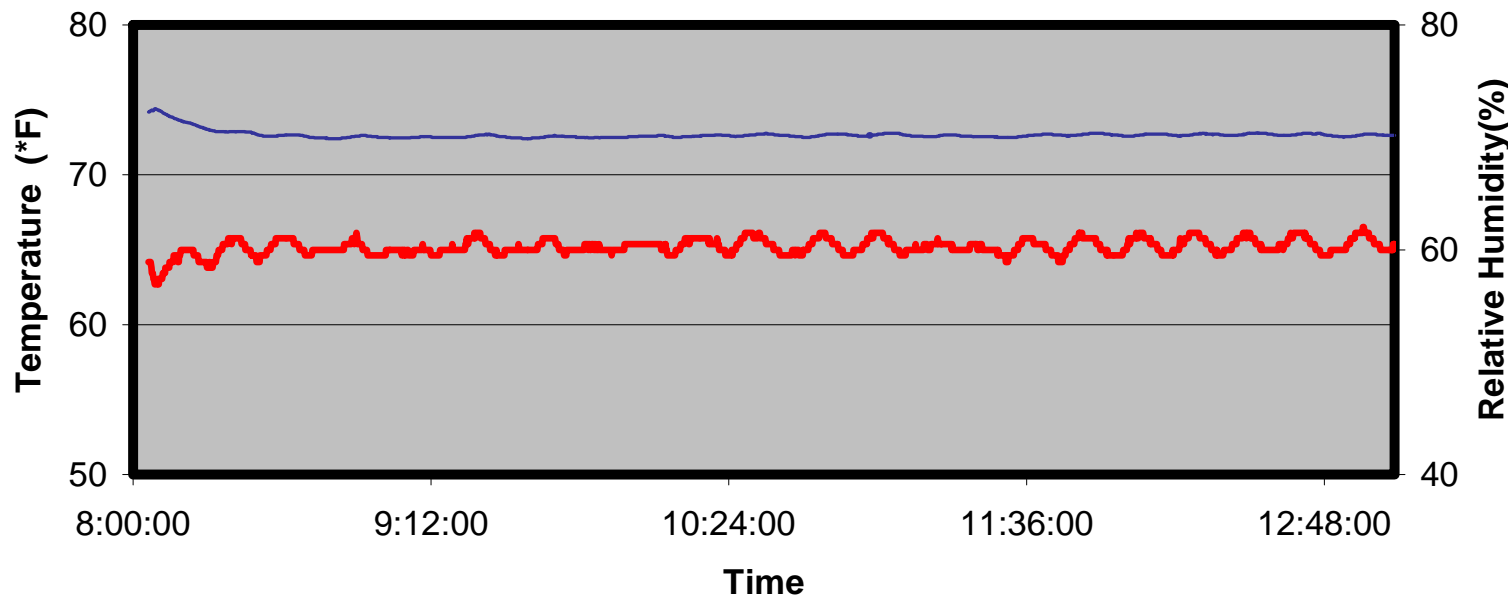

Temperature( $\left.{ }^{*} \mathrm{~F}\right) \longrightarrow$ Relative Humidity (\%) 


\title{
APPENDIX H
}

\author{
Statistical Data
}

\section{Statistical Models}

The statistical program, Proc Mixed in $\mathrm{SAS}^{13}$, provides estimates for the fixed effects and also estimates of variance components for the random effects.

For the analysis of the mist generation data from this study, all data were natural logtransformed. Residuals from the fitted models supported the log normality of the data.

Separate models were first developed to evaluate the collected data. For milling, the basic model for was the following:

$$
\ln (\text { determination })=\mu+\alpha_{\text {speed }}+\beta_{\text {fluid }}+\alpha \beta_{\text {speed }}^{* \text { fluid }}+\text { error }
$$

Where: $\mu=$ overall mean,

$$
\alpha_{\text {speed }}=\text { the speed effect (lower or higher speed), }
$$

$\beta_{\text {fluid }}=$ the fluid effect (EPA or baseline fluid),

$\alpha \beta_{\text {process } * \text { fluid }}=$ the interaction effect between fluid and process,

$$
\text { error = random components. }
$$

For milling the initial form of the error was taken to be:

$$
\text { error }=a_{\text {pair(fluid })}+\text { residual, }
$$

where $a_{\text {pair(fluid, speed) }}=$ the random effects due to pairs, for which the variance was postulated to differ by combination of fluid and speed.

$$
\begin{gathered}
\text { Residual }=\text { the unexplained variation after accounting for the } \\
\text { variation due to pairs. }
\end{gathered}
$$

Since the baseline fluid pairs were always collected on the same day, and the EPA fluid on different days, it seemed quite possible that their variability could differ, and equation (1) allows for that. 
The following procedures were used in choosing a model for the milling data:

1) The full fixed effect model (0) was retained, since even the interaction term had a p value less than 0.2 .

2) The model (1) for the error required modification, since the residual error varied by fluid, in that the baseline fluid was more variable. Separate models were fitted to the baseline and EPA fluid data:

$$
\ln (\text { determination })=\mu+\alpha_{\text {speed }}+\left(a_{\text {pair }}+\text { residual }\right)
$$

The term $\mathrm{a}_{\text {pair }}$ did not vary by the two speeds. It happens that for the EPA fluid there was no estimated variability among pairs, and for the baseline fluid, the statistical significance of the pairs was between $5 \%$ and $10 \%$. However, since the experiment was set up with the randomized pairs, they were retained. The residual variance estimates are 0.584 (baseline) and $0.0337(\mathrm{EPA})$, a ratio greater than 16, which corresponds to an $\mathrm{F}$ variable with 4 degrees of freedom in numerator and denominator, which exceeds the 0.01 percentile of the $F$ distribution (15.98). Thus, there is reason to regard the residual variance of the two fluids as different and to use as weights the reciprocals of these variances in fitting equations (0) and (1). All EPA determinations were collected on different days, so it might be thought that the lack of pair to pair variation indicates that there was substantial variation between days. However, the residual variation, which includes day to day variation for the EPA fluid, is quite small.

When weights are used as described above, likelihood methods indicate that the error term of equation (1) does not require the term $\mathrm{a}_{\text {pair (fluid, speed) }}$ but only the term $\mathrm{a}_{\text {pair (fluid) }}$, significant at the $5 \%$ level. However, since there was no variability associated with pairs for the EPA data, and since each baseline pair was collected on one day but different pairs were collected on different days, results are the same if $\mathrm{a}_{\text {day (fluid) }}$ or $\mathrm{a}_{\text {pair( fluid) }}$ is used in model (1a) below:

$$
\text { error }=a_{\text {day (fluid) }}+\text { residual, }
$$

using weights, as is described above.

For turning, the model was simpler, since only the lower speed was studied:

$$
\ln (\text { determination })=\mu+\beta_{\text {fluid }}+\text { error } .
$$

The main difference from the milling data is that there were no pairs. However, there were samples within each fluid collected on the same day. These were allowed for by including a random term for day in the analysis. Thus, the form of the error was:

$$
\text { error }=a_{\text {day }(\text { fluid })}+\text { residual, }
$$

where the day to day variance was permitted to vary by fluid type, which is what the subscript on "a" indicates.

Ratios of EPA/baseline variances, after averaging by day, are less than 3, and, therefore, there is no significant difference in the variances and no reason to weight. Based on the loglikelihood ratios, the inclusion of the random term for day (fluid) is appropriate (p-value less than 0.05 ). The results indicate no difference between fluids. The data were also 
analyzed without the natural log transformation, and the same models result after doing the corresponding analyses.

Since there was interest in comparing milling and turning, the data sets were combined, and a model was fitted to the combined data. The modeling that had been done separately for each process was used to identify an appropriate model for the combined data. The model (0) used for the milling data was expanded as follows:

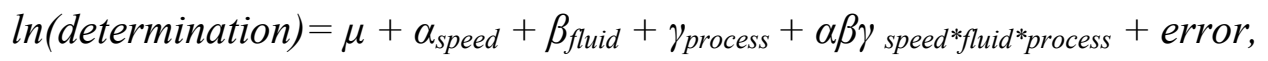

where $\gamma_{\text {process }}$ denotes the process effect (milling or turning)

and $\alpha \beta \gamma_{\text {speed }}^{*}$ fluid*process denotes the speed*fluid*process interaction effect.

The model used for the error was:

$$
\text { error }=a_{\text {day (fluid, process) }}+\text { residual, }
$$

based on the models (1a) and (4) for the milling and turning data, respectively, and the weighting scheme based on model (2) was again used for milling. Weights were provided for turning, using the reciprocal of the estimated residual variance associated with the error model (4) for the turning data. In addition, the variance associated with $a_{\text {day(fluid,process) }}$ varied by process and fluid: turning, milling baseline, and milling EPA (p value between 5 and $10 \%)$.

This model (5) was used to make the required comparisons.

In the model for the errors, model (6), where more than one variance component was used in the computation of the standard error of the estimate, the Satterthwaite approach was used to estimate degrees of freedom for estimates of the mean and for differences of means, since the estimates had variances that were combinations of more than one mean square ${ }^{14}$.

The last higher speed run (in the fifth pair) for the baseline fluid was quite low compared to the other four runs. Two outlier tests (Grubbs and Dixon $\mathrm{r}_{10}$ ) ${ }^{15}$ for this value produced results whose p-value was between $5 \%$ and $1 \%$. Without a physical reason for removing data, it seems best to require significance at the $1 \%$ level before removing a value. Thus, in the results presented in the paper, no data are excluded.

Nevertheless, the milling data were reanalyzed with the pair removed, after which no weighting was necessary, since the ratio of the baseline EPA residual variances was about 3 and was not statistically significant. As before, the fitted model (1a) was appropriate, based on likelihood methods and examination of residuals. However, the higher /lower speed generation rate ratio is no longer statistically significant for the EPA fluid. This may seem peculiar, but it is the differences in variances of the baseline data and the EPA data that are responsible for the determinations of statistical significance when no data are removed. Without the fifth pair the difference in variances of the two fluids is reduced, so that a variance pooled over both fluids is appropriate. The use of the larger pooled variance for all determinations results in non-significance for the smaller ratio, that for the EPA fluid. 
However, since the revised confidence interval for the higher/lower speed ratio for the EPA fluid is $(0.90,2.64)$, the observed ratio is not far from statistical significance (the interval includes the value 1 , indicating possible equality of the fluid geometric means), even with exclusion of the fifth pair.

\section{Adjustments for Many Comparisons}

Statements about statistical significance are based on results of Student's t-tests. For the milling data, there were eight means or comparisons of interest, for which confidence intervals were to be calculated: means for the four combinations of (speed, fluid), and the four comparisons: (higher speed/lower speed, EPA fluid), (higher speed/lower speed, baseline), (lower speed, EPA/baseline), (higher speed, EPA/baseline). In addition, there were three means or comparisons of interest for turning: means for (lower speed, EPA) and (lower speed, baseline) for the comparison (lower speed, EPA/baseline). Also, there were four comparison required for turning versus milling: Baseline fluid at normal speed for milling versus turning, and the corresponding comparison for the EPA fluid; also each fluid's turning results were compared to the corresponding results of that fluid at milling, higher speed.

This is a total of fifteen comparisons, and the aim is to control the error rate at 5\%, or equivalently, to obtain simultaneous 95\% confidence intervals for the comparisons or estimates of interest. The Bonferroni method is used to obtain these intervals ${ }^{16}$. This method widens the Student-t based confidence intervals to allow for the total number of comparisons. However, we have divided the 15 comparisons into two groups, the five that involved the ratios of fluids (EPA/baseline) or ratios of speeds (lower/higher) for each process individually, and the remaining ten comparisons. The first five are the main comparisons. In each group the provided confidence intervals provide simultaneous 95\% probability of coverage.

The four milling comparisons in the final group may be expressed alternatively in terms of three comparisons: EPA versus baseline fluids (averaged over speed), fast speed versus normal speed (averaged over fluid) and EPA/baseline ratio for fast versus normal speed. After allowing for multiple comparisons, each comparison is statistically significant at the $5 \%$ level.

The Bonferroni procedure may be described as follows. For the ten estimates of second group, instead of using the $97.5 \%$ value of the Student's t-distribution (which correspond to a $95 \%$ confidence interval, since the error rate is $2.5 \%$ on both the lower and upper ends, or $5 \%$ error rate overall), the $100(1-0.025 / 10) \%$ value (or $99.75 \%$ value) of the t-distribution is used, for each of the ten estimates. Thus, a larger $t$ value is used to allow for the ten estimates. Each comparison has an error rate of 2(1-.9975)=0.005, and since error rates add (approximately), 10(0.005) $=0.05$, the desired overall error rate. For the group of five comparisons, five rather than ten estimates were allowed for. 